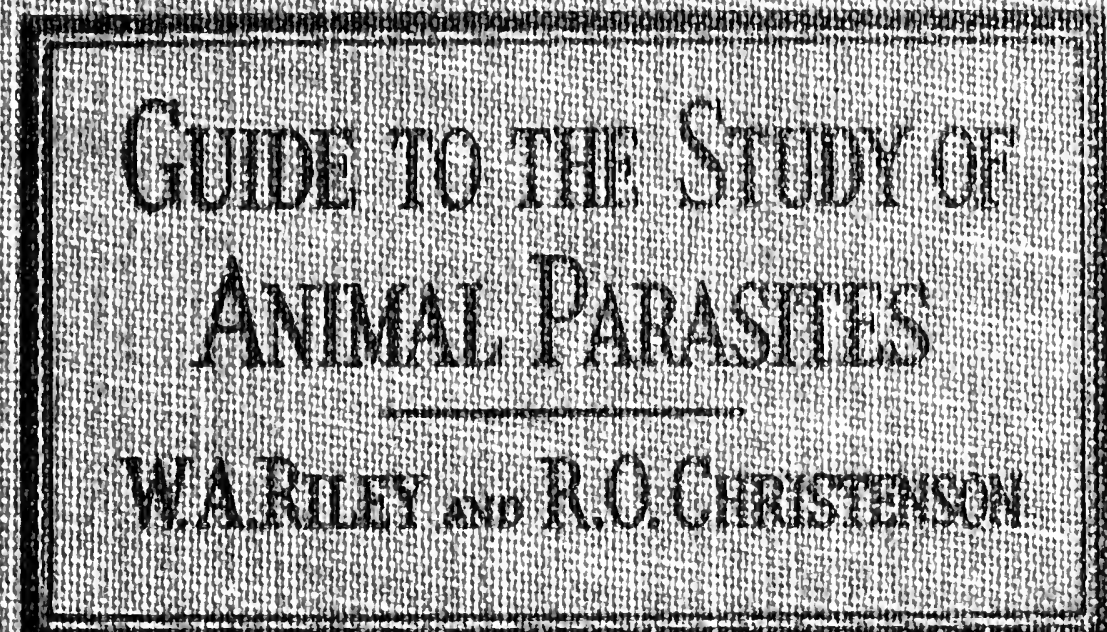

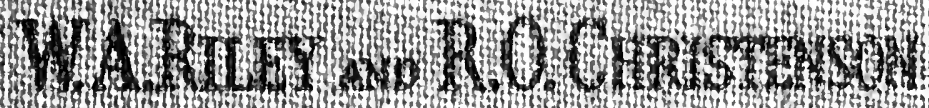



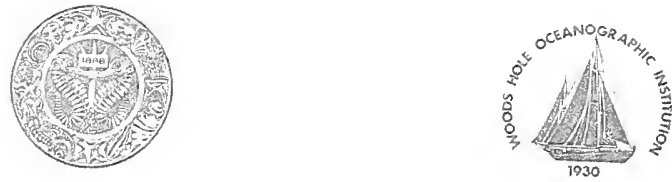

\section{MBL/WHOI LIBRARY}

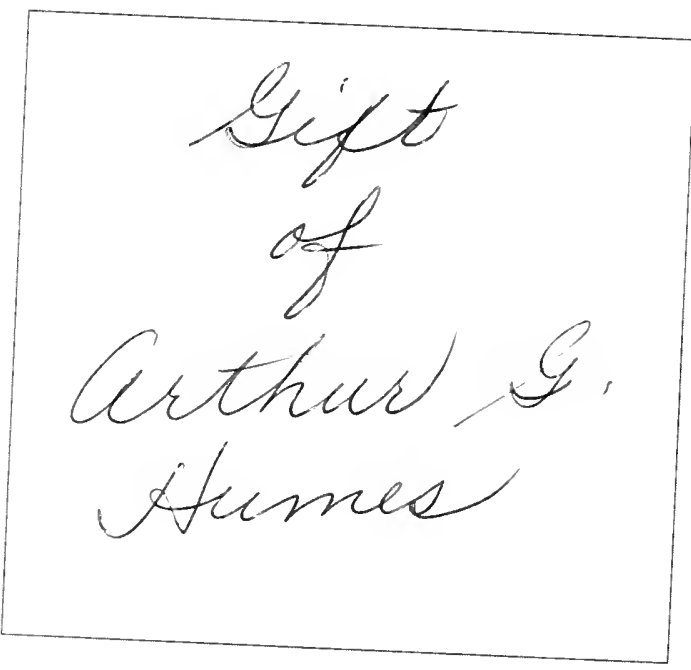


Arthur H. burnes 236 St. Lapoleon St. Baton Rouge, La. 



MCGRAII-IIILL PIBILCATIONA IN THE ZOÖLOGICAL SCIENC'ES

A. FRANLLIN SHCLI, CoNetlting Fintor

\section{GUIDE TO THE STUDY OF ANIMAL} PARASITES 


\section{McGRAW-HILL PUBLICATIONS IN THE ZOÖLOGICAL SCIENCES}

\section{A. Franklin Shull, Consulting Editor}

Fernald-Applied Entomology

Graham-Prineiples of Forest

Entomology

Haupt-Fundamentals of Biology

Haupt-Laboratory Directions for General Biology

Metcalf and Flint-Destruetive and Useful Inseets

Mitchell-General Physiology

Pearse-Animal Ecology

Reed and Young-Laboratory Studies in Zoology

Riley and Christenson-Guide to the Study of Animal Parasites

Rogers-Comparative Pliysiology

Rogers-Laboratory Outlines in Comparative Physiology

Shull-IIeredity

Shull, LaRue and Ruthoen-Aninal Biology

Shull, LaRue and Ruthven-Laboratory Directions in Animal Biology

Snodgrass-Anatomy and Physiology of the IIoneybee

Van Cleave-Invertebrate Zoölogy Wieman-General Zoölogy

Wieman-An Introduction to Vertebrate Embryology

Wieman and Weichert-Laboratory Manual for Vertebrate Eubryology

\section{McGRAW-HILL PUBLICATIONS IN THE AGRICULTURAL AND BOTANICAL SCIENCES}

Edmend W. Sinnott, Consulting Editor

Adams-Farm Management

Babcock and Claus n-Geneties in Relation to Agriculture

Baberck and Collins-Genetics Laboratory Manual

Belling-The Use of the Micros cope

Boyle-Marketing of Argieultural Products

Broun-Cotton

Carrier-Beginnings of Agriculture in Anerica

Cruess-Commereial Fruit and Vegetable Produets

Cruess and Christie-Laboratory Manual of Fruit and Vegetable Products

Eames and MacDaniels-Plant Anatomy

Eckles, Combs and Macy-Milk and Milk Products

Emcrson-Soil Characteristies

Fawcett and Lee-Citrus Diseases

Fitzpatrick-The Lower Fungi

Gardner, Bradford and HookerFruit Production

Gardncr, Bradford and HookerOrcharding

Gäumann and Dodge-Comparative Morphology of Fungi

Hayes and Garber-Breeding Crop Plants

Heald-Plant Diseases

Horlacher-Sheep Production
IIutcheson and Wolfe-Field Crops Jones and Rosa-Truek Crop Plants

Loeb-Regeneration

Löhnis and Fred-Agricultural Bacteriology

Lutman-Microbiology

Maximor-A Textbook of Plant Physiology

Piper and Morse-The Soybean Pool-Flowers and Flowering Plant 8

Rice-The Breeding and Inprovement of Farm Animals

Shar $p$-Cytology

Sinnott-Botany

Sinnott-Laboratory Manual for Elementary Botany

Sinnott and Dunn-Prineiples of Genetics

Swingle-A Textbook of Systematic Botany

Thatcher-Chemistry of Plant Life

Thompson-Vegetable Crops

Waite-Poultry science and Practice

Weaver-Root Development of Field Crops

Weaver and Bruner-liont Development of Vegetable Crops

Weaver and Clements-Plant Ecology 


\section{GUIIE TO TIIE STUDY}

()F

ANIMAL PARASITES

$B Y^{\circ}$

WILLIAM A. RILAY, Ph.D., Sc.D.

Department of Zooloys. T niversity of Minnesota

ANI)

REED O. ('HRINTENSON, M.A.

Department of Zoology, Cnitrsity of Minnesota

First Edition

Second IMpression

MCGRAW-HILL BOOK COMPANY, INC.

NEW YORK AND LONDON

1930 
Copyright, 1930, by the

McGraw-Hill Book Company, Ine.

PRINTED IN THE UNITED STATES UF AMERICA 


\section{PREFACE}

The subject of animal parasitology has in the past received but scint attention in the courses in zoology in this country. The student has had presented the general outline of the life history of the pork tapeworm of man, of the liver fluke of the sheep, and of trichina. As a rule he has seen only demonst ration specimens, covering but a portion of the life cycles of these forms.

The present generation has seen a revolutionary change of attitude towarls the subject. The remarkable discoveries of the relation of insects and their allies to animal parasites of man, the recognition that hookworm disease was widely prevalent in this country, and the extensive findings of other parasites of man and of animals which resulted largely from the hookworm campaigns, aroused a new interest in the parasites of man and of animals.

With this stimulus there has been an insistent demand for more attention to parasitic forms by departments of zoology.

In many of our eolleges and universities special courses in this subject are being offered and are being sought not only by premedical and veterinary students, but by those interested in public health work and animal husbandry. Increasing numbers of students of general zoology are finding in such courses an introduction to some of the most fascinating problems in their chosen field of work.

The demand for this special work has brought its problems to the teacher. In many eases he has been at a loss as to where and how to obtain material for his rapidly growing elasses. Unlike the standard materials of the first-year course, it was not to be found in the regular biological supply houses. There was a general feeling that it was rare and inaccessible to the average department, and there was little idea as to what suitable forms were a vailable from domesticated or wild animals. There has been almost eomplete dearth of suitable texts and at the present time there is little choice in the way of a laboratory guide for a general course in animal parasitology. 
Under these circumstances the writers have felt that there is a place for the "Guide to the Study of Animal Parasites" which is here offered. It is the outgrowth of fifteen years of experience on the part of the senior author in presenting the subject to a group of students with varied interests, such as is to be found in most of our schools. It is hoped that the suggestions as to sources of material will considerably lighten the work of the non-specialist who is called upon to present the subject. They are also intended to aid the independent student of zoology in getting an introduction to the field of parasitology. It will be noted that the introductory study of the incidence and distribution of the animal parasites of the frog is followed by the study of the trematodes and that consideration of the protozoan parasites is reserved for the later periods of the course. We have found this the most feasible sequence for classes with a background of only general zoology, but some instructors may prefer to reverse this treatment.

The omission of the arthropods from such a text needs explanation. In most of the schools of this country where the subject of animal parasitology is taught, the work in medical and veterinary entomology is presented in a separate course. In any event, there are available excellent outlines for the study of the elements of entomology. The protozoologic and helminthologic aspects of the relation of arthropods to disease are those which cannot be presented satisfactorily without more of a background than most of the courses in medical entomology provide.

It is with much reluctance that the authors have restricted the references to literature to so small a number and these almost exclusively in English. The original plan of citing original monographs regardless of place of publication was discarded because it was evident that most of these would be inaccessible outside of research centers. The papers cited contain, in most cases, special bibliographies, and many of the comprehensive texts listed in the Appendix include very extensive references to the literature. The student should be urged to consult original sources and should have emphasized the importance of preparation in modern languages if he expects to do advanced work in any field of zoology.

A section on the essentials of technique of collecting and preparing animal parasites is appended. In addition there is given a list of the more important parasites of laboratory 
animals which will not only be of aid to the instructor in locating material but will serve as a starting point for special survey work by the interested student.

The senior author particularly wishes to acknowledge his indebtedness for suggestions by W. L. Chandler, Laurene Krogh, Gerard Dickman, and Nordahl Peterson, former student assistants who were associated with him in presenting this course. The efficient services of Miss Grace E. Jones in preparing, redrawing, and arranging illustrations also deserve special inention. To the various publishers and authors who have granted realy permission to use illustrations, thanks are due.

The Authors.

Minnearolis, Mixis.

January, 1930 



\section{CONTENTS}

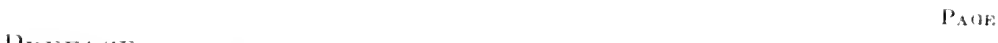

Preface. . . . . . . . . . . . V

INTROACTION . . . . . . . . . . . . . xiii

('HAPTLR I

T'he Major Groeps and Diatrhimtion of Animal Para-

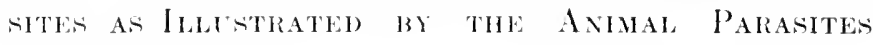
OF THE Frog. . . . . . . . . . . . . . . . 1

('IHAPTER II

The Morphology of the Trmatoma, or Flykes . . . 9

('HAPTER III

The Life Crcle of a Trpical Trematode . . . . . 14

('HAPTER IV

The Structure and Life History of a Tapeworm, Tania Pisiformis (BLoch 17S0) . . . . . . . . . . 19

CHAPTER V

Comparative Study of Some Important Cestodes. . . . 26

CHAPTER Y'

Ascaris Lumbricoides as a Trpe of the Nematoda . . . . 33

C'HAPTER VII

The Hookworms of Man and Animals. . . . . . . 39

('IHAPTER VHII

Trichinella Spiralis and Related Forms ....... . 43

CHAPTER IX

The Determination of Helminth Infections through Fecal fxaminations. . . . . . . . . . . 47 
CHAPTER X

The Examination of Silall Mammals for Parasites .

CHAPTER XI

The Amokbe of MaN.

CIIAPTER XII

The Trypanosomes and Allied Forms

('HAP'TER YIII

Intestinal Flagellates of Vertebrates . . . . . . . 68 CHAP'TER XIV

A Simple Life Cycle of a Sporozoan. . . . . . . . 74 CIIAPTER XV

The Life Crcle of the Coccidia. . . . . . . . . . 78 CHAPTER XVI

The Hamosporidia.

CHAPTER XVII

The Sarcosporidia.

CHAPTER XVIII

Examples of Parasitic Infusoria. CHAP'TER XIX

The Literature of Animal Parasitology

\section{APPENDIX}

Collection and Preservation of Animal Parasites. Intestinal Protozoa-Cestoda-Trematoda-Nematoda -Soil nematodes-Intestinal Trichinx-Permanent mounts of Helminth eggs-Preparation and staining of blood smears. 
Formelas for Reagent' and Mounting Media.

The More Important Endozoa of Laboratory Animals. 114

Supply Houses Handling Parasitological Materiala , 12:

Conprehlenshe Texts . . . . . . . . . . . . . . 125

INDEX . . . . . . . . . . . . 129 



\section{INTRODUCTION}

The laboratory exercises outlined in the following pages are designed to introduce the student to the study of animal parasitology. Normally, the work will be undertaken after a preliminary course in general zoology or biology and it is thus unnecessary to discuss at length the equipment to be used or methods of study.

A knowledge of the use of the compound microscope is assumed, though any user of the instrument would profit by reading over carefully the booklets on this subject which are furnished by the makers. Certain elementary rules are so commonly ignored, even by advanced and graduate students, as to need further cimphasis.

Care of the Microscope.-It must be remembered that the microscope is an instrument of precision and should be treated as such. It should be protected from dust and from fluids. The glass surfaces of the lenses must not be touched with the fingers for that will soil them. There is probably no elementary rule of microscope manipulation which is more commonly violated, yet its validity is obvious.

Students often have difficulty in determining the location of dirt and films which cause indistinctness of the image. If the fault is in the preparation the fact will be obvious if the slide is observed carefully while being moved; if in the eyepiece, by rotating it while looking through the microscope; if in the mirror by moving it.

Lenses should be cleaned carefully by breathing on them and wiping with special lens paper (Japanese filter paper) or a clean soft linen rag. If this is not sufficient moisten the edge of the rag slightly with alcohol. If the cloudiness should be due to balsam or an oily substance, it will be necessary to use a small amount of chloroform or xylol but this must be done quickly to obviate the possibility of these fluids penetrating and injuring the setting of the lens.

Care of Preparations. - In cleaning the cover glasses of prepared slides be very careful not to exert pressure as the chances xiii 
are that the slide will be ruined, even though it does not show injury. Microseope elips must not be placed over the cover glass for they, too, will cause movement of the mounting medium and irreparable injury to the preparation.

Do not attempt to use high power lenses on thick preparations such as those of trematodes, tapeworm proglottides and the likethe proper manipulation of the mirror and the iris diaphragm are important factors in bringing out detail under the low power lenses.

Use of Oil Immersion Lenses.-In the study of parasitic protozoa it is often necessary to use the oil immersion objective. This is, as its name implies, an objective whose front lens is immersed in a special cedar oil of the same refraetive index. As it has a very short working distance it can be used only on preparations having very thin cover glasses or on dried uncovered films with only the oil. Special precautions must be observed to prevent injury of either the lens or the preparation. A small drop of oil is applied direetly to the lens or placed on the preparation and the lens lowered until it is in contact with the fluid, the observer watching closely meanwhile with the head at the level of the stage. Focus eautiously - if there is apparent movement of tissues in a balsam mount it is a danger signal that the eover glass or the layer of balsam is too thick and the lens must immediately be focussed upwards.

Dissecting Microscopes.-The modern binocular dissecting mieroseopes are a great aid to the student of parasitology. An equipment of lenses giving a range of magnification of from seven to thirty times, is the most satisfactory. The higher magnifieations are of little use in general work.

The student, however, must not get the idea that these are essential for his work. Most of the anatomical details discussed in the following pages were worked out long before the binocular dissecting mieroscopes were invented. Some simple type of dissecting stand, even if only the tripod with a lens which is focussed by screwing up and down in the metal frame can be provided in any laboratory. Skill in dissection of minute objects under the ordinary compound mieroscope is readily aequired and even today is an essential equipment of the student of zoology.

Noreover, every student of the subject should own and habitually use a good magnifier, mounted in a folding pocket ease. While the higher-prieed lenses are of course preferable, very good 
service is given by the cheiper doublet type. The mannifying power should not execed 10 to 14 diameters.

Dissecting Instruments.-The ordinary dissecting set as required in the elementary course in zoölogy is sufficient for this course. Heavy scissors with one blunt probe point, or the regular enterotony scissors are very useful in the examination of animals for intestinal parasites. Bone-cutting forceps should be available. For examination of large animals special equipment of skinning knives and other tools is necessiry.

Preservation and Mounting of Specimens.-It will add much to the value of the work if the student will take advintage of opportunities to examine various animals for parasites. These can be preserved by the methods given in the appendix. In every case care should be taken to preserve accurate data as to the host and the organs from which the specimens were taken and the date and locality. 



\title{
GUIDE TO TIIE STUDY OF ANIMAL PARASITES
}

\author{
CHAPTER I
}

\section{THE MAJOR GROUPS AND DISTRIBUTION OF ANIMAL PARASITES AS ILLUSTRATED BY THE ANIMAL PARASITES OF THE FROG}

\section{TECHNICAL SUGGESTIONS}

At the outset of the work, when the general prineiples of animal parasitism are being diseussed in the lectures, two laboratory periods may be devoted profitahly to a general survey of the parasites of the frog. For these practicums freshly killed frogs of any speeies may be used. It is not necessary that they be large enough for ordinary anatomical work. When feasible it is advintageous to have them from different habitats and, preferably, recently caught. Shortly before the elass period they should be chloroformed.

For purpose of future study and statisties it is well at the close of the period to colleet the specimens found and to preserve them, with aceurate data as to sources, according to the direetions given in the Appendix. If time and facilities permit, it is still better to have this done by the students themselves.

\section{SYSTEMATIC REVIEW}

Before undertaking the practical work outlined, the student should review the characteristics of the animal phyla and classes with which our course will be chiefly concerned.

Phylum PROTOZOA.-Animals in which the entire body consists of a single cell which, however, may possess a highly complicated structure. Four classes are usually recognized.

Class RIIIZOPODA.-Protozoa in which the motile organs are pseudopodia.

Class MASTIGOPIIORA.-Forms possessing an outer cell integument and flagella as motile organs.

Class SPOROZOA.-Parasitic Protozoa typically without organs of locomotion; reproduce by spore formation. Group not a natural one. 
Class INFUSORIA.-Protozoa with an outer cell integument; always ciliated either through life or in the young condition.

Phylum PLATYHELMINTHES.-The platodes, or flatworms. Bilaterally symmetrical animals devoid of true metameric segmentation and without body cavity. There is no bloodvascular system, but an excretory (water-vascular) system is present.

Class TREMATODA.-Flukes. Parasitic flatworms without a covering of cilia in the adult state; with a well-developed digestive apparatus typically with a single opening, the mouth, at the anterior end of the body. The sheep liver-fluke is an example.

Class CESTODA.-The tapeworms. Endoparasitic flatworms, without cilia and without a digestive cavity; usually becoming segmented as they mature.

Phylum NEMATHELMINTHES.-The roundworms, or threadworms. The body is cylindrical, spindle-shaped, or thread-like, unsegmented, and covered with a thick cuticle; the body cavity (not a true colom) is usually spacious. The sexes are usually separate but hermaphroditic species occur.

Class NEIIATODA.-With an alimentary canal but without a proboscis. Both free-living and parasitic forms.

Order EUNEMATODA.-Alimentary canal typically complete and present throughout life. Familiar exanples are the ascaris worms, pinworms, hookworms.

Order GORDIACEA.-The so-called "hrair-snake." Larval stages parasitic and possessing an alimentary canal. Adults free living, without an alimentary canal.

Class ACANTIIOCEPIIALA.-The thorny-headed worms. Lacking alimentary canal; possessing a protrusable proboscis which is covered with many rows of recurved hooks.

Phylum ANNULATA.-The segmented, or annelid worms. Body composed of similar segments, without jointed legs; alimentary canal with two openings. Only one class contains a considerable number of parasitic forms.

Class HIRUDINEA.-The leeches. Segments marked externally by secondary rings. Each end of the body is furnished with a sucker.

Phylum ARTHROPODA.-Crustaceans, mites, ticks, and insects. Bilaterally symmetrical animals in which the body is segmented and bears a pair of jointed appendages on each or some of the segments. Not considered in this course. 


\section{PRACTICAL WORK}

The object of this exereise is to illustrate the common types and general distribution of parasites in the organs and tissues of an animal host. For this purpose the frog is an exeeptionally favorable subjeet. It harbors a large number and variety of entozoa, illustrative not only of the major groups but even of genera of important parasites of man. The work of this practicum is of a general nature, but we shall return to the study of frog parasites in greater detail as we take up partieular groups.

Lay the frog on its back on a disseeting board or tray and extend and pin flown the legs. Open the abdominal and thoracic cavities by a median ventral incision and pin back the flaps. By way of review identify the general internal anatomical struetures before making the speeial study of them for parasites.

Examination of the Blood.-Using slides and covers which have been thoroughly cleaned in alcohol to remove all grease, mount a small drop of blood. Cut down the light in the mieroseope and earefully search through the entire field for blood parasites. Care should be taken not to make the mount too thick, thereby rendering it opaque. If neeessary a drop of physiologieal salt solution $(0.75$ per cent $\mathrm{NaCl})$ may be added to dilute the blood.

Trypanosoma rotatorium is a flagellated protozoan found free in the blood plasma. It is approximately twice the length and about the breadth of the red eorpuseles of the frog, moves about actively, and presents marked changes in form. It is rarely abundant but, if present, can usually be found in the blood from the kidney.

Lankestrella ranarum is a sporozoan which, like the parasite of malaria, is found within the red blood corpuscles and blood plasma of the host. In the fresh eorpusele it appears as a clear, spindle-shaped body. Spindle- or creseent-shaped forms predominate in the blood. Another sporozoan, Dactylosoma ranarum, also occurs in the red blood cells of frogs and undergoes an asexual multiplication within them. If heavily infeeted frogs are found, permanent preparation may be made as directed in the Appendix.

Blood filaria, minute larval roundworms, have been reported for frogs but have not been recorded for our native speeies.

Body Cavity.-Clinostomum attenuatum.-Examine the mesenteries, the peritoneum of the body cavity, and the lymph spaces 
between the skin and muscles of various parts for little creamcolored nodules, about the size of a pinhead. If such are noted, carefully tease one open and there will be found a larval fluke, which is capable of developing to maturity in various aquatic birds that prey on frogs. Other undetermined larval flukes have
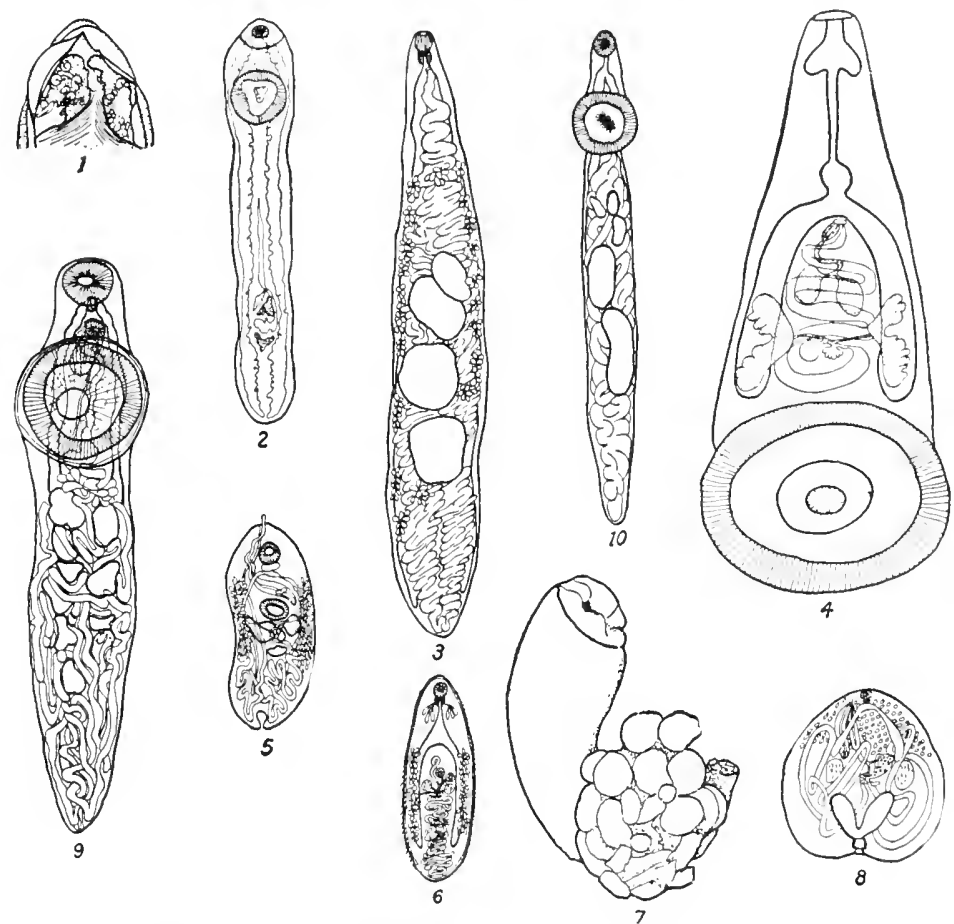

FIG. 1.- Recognition sketches of common trematode genera from native frogs. Magnification (except 1 and 7 ) $10 \times . \quad 1$, Clinostomum larve under skin of throat: 2 Clinostomum, isolated; 3, Preumonaces from lung; 4, Niplodiscus; is, (ilgpthetmins; 6, C'phalogonimus; 7 , "ysts of Loxogeness on pylorie end of stomath; $\rightarrow$, Lorogenes; 9, Gorgodera; 10, Gorgoderina.

been reported in the muscles of frogs; and the sporozoan, Glugea danilewskyi, has also been noted. It occurs as white striations in the muscles, eontaining spherieal granules and many spores.

Lungs.-Remove the lungs and tease them apart in a dish of physiological salt solution. Probably both roundworms (Nematoda) and flukes (Trematoda) will be found. Note the number of each.

Rhabdias rance is a nematode measuring from 3.5 to $5 \mathrm{~mm}$. in length which is commonly found in the lungs of Americun frogs. 
Rhabdias bufonis, an European species measuring from 11 to $13 \mathrm{~mm}$. has been reported for our native frogs as well. Both species are viviparous and their larve may be found in the alimentary canal of the frog.

Pneumonaces sp.-At least six different species of flukes belonging to this genus are to be found in the lungs of North American frogs. Mount a specimen and note under the mieroseope the characteristic suckers. The dark brown eggs, present in enornous numbers, obseure most of the anatomical details. The discharged eggs, with a characteristic cap, will be noted later in the intestinal contents.

Surface of Abdominal Organs.-Loxogenes areanum is a small trematode living in thick-walled closed cysts on the stomach, liver, and bladder of various frogs. Two individuals occur in each eyst.

Nematodes. - Several imperfectly known nematodes oceur as immature larve in eysts on the walls of the stomach and various other organs.

Alimentary Canal.-Beginning at the mouth, slit the alimentary canal, examining carcfully for various parisites.

Flukes.-Halipegus occidualis is a moderate-sized fluke with powerful suckers, which is reported from the mouth and Eustachian tube of a frog.

Glypthelmins quieta occurs in the intestine, as does Cephalogonimus americamus. These two species are small flukes superficially resembling each other very much. They are both cylindrical, eigar-shaped flukes measuring about one-eighth of an inch $(3 \mathrm{~mm}$.) in length. A positive differentiation of the species will not be attempted at this time.

Diplodiscus temperatus, found in the rectum, is recognized by the fact that the enormously developed ventral sucker is at the caudal end of the body.

Nematodes.-Several species of nematodes may be found in various parts of the alimentary canal. They should be examined, but further study will be postponed.

Cestodes.-Several species of tapeworms have been reported as adults in the intestines of frogs. Another lives as an encysted larva in the muscles.

Protozoa.-Numerous Protozoa, representing each of the four elasses, are to be found in the alimentary canal and will be studied more in detail at a later practicum. The following 
should be espeeially sought at present, by mounting a little of the black content of the reetum in salt solution. An excess of water should be avoided. In order to get the best results the mount should be sufficiently transparent to read ordinary print through it.

Opalina is a ciliated protozoan so large as to be visible to the naked eye as a white dot. It is greatly flattened, eovered by minute cilia which give the surface distinct oblique striations.

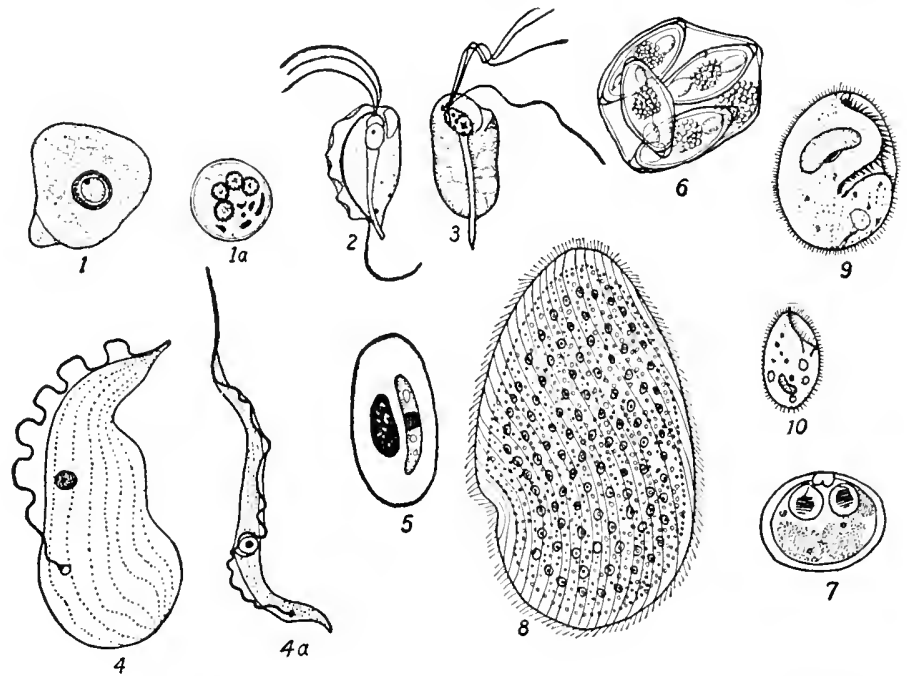

FIG. 2.- Recognition sketches of genera of common protozoal parasites of frogs; except as noted, all from the intestine. 1-7, drawn to the same scale; i-10 to one-third. 1, Endamobra; 1a, Endamerba ryst; 2, Trichomonas; 3, Trichomastix; 4, 4a, Trypanosoma from blood; 5, Lanke'strella in nucleated red cell; 6, Eimeria eyst containing four spores; 7, Leptotheca spore from kidney; s, Opalina; 9, Nyctotherus; 10, Balantidium. (Adapted from various authors.)

Numerous speeies have been described for frogs and other batrachians.

Balantidium entozoön is of espeeial interest because of its close relationship to Balantidium coli, which is a serious parasite of man. It is larger than the free-living Paramecium studied in courses in general zoölogy and has a terminal gullet, lined by cilia much coarser than those of the rest of the body.

Nyctotherus cordiformis is similar to Balantidium entozoon but is readily distinguishable by the presenee of a gullet running obliquely aeross the body rather than a terminal gullet as in the latter speeies. 
Mastigophora ("Flagellata") may also be found in abundance. The larger tadpole-shaped individuals belong to the species Triehomonas batraehorum, a genus represented among the parasites of man.

Endamaba ranarum is a representative of the Rhizopoda which is not uncommon in frogs. It very closely resembles some of the amober of man. I'nder favorable conditions motile and encysted forms maly be found.

Eimeria rane is a sporozoan elosely related to the coceidian which causes fatal epidemies among rabbits and other mammals. The oöeysts of the E. rana may often be found in the contents of the large intestine.

Bladder.-Gorgoderine.-Some half dozen speeies of flukes belonging to the genera Gorgodera and Gorgoderina are to be found in the bladder of frogs.

Polystomum integerimum.--This interesting fluke, characterized by the possession of six suckers at the caudal end, is common in the bladder of frogs in Europe. Related species are occasionally found in our native frogs.

Kidney.-Diplospora lieberkühni and Leptotheca rance are sporozoans, which have been found in the kidneys of various frogs.

Directions for the preservation of parasitic worms and Protozoa and for the preparation of permanent slides will be found in the Appendix.

\section{References}

Cont, W. W., 1912. North Ameriean frog bladder flukes. T'rans. Am. Micro. Soc., $30: 151-166$.

Cont, W. W., 1915. North American frog lung flukes. Trans. Am. Micro. Soc., 34: 203-240.

Dobell, C. C., 1909. Researches on the intestinal protozoa of frogs and toads. Quart. Jour. Nicro. Sci., 53: 201-277.

Jewell, Minna E., 1916. Cylindrotania americana nov. spec. from the cricket frog. Jour. Parasitology, 2 : 181-192. (Includes review of frog cestodes.)

Leuckart, R., 1865. Zur Entwickelungsgeschichte der Ascaris nigrovenosa. Arch. Anat. Physiol. u. wiss. Mcd., 1865: 641-658.

Mecznik ow, El., 1865. Ueber die Entwickelung von Ascaris nigrovenosil. Arch. Anat. Physiol. u. wiss. Med., 1865: 409-420.

Metcalf, M. M., 1923. The opalinid ciliate infusorians. U.s. Nat. Museum Bull. 120, 484 pp.

NöLler, W., 1913. Die Blutprotozoen des Wasserfrosches und ihre Übertragung. Arch. Protistenk., 31: 169-238. 
Osborn, H. L., 1911. On the distribution and mode of occurrence in the United States and Canada of Clinostomum marginatum, a trematode parasitic in fish, frogs, and birds. Biol. Bull., $20: 350-366$.

Walton, A. C., 1929. Studies on some nematodes of North American frogs. Jour. Parasitology, 15 : 227-240.

Ward, H. B., and G. C. Whipple, 1919. "Fresh-water Biology."

Wenyon, C. M., 1926. "Protozoölogy," Vol. 2. 


\title{
C'HAP'TER II
}

\section{THE MORPHOLOGY OF THE TREMATODA, OR FLUKES}

\author{
TECHNICAL SUGGESTIONS
}

For demonstration of the monogenetic flukes, species of the wellknown genus Polystemum may be found in the mouth and the urinary bladkler of various turtles, or in the urinary bladder of our native tree frogs. Specimens of the hest-known species, $P$. integerrimum, can be purchased from European dealers. The minute Gyrodactylidæ may be secured from the gills and skin of various fish.

For sturly of the anatomy of a digenetic fluke, the commonty used sheep liver fluke is so complieated as to be wholly unsuitable for heginners. Little better are the various hung flukes of frogs which are often substituted. Much more suitable speeies are Opisthorchis pseudofelincus from eats and Clonorchis sinensis from the liver of man. Prepared slides of the latter are now readily availahle from dealers and we shatl use them as a type. In dofault of both, the immature r'linstomum from the flesh of perch and other fish, or from frogs, may be uscal. Study of the simpler forms miy be followed by that of the frog lung flukes and the sheep liver fluke.

\section{CHARACTERISTICS OF THE TREMATODA}

The Trematoda, or flukes, are exclusively parasitic flatworms (Platyhelminthes), often leaflike in shape, without a covering of cilia in the adult state. They possess a well-developed alimentary canal with but one opening, the mouth, at the cephalic end of the body. Suckers are developed on the ventral surface and in the region of the mouth, their position and structure being of much systematic value. With rare exceptions (blood flukes) trenatodes are hermaphroditic.

The cliss is divided into two subclasses, the Monogenea and the Digenea. As indicated by the names, the monogenetic: flukes develop directly, on a single host, while the digenetic forms require two or more host species for their development.

\section{PRACTICAL WORK}

Polystomum sp.-As an illustration of the more primitive flukes, or Monogenea, there will be demonstrated a representa- 
tive of the genus Polystomum from frogs or turtles. Note the six posterior suckers, the small hooks, and the two large hooks, the branched alimentary canal, and the short uterus containing a single egg. Make a sketch showing these points.

Clonorchis sinensis, the Asiatic liver fluke of man, or a related species will be taken as a representative of the digenetic flukes. Study under low power the prepared slide furnished and note the following features:
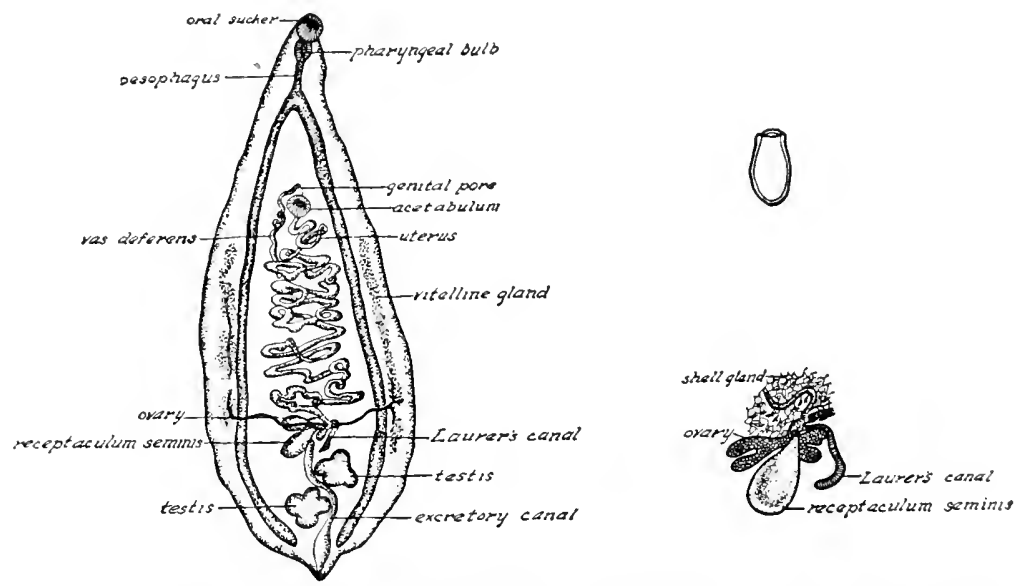

Fic, 3.-Anatomy of a trematode, Opisthorchis viverrina. (Barker, after Poirier.)

External Characters. - Shape and size. Is the cuticle smooth or spinose? (In order to determine this, cut down the iris diaphragm of your microscope and examine the margins of your specimen.) What is the number, position, and relative size of the suckers? What is their relation to the mouth? Close to the median anterior margin of the ventral sucker is the genital pore, the common outlet of the male and female organs. Locate the excretory pore at the caudal tip of the body.

Alimentary Canal.-Distinguish the mouth, the muscular pharynx, the short, unbranched resophagus, and the two branches, or intestinal rami. How far caudad do these rami extend? Do they exhibit lateral branches, or diverticula? Is there an anus present?

Reproductive System.-As in the great majority of flukes, Clonorchis is hermaphroditic; that is, both male and female organs are found in the one individual. 
The male organs consist of two testes, with their ducts, the vasa deferentia, and a seminal vesicle. In some flukes there are in addition a well-developed cirrus, or penis, and a eirrus pouch; these are lacking in Clonorehis.

The testes are a pair of much-branehed organs lying in the posterior fourth of the body, one behind the other, and extending laterally beyond the rami of the alimentary canal. How many lobes has each?

The vasa deferentia (singular, vas deferens) arise near the middle of each testis and run forward to about the middle of the body, where they unite and, eontinuing forward over the loops of the uterus, open into the seminal vesicle. The wide seminal vesicle eurves ventrally along the right side of the ventral sucker and unites with the terminal portion of the uterus to form a short eommon genital duct opening through the genital pore already noted as lying elose to the median anterior margin of the ventral sucker.

The female organs consist of the ovary, the vitellaria or yolk glands, the Mehlis gland, the seminal receptacle, the Laurer's canal and the uterus.

The seminal receptacle is a conspicuous, lightly staining ovoid body just anterior to the first testis. It lies somewhat obliquely to the longitudinal axis of the fluke, with its left end the more anterior.

The orary is a lobed organ lying in the median line just anterior to the seminal receptacle. It stains more deeply than the latter but is somewhat concealed by other parts.

The vitellaria lie exterior to the two intestinal rami and extend approximately from the region of the ventral sucker to that of the seminal reeeptacle. They are made up of numerous rounded glands conneeted by tubules and ultimately discharging through the paired vitelline ducts. These originate near the posterior ends of their respective vitellaria and eurve to the middle line, where they are united on the dorsal side of the ovary. At the point of union the common duct expands somewhat to form the so-ealled yolk reservoir.

The oviduct is a tube which originates from the dorsal surface of the ovary and unites with the yolk reservoir.

Laurer's canal is a sharply defined sinuous tube which originates from the oviduct just before its fusion with the yolk reservoir and runs posteriorly around the left end of the seminal receptacle, 
to open through a dorsal pore near the center of the anterior testis. Its significance and function are matters of much dispute.

The Mehlis gland, formerly regarded as a shell gland, surrounds the junction of the oviduct and the yolk reservoir. It is in reality an aggregation of unicellular glands.

The uterus is a much convoluted tube packed with eggs, occupying the whole median portion of the body between the ovary and the ventral sucker, within the rami of the intestine. It opens through the genital pore.

The egg is dark brown, ovoid, and, like most fluke eggs, possesses a eap, or operculum, through which the embryo escapes. Is the opposite pole evenly rounded?

Excretory System.--Running forward from the excretory pore is the main duct of the excretory system, appearing as a clear median tube which extends forward to the region of the seminal receptacle where it bifureates and is continued forward as a slender tube on either side to the anterior region of the worm. The finer tubules and their ultimate endings as the so-eallec? flame cells cannot be seen in these preparations.

Nervous System.-The paired cerebral ganglia can be seen as somewhat stellate, more deeply stained spots laterad and dorsal to the midclle portion of the osophagus. Indications of the origin of the anterior and posterior nerves can be seen in favorable specimens.

The circulatory and respiratory systems are not present in the Trematoda.

\section{OTHER SPECIES}

Frog lung flukes belonging to the genus Pneumonoces are readily available and should be compared with Clonorchis. In the lack of the latter they ma even be used as a type. Note particularly the feeble development of the ventral sucker, the shape of the testes and ovary, the distribution of the vitellaria, and the extent of the uterus.

The Liver Fluke of the Sheep.-This species, Fasciola heputica, which is so widely used as a type in courses in general zoölogy, should now be examined in the light of the above studies. Note the very great development of the branches, or cieca, of the alimentary canal, the extensively branched testes, the smaller ovary and restricted uterus, and the position of the genital pore. 
A blood fluke, Schistosoma hamatobium, will be demonstrated as an example of a fluke in which the sexes are separate.

\section{References}

Cont, W. W., 1915. North Americin frog lung flukes. Trans. Am. Micro. Soroc, 34 (4): :203-240.

FaUst, E. C., and H. E. Nelener, 1924. Studies on schistosomiasis japmica. Am. Jour. IIyg., Monographir series 3, 339 pp.

FaUst, E. C., and O. K. Kinaw, 1927. Studies on ('lomorchis sinensis (Cohbald). Am. Jour. IIyg., Monographie series 8, 284 pp.

Kobayanin, H., 1915. On the life-history and morphology of Clomorchis sinensis. Centr. für Bakteriologic und Parasitenkunde, Originale, $75(4): 299-318$.

OsBons, H. L., 1912. On the structure of Clinostomum marginatum, a trematode parasite of the frog, bass, and heron. Jour. Worpholugy, $23(2): 189-227 . \quad\left(f_{f}\right.$, also, Cort, 1913).

stenkard, H. W., 1917. Studies on North Ameriean Polystonidie, Aspidog:astridx and Paramphistomidix. Illimisis Biol. Monograph, $3(3), 114$ pp., 11 plates. 


\section{CHAPTER III}

\section{THE LIFE CYCLE OF A TYPICAL TREMATODE}

\section{TECHNICAL SUGGESTIONS}

For the study of the characteristic operculate eggs, the most certain source of supply is in the various species of frog trematores. Permanent mounts, in balsam, are convenient.

Living miracidia are readily obtained from the eggs of Diplodiscus from the rectum, or of various Gorgoderine from the bladder of frogs. Placed in water at room temperature ther will hatch overnight. If wanted more promptly, the miracidia will emerge within a lalf hour or so if placed in water heated to 35 to $40^{\circ} \mathrm{C}$. For permanent mounts they may be collected in a watch glass with a minimum of water, killed in hot saturated corrosive sublimate solution, stained in borax carmine, and mounted in balsam in the usual manner.

For the study of the larval stages, snails should be collected from different localities, as considerable variation in intensity of infection as well as in species occurs. The best sources of material may be determined in advance of laboratory work by sorting as to species the snails from different localities and placing a half dozen specimens of each group in wide-mouthed s-ounce bottles one-third full of water. Kept in this manner overnight the cercaria escape and the intensity of infestation of the various groups can be determined by examining the water. Infected snails may be kept alive ancl will contimue to discharge cercarice for months if the water is changed frequently and lettuce is provided for food.

Permanent balsam mounts may be made after fixing in hot corrosive sublimate or in one of the picro-formal fixatives.

\section{THE LIFE HISTORY OF THE SHEEP LIVER FLUKE}

Preparatory to the practical work the student should review the life cycle of the sheep liver fluke, a form very generally discussed in beginning courses in zoölogy.

The adult fluke in the bile ducts of the liver deposits eggs which pass into the intestine of the host and out with the droppings. These eggs are operculate and develop the ciliated embryo, or miracidium. After two or three weeks in water the miracidium escapes and bores into the pulmonary chamber of a particular species of snail where it transforms into a sporocyst, an irregular mass without cilia and without a digestive tube. 
Within these are developed numerous elongate redice, with simple, unbranched alimentary canal. These rediæe leave the sporoeyst and invade the liver of the snail where they give rise to daughter redice or directly to the third form, or cercarice. These are minute, talpole-like forms with a bifurcate intestine, a tail, and, in this species, two suckers. The cercarice escape from the snail and, losing their tail, become encysted on grass and other herbage.

\section{PRACTICAL WORK}

While Fasciola hepatica, the sheep liver fluke, oceurs only in limited areas in the United States, most of our vertebrate animals, from fish, frogs, and reptiles to man, are infested by their own special speeies of flukes which undergo essentially the same eycle of development as loes the better known speeies from the sheep. The larval stages of these flukes are to be found in snails from our ponds and lakes, sometimes two or more species together. Study and make drawings of the following stages:

Eggs.-These may be studied in prepared slides or by obtaining living flukes from the lungs or intestines of a frog, teasing them apart, and mounting them in water. The eggs are ovoid bodies with a smooth brownish shell and a minute eap, or opereulum, at one end (Fig. 3). The contained proto-

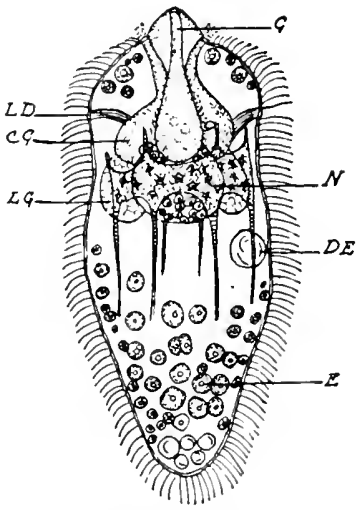

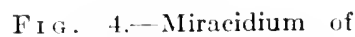
Schistosomum japanicum (' $G$, eephalic gland; $D E$, degenerate embryo; $E$, developing embryo; $G$, gut; $L G$, lateral gland duci; $N$, nerve center. (After Faust and Meleney.) plasm may be undivided or in varying degrees of segmentation depending on the species. When the embryo develops, it pushes open the operculum and escapes as a free-swimming miracidium.

The miracidium (Fig. 4), is more or less conical, with a short papilla at its anterior end. The surface is covered by cilia giving the living organism a superficial resemblance to a rapidly moving infusorian. An eye spot is usually to be seen a short distance from the anterior end. A deeply staining mass posterior to the middle of the body is made up of the germ cells. The miracidia 
enter the pulmonary chamber of a preferred species of snail and transform into sporocysts.

By use of the appended key (p. 18) determine the genus of the living snails furnished for this exercise. This done, earefully snip away the shell and remove the snail to a dish of water. Note the large respiratory chamber on the dorsal surface and the very large yellowish or brownish liver which forms a litrge part of the coiled portion of the snail.

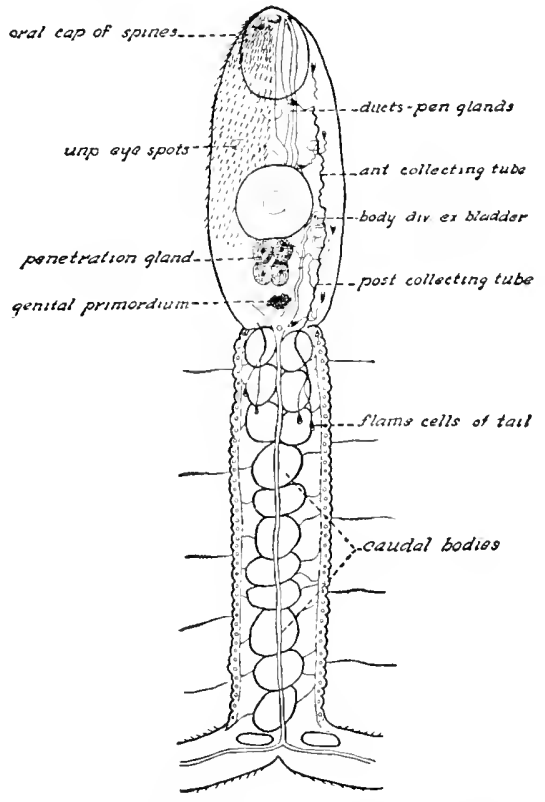

FIg. 5.--Semi-diagramatie drawing of Cerearin longifured. The body spinattion is shown only on the left side and the excretory system on the right. (After Cort and Brooks.)

At this stage there may be scen one or more clear colorless worms about half an inch in length, with well-cleveloped setae, or bristles. These have no relation to the developmental stages of the fluke but are commensal annelid worms of the genus Chatogaster.

Open and examine the pulmonary chamber of your snail. In a high percentage of specimens will be found the early larval stages of some fluke.

The sporocyst is an elongated sac with an outer cuticle, a thin muscular layer, and an inner epithelial layer. In the interior are 
groups of eells of varying size from which develop the next generittion, the rerliat.

The redie are chatracterized by an unbranched siclike alimentary eanal with a single opening, the mouth. The rediae wander about in the snatil, being cspecially abundant in the liver. Within then may be produed denghter redior or, sepecially in the fall and winter, the next larval form, the cercarial.

The cercurice (Fig. 5) are usually tadpole-like in shape and are at first very active. They possess a tail, one or two suckers, a bifurcate alimentary canal with a single opening, the mouth, and the rudimentary genital organs. The excretory system, which consists of a complicated series of "flame cells" and of collecting tubules, will be demonstrated (see p. 16). Its development in one of the holostone ecrearia is shown in the accompanying figure from Cort and Brooks, 1928. In any locality there may be found cerearise of several types which should be determined by the appended key. Oceasionally while being studied, a cerearia may be seen to contract, form a clear colorless cyst about its body, and discarel its tail, which ma continue to thrash about independently for a time. The encysted forms are known as metacerearie.

The encysted metacerearice occur on vegetation or on, or in, other animals, depending on the species of fluke from which they are derived. Various erustaceans and insects, fish, and frogs are commonly infected and are the intermediaries through which the parasite is passed on to its final host.

Certain flukes, such as the schistosomes, or blood flukes of man and animals, onit the redia stage in their life cycle, cercaria being produced within the sporocysts. Their characteristic fork-tailed cercarice do not becone encysted but bore actively into the skin of the final host. There will be demonstrated Cercuria elme, a species which is parasitic on some of the lower mammals and is often a cause of transitory skin irritation of man, known as "swimmer's itch." 


\section{Ké to the Chief Groups of Cercalriæ \\ Adapted from Lühe, 1909}

A. Body of the cercaria with strong longitudinal projections along the side.................... Lophocercaria

AA. Borly without such longitudinal projections.

B. Two long, symmetrical projections from the end of, and several times exceeding the length of the body. Mouth opening in the middle of the ventral surface. Intestine simple, sac-like. . . . . Gasterostome cercaria BB. Tail variously formed but never split to the base.

Mouth at anterior end. Intestine forked.

C. Ventral sucker lacking....... Monostome cercarie CC. Ventral sucker present.

D. Ventral sucker at the very end of the body directly before the base of the slender tail............. Amphistome cercarive

DD. Ventral sucker in front of the caudal end of the body.

Distome cercaria

Key to The Major Genera of Fresh-water Snalls

A. Shell spiral, dextral (i.e., with aperture to right of the axis when held apex uppermost with aperture facing you) Spire more or less clongate. . . . . . . . . Genus Lymnce

B. Shell discoidal, usually sinistral. . . . . . . Crenus Planorbi.s C. Shell spiral, sinistral............... Genus Phys

\section{References}

Cont, W. W., 1915. Some North American larval trematoles. Illinois Biol. Monographs, 1: 447-532.

Fausr, E. C., 1917. Life history studies on Montanat trematodes. Illinois: Biol. Monographs, 4 (1): 120.

Faust, E. C., 1919. A biologieal survey of describer cereatiate in the United States. Am. Naturalist, 53: S5-92.

LüHe, M., 1909. "Patrasitische Plattwürmer. I. Trematodes. Siisswasserfauna Deutschlands." Heft 17, 217 pp.

MrLler, H. M., 1925. The larval trematode infestation of the fresh-water mollusks of San Juan Island, Puget Sound. Washington Univ'. Studies, 13 (Science series 1): 9-22.

Ward, H. B., 1918. Key to North American fresh-water Trematodit. In WARD and Whipple, "Fresh-water Biology," pp. 374-424 
('HAP'TER IV'

\section{THE STRUCTURE AND LIFE HISTORY OF A TAPEWORM, TENIA PISIFORMIS}

(BLOCH 1780)

\section{TECHNICAL SUGGESTIONS}

The cosmopolitan Tarnia pisiformis (T. serrata) of dogs is the most available material for this pratetien. For the morphological study, spereies of Multiceps or any of the other tanioid restodes of the doy are equally suitable. Proglottides of T'unia saginata of man are oreasionatly available from hospitals or may be purchased from hiologicitl supply houses.

Prepared slides of entire specimens of Tarnia pisiformis are instructive, but in general it is more satisfactory to have separate mounts of developing, mature, and ripe proglottides and of the seolex. Direetions for the preparation of these will be found in the Appendix, page 101.

The hexaeanth embryos are more readily studied in egges of the hrmenolepid tapeworms. Rats and miee, inchuding laboratory varjeties, are commonly infested by these worms, as are also chickens. At most seasons of the year viscera of freshly killed poultry can be seeured from butcher shops and will yield ample material.

Cystie stages may be found in wild rabbits the conntry over, but in order to insure a supply of suitable material, eggs from ripe proglottides of Trenia pisiformis should be fed to tame rabbits some two months hefore needed.

If there are facilities for experimental work, cysts of this age may be fed to a dog at the time of the laboratory practicum and the adult worms may be recovered in about six weeks.

In lien of rabbit material, cysts of Tonia tonioformis of eats may be found in the liver of a high pereentage of wild rats and mice. These are readily developed in kittens.

\section{CHARACTERISTICS OF THE CLASS CESTODA}

The Cestoda, or tapeworms, are flatworms which have, typically, the form of a ribbon made up of a large number of segments, or proglottides (singular, proglottis). At one extremity is the organ of attachment, the scolex, provided with suckers of varying form and number, and, in some cases, with hooks. The body cavity is lacking, as is also the digestive tract. Food 
is absorbed directly throwgh the integument. Witl rare exceptions, the life eycles of tapeworms involve at least two hosts of different species.

The class Cestoda is divided into two subelasses, the Monozoa and the Merozoa. The former contains the most prinitive Cestoda, unsegmented forms which are of special interest as showing relationships to the Trematoda, or flukes. Most of the described speeies are from fish.

The typical tapeworms belong to the subclass Merozoa. We shall take as a type Trenia pisiformis, one of the most eommon tapeworms of the dog.

\section{PRACTICAL WORK}

Gross Examination.-A fresh or prepared specimen of Temia pisiformis will be furnished for examination. Note the length, the shape of body, the head or seolex, the neck, and the strobila, or chain of proglottides, or segments. About the middle of one side of the larger proglottides note the genital pore. Do these oeeur on the same side of all the proglottides? Count the number of proglottides. Make an outline drawing illustrating these points, inclicating by dotted lines regions only partially represented.

Detailed Study.- C'sing stained and mounted preparations, study carefully the following points, making enlarged drawings of each region. As the specimens are thick and more or less opaque, it is important carefully to regulate the lighting and to use great caution to avoid injuring them.

Seolex.-Note the shape and relative size of the seolex. It is provided with four suckers for attachment to the host. In addition, Trenia pisiformis is "armed" with a double eirclet of attachment hooks, borne upon a shightly projeeting rostellum. The hooks vary in number, size, and shape in different species of tapeworms and should be carefully studied in the specimens available. Bxamine several slides giving different aspects of those struetures. Indicate also in your chart the short, unsegmented neek.

Developing Proglottides.-Wxamine proglottides from the first sixth of the body length and note the carly traces of the reproductive organs. It should be recalled that the Cestodal are hermaphroditic. Two more deeply staining lines rumning in from the genital pore represent the vas deferens and the vagima. In the 
mesal line, near the lower portion of the proglottis, the vaginat bends down to an indistinetly out lined mass, which is the developing ovaries. Passing forward from this is the unbranched uterus. The floceulent mass largely filling the proglot tis is made up of the lobes of the testes.

Mature Proglottides. - Selecting a proglot is somewhat beyond the midelle of the strobila, study the mature reproductive system. Compare lig. 6, illustrating a relaterl gemus.

The more anterior duct passing mosad from the genital pore is the vas deferens. The racemose lobes of the testes are attached

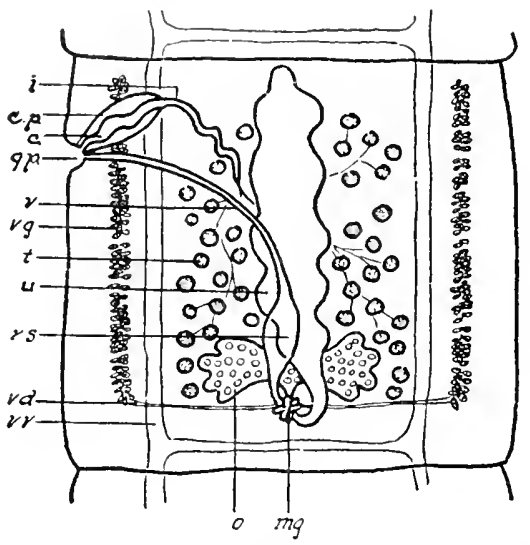

Fig. 6.-Mature proglottis of a tenioid tapeworm Ichthyolenia. c, eirrus; c.p., cirrus pouch; $g . p .$, genital pore; $i$, vas deforens; m.g., Mehlis gland; o, ovary; $r . s$. receptaculum seminis; $t$, testicle; $n$, uterus; $v$, vagina; v.d., vitelline duct: $v . g$. , vitelline gland; $v . v$, ventral excretory vessel. (After Fuhrmann.)

to the vas deferens by very delicate efferent ducts. They occupy what is generally interpreted as the dorsal surface of the segment. At its outer extremity the vas deferens enters the swollen cirrus pouch, within which it terminates in the cirrus or penis.

Running parallel and caudad to the vas deferens is the vagina. Towards the middle of the proglottis the vagina bends caudad and unites with the oviduct passing from the paired ovaries. Near its point of union the vagina enlarges slightly to form a receptaculum seminis. The ovaries, lying to either side of the mesal line, are of unequal size and are composed of a number of tubular follieles. In the middle line just back of the ducts from the ovaries is the rounded Mehlis gland, or so-called shell gland. Close to the caludal margin of the proglottis is the yolk, or vitelline gland. The 
vitelline duct runs forward from this to the Mehlis gland. From this point the uterus passes forward as an unbranched tube in the mesal line, extending to the anterior end of the proglottis. The female organs are confined to the ventral surface of the proglottides.

At either side of the proglottis may be seen two clear lines. The inner, larger of these represents the main canal of the excretory system. Close to the posterior margin of each proglottis is a transverse canal connecting the longitudinal canals. A second, much smaller longitudinal canal lies entad of the above described and may be seen in sections.

Outside of the excretory canal is the principal longitudinal nerve, on each side. Smaller nerves are present but cannot be seen in whole mounts.

The excretory and the nervous system are continuous throughout the length of the strobila.

Ripe Proglottides.-In the terminal segments the generative organs have been in large part supplanted by the uterus, which has become much branched and is filled with eggs already containing the six-hooked or hexacanth embryo. The number and form of the branches of the uterus are points of importance in classification, there being eight to ten irregular ramifications on each side in Tania pisiformis.

Examination of Sections.-Cross-sections through a mature proglottis emphasize the lack of alimentary canal and of body cavity, a condition typical of the Cestoda. The outermost layer of the body is a thick resistant cuticle, which is secreted by prominent, deeply staining, fusiform matrix cells embedded in the parenchyma, or tissue which fills all the space between the different organs and muscles. Immediately under the cuticle is a delicate layer of circular muscles, followed by a layer of longitudinal muscles whose cut ends can be seen among the matrix cells at their outer end. A second and much more extensive set of longitudinal muscles lies in the parenchyma entad of the matrix cells. Within these are the transverse muscles which run across the proglottis. Scattered through the parenchyma are the light-refracting, concentrically striated calcarious bodies which give to the worm its opaque white color.

The large pore near the lateral margin of the section is the external excretory vessel in cross-section. Immediately entad of this is the smaller internal exeretory vessel. Lying just outside of 
the external exeretory vessel is the large longitudinal nerve. Two smaller nerves aecompany this but are hardly distinguishable in the sections.

Occupying the central portions of the section, between the exeretory vessels of the two sides, are sections of the reproductive organs. In the seetions furnished the major portions of this mass consist of lobes of the testes.

Life History.-Examine eggs from a ripe proglottis. These are best studied in fresh material, even if another speeies is the only one available; but prepared slides may be used.

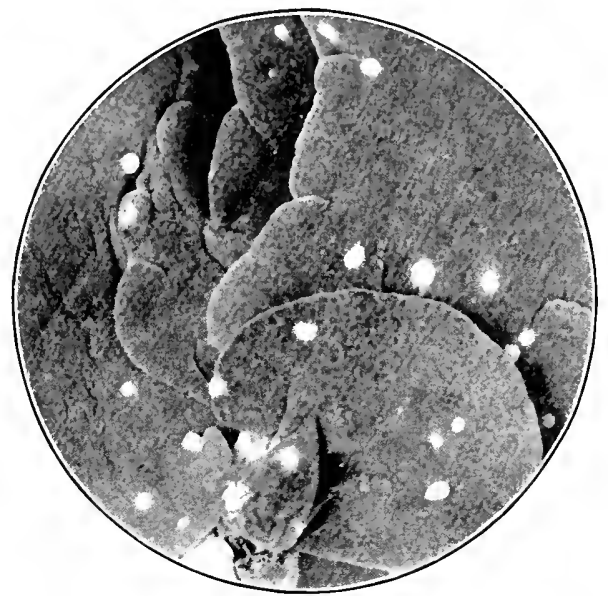

Fit. 7.-Cysts of Tania pisiformis in the liver of a rabbit 24 days after experimental feeding. (Orig.)

It will be found that in the eggs ready to be discharged from the body, the six-booked or hexacanth embryo is already formed. In the fresh material movements of the embryo can be readily studied. It should be noted that the so-called shell of eggs of tapeworms of the group under consideration is in reality an embryonie membrane, the embryophore, formed from cells of the egg itself. In Tania pisiformis and related forms, this embryophore is finely striated, appearing to be made up of many fine rods placed side by side. The hexacanth embryo is also commonly known as the oncosphere.

Hatching of the Eggs. - When the eggs of the tapeworm are taken up by an appropriate animal, the embryo is liberated by the aetion of the digestive juices. In the ease of Trenia pisiformis 
the intermediate host is the rabbit, and it should be understood that while the general features of the life cyele are typical for the group, the details apply to this species only.

Development within the Liver.-The liberated embryos, by means of their armature of hooks, penetrate the walls of the intestine and are earried by the blood eurrent to the liver. There they lose their hooks and by the sixth day they have enlarged suffieiently to appear as little transparent vesieles (Fig. 7). By the twelfth day, having attained a size of $3 \mathrm{~mm}$., they present the appearanee shown in the slides provided, that of little whitish

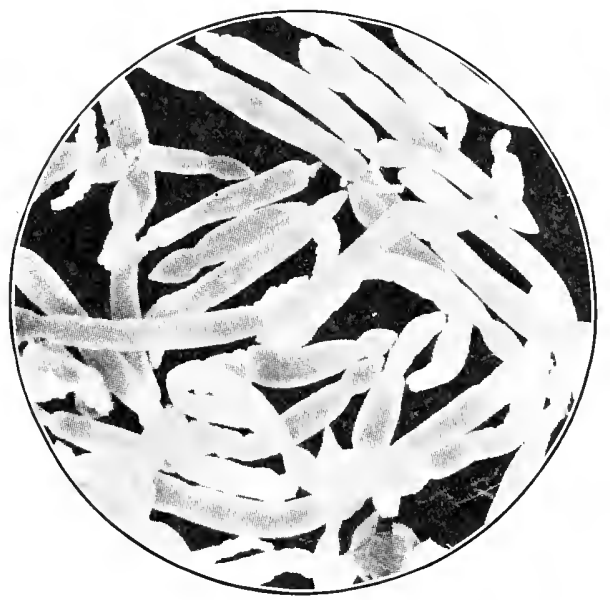

Fic. 8.- Migratory larre of Tenia pisiformis as they may be found free in the body cavity of the rabbit 5 weeks after infection. (Orig.)

bodies made up of a very loose parenchyma tissue, limited by a delieate eutiele. The head of the future tapeworm begins to form at this stage.

Development in the Mesenteries.-About a month after infestation the very active larva squirms out from the liver and lives free in the body eavity of the rabbit for several days (Fig. 8). The eentral part of the larva degenerates and becomes filled with a fluid, and the rounded mass attaehes to the peritoneum or mesenteries of its host as a cysticercus. This cysticereus, with its invaginated head of the future tapeworm, at the end of a few weeks is about the size of a pea, and is ready to transfer to the definitive host and there develop into the mature tapeworm. This proeess requires about two months before ripe segments are ready to be discharged. 
Sketch a bit of mesentery of an infested rabbit, showing the eysts of Tenia pisiformis, in situ. Make careful drawings of mounted eysts, showing the extruded linva.

\section{References}

The discussion of a tanioid tapeworm of man, in any good textbook of parasitology, will be hroally applicable to the species here used. In addition the following referenees may be consulted:

DefFke, O., 1\$91. Dio Entozoa des Hundes. Arch, wisscnsch. u. pratit. Thierheilliumle, 17 (1): 1-60; (3): 253-2s9.

HALL, M. C., 1919. The adult taenioil cestodes of dogs and eats, and of related camivores in North America. Proc. U. S. Not. Museum, 55 : $1-94$.

Moniez, R, 1s80. "Essai momographique sur les eysticerquues," 190 pP., 3 plates. Theres, Lille. 


\section{CHAPTER V \\ COMPARATIVE STUDY OF SOME IMPORTANT CESTODES}

\section{TECHNICAL SUGGESTIONS}

Mature and ripe proglottides of Tornia saginata of man are readily obtainable. The former is so similar to that of Ternia pisiformis that it is not neessiry to devote time to its sturly, but the ripe proglottides should be available for comparison with those of Taria solium, which ean be purchased from dealers. Demonstration speeimens of the rysticerei, entire and in section in heef or pork, should also he purchased.

Scoliees of these worms are rarely available, but the everted heads from the cysticerci of the two species are more readily obtainable.

Hymenolepis nana and Hymenolepis diminuta are commonly found in both wild and laboratory rats and mice. Whole mounts should be made for morphologienl study. The cystieereoids of H. nama may be obtained by feeding the eggs in numbers in bread and milk to rats and sectioning the intestine 24 to 48 hours later. II. diminuta developmental stages may be obtained most readily by feeding eggs to adult meal beetles, Tenebrio molitor.

Dipylidium caniuum and closely related species are very common in pet dogs and eats. Their characteristic egr packets in fecal material should lo preserved in 10 per cent formalin. Cysticereoids develop in larval fleas and may be found in a small percentage of the adult insects from infeeted dogs.

Diphyllobothrium latum is endemic in some sections of this country; but, in general, reliance must be placed on dealers. If living specimens are available, the eggs should be cultured in water at summer temperatures and the eiliated embryos will escape in 10 to 12 days.

Multiceps serialis is a widely distributed parasite of dogs. The cystie state of this parasite is often noted in the muscles of ralhits. Sections of such cysts should be mark to show the multiple invaginated heads. Experimental feedings of dogs are readily carried out, if there are facilities for keeping the animals under control.

Echinococeus eysts are most readily obtained from slaughter houses in our Southern states. Sections of the cyst wall and mounts of fragments of the germinal layer showing larval seoliees should be made or purchased. Strangely enough, the mimute adult worms have been very rarely found in dogs in this country. They should be sought in examination of these animals in the south, due regard being taken of the danger to humans from careless handling of infective mat erial. 


\section{PRACTICAL WORK}

The purpose of this praticum is to become aequainted with the prineipal tapeworms affecting man and some of the animals with which he is closely associated. Using your study of Ternia pisiformis as a basis, earefully examine such of the following speeies as are available, making drawings of signifieant features.

Tænia solium L., the pork tapeworm of man, develops as a cystiecreus or "bladderworm" in the flesh of hogs. The adult worm in man measures 2 to 4 meters or more in length and has 300 to 1,000 proglottides. The head bears a short rostellum with a double erown of hooks. The ripe proglottides are usually diseharged from the human host in short chains and since the species is a dangerous one it is important to note that the uterus of these ripe segments is characteristically branched in a dendritic (treelike) manner with only 5 to 10 branches on each side. The eggs are globular, about $50 \mu$ in diameter, with a thick, radially striated embryophore ("shell").

Tænia saginata (Goeze), the beef tapeworm, undergoes its larval stage in beef. It is the commonest of the large tapeworms of man in the United States and in most parts of the world. It may measure 12 meters or more in length and possess as high as 2,000 proglottides. The head has four suckers but is unarmed, i.e., it lacks hooks. In the ripe segments the uterine branches are more numerous ( 15 to 30 ) than in T. solium and are dichotomous. The eggs closely resemble those of $T$. solium but average slightly larger.

Compare mature proglottides of $T$. solium and $T$. saginate with those of $T$. pisiformis and earefully compare the uterine branching in the ripe segments of the three speeies.

Examine demonstration specimens of the eysts in pork or beef, if available. The characteristics of the heads of the two species may be seen in everted heads of the larve.

Hymenolepis diminuta (Rudolphi) is a rat and mouse tapeworm that is also transmissible to man. It is a slender worm 20) to $40 \mathrm{~cm}$. in length and $3.5 \mathrm{~mm}$. at its greatest breadth. The head is unarmed and has four suckers. The segments, which may number upwards of 1,000 , are very short and have the genital pores all on the same side. In each mature segment there are three large round testes, in transverse order. Between the first and second of these are the paired, branched ovaries and the 
vitelline gland. The sac-like uterus completely fills the ripe proglottides. The eggs are large and transparent with two envelopes, the inner double, and with two polar knotlike projections. The larval stages develop in various cereal-infesting insects. (Fig. 9).

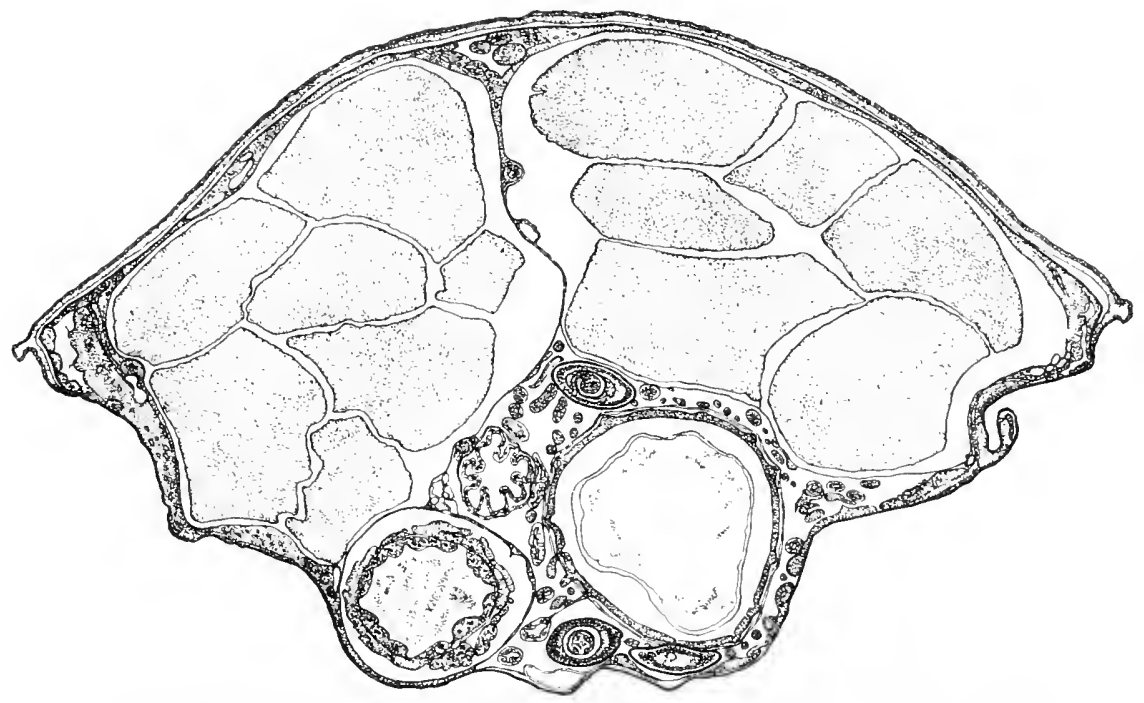

Fig. 9.- Cysticerenids of Hymenolepis diminuta in body eavity of at beetle, Tenchrio molitor. The three specimens lie adjacent to the large section of the alimentary canal.

Hymenolepis nana (von Siebold) is the dwarf tapeworm of man, a species so minute and threadlike that it is usually overlooked in macroscopic examinations. The adult worms measure from 10 to $25 \mathrm{~mm}$. (1 inch or less). The head has four suckers and a simple crown of hooks. The general morphology is similar to that of $I I$. diminuta. The eggs can be distinguished by the fact that there are filiform projections from the knobs of the inner membrane. A striking exception to the usual rule is the fact that these worms are able to complete their development in a single host.

Dipylidium caninum (Linn.) is one of the commonest tapeworms of pet dogs and is also capable of developing in man. It measures 10 to $40 \mathrm{~cm}$. in length. The retractile rostellum is provided with three or four rows of minnte, thornlike, easily detached hooks; the suckers are relatively large and cllipsoid. The mature proglottides somewhat resemble cucumber seods in 
shape and are provided with a genital pore on each side and with double sets of reproductive organs. 'The uterus forms numerous diverticula, enclosing packets of $S$ to 15 eggs. Distinguish in mature segments the genital pore on each side, with cirrus, (irrus pouch, vas deferens, vagina, ovary, vitelline glands, and the diverticula of the utrus. The eysticercoid stage develops in fleas and lice of the dog and eat.

Diphyllobothrium latum (Limn) (=Bothriocephalus of older writers) is the broad or fish tapeworm of man and various carnivores. It is the largest of the tapeworms of man, since

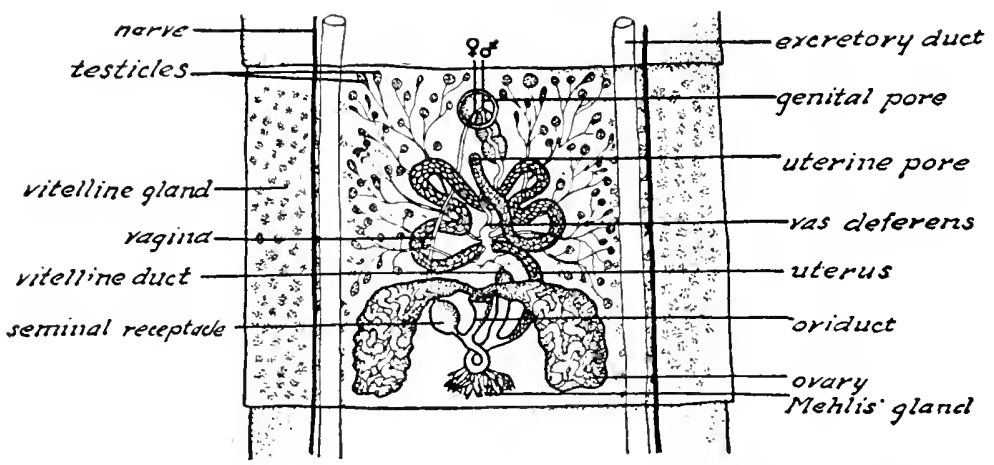

Fig. 10.-Diagram of a mature proglottis of Diphyllobothrium. (After Verdun and Mandoul.)

it may attain a length of 15 meters or even more and possess from 3,000 to 4,000 proglottides. The ovoid head has two elongate attachment grooves, or bothridia. The proglottides are much broader than long and in their center is the uterus, in a rosette-like coil (Fig. 10). In the fresh specimen this appears as a dark median area which readily distingushes the worm from the large tænias of man. The genital pore is situated in the mid-ventral line instead of laterally, and slightly farther back is a second opening through which the eggs are laid. The paired ovary is at the posterior end and the vitelline glands at the sides of the proglottides. The eggs are large, elliptical, brown, and provided with a cap, or operculum.

The fish tapeworm of man is one of the few eestodes known to require three hosts for its life cyele. From the egg there emerges a free-swimming eiliated embryo known as a coracidium, which after a short time enters one of various minute Copepod 
crustaceans. Here it develops into a first larval stage, and when the infected crustacean is devoured by pike, piekeral, burbot, and certain other fish, the larva develops into an elongate wormlike plerocercoid encysted in the museles. In this stage it is infeetive to man.

Make sketches of a mature segment, a seolex, and eggs, showing the above features. Plerocercoids of this or related species will be demonstrated.

Multiceps serialis (Gervais) is a tapeworm of dogs which in its morphology closely resembles Tania pisiformis. In its

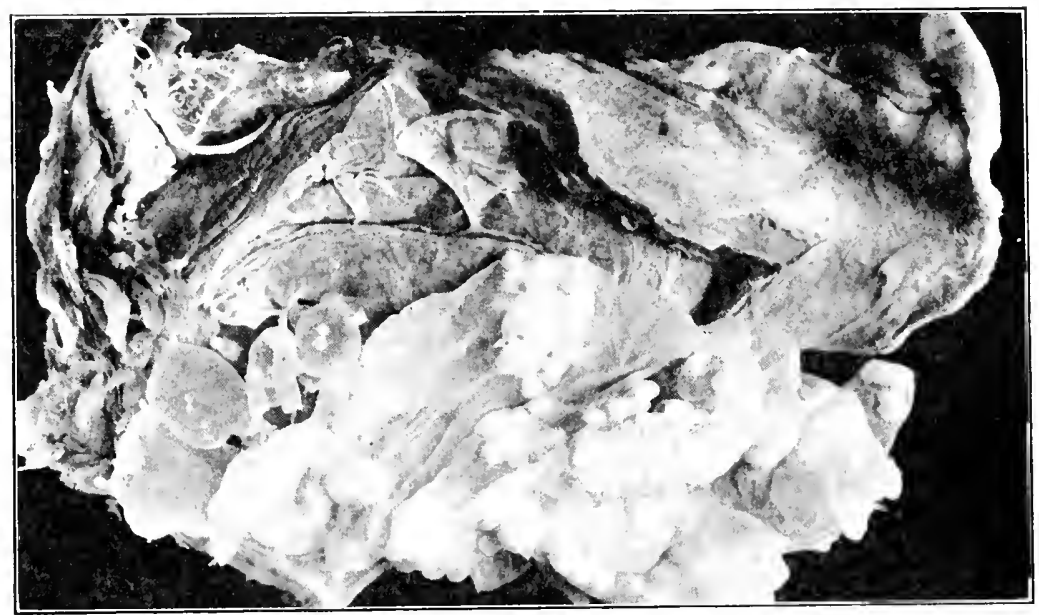

FIG. 11.-A cyst of Multiceps serialis from the shoulder of a jack-rabbit. Eareh of the rounded white bodies is a head capable of developing into a tapeworm if ingested by a dog. (Orig.)

development in the intermediate host it presents a striking departure from the usual type. The eysts (Fig. 11), occur as large, so-called "boils" in the muscles of ribbits. They are filled with a limpid fluid, and on the interior are great numbers of minute granular bodies, each of which represents the invaginated head of a future tapeworm. In other words, worms of the genus Multiceps exhibit polyembryony, or the production of many individuals from a single egg. Examine demonstration specimens of the cysts in situ, and study prepared slides showing the invaginated scolices.

Echinococcus granulosus (Goeze) is the dangerous hydatid tapeworm which develops its cystic stage in a wide range of 
mammals, ineluding man. The adult is a very small worm living in the intestine of dogs. It measures a fourth of an inch or less in length and has but three proglotticles. The head is very small, with a prominent rostellum armed with a double row of hooks. The terminal, ripe proglottis comprises about half the entire length of the worm but contains a relatively small number of eggs.

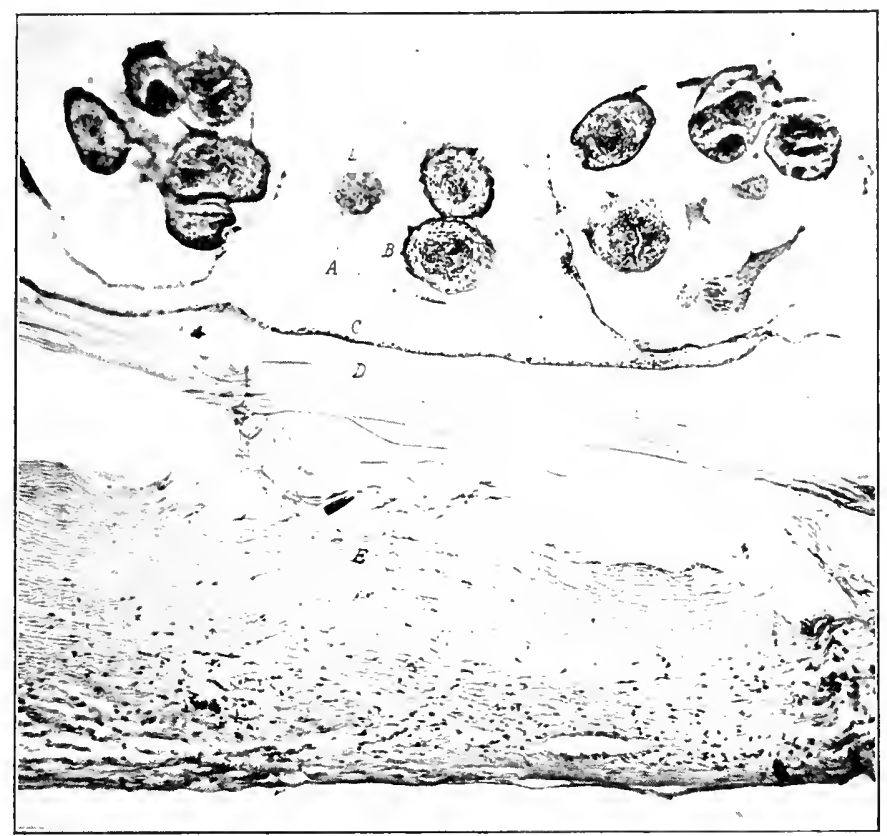

FIG. 12.-A section of the cyst of Echinococcus granulosus in the liver of a pig. $A$, brood capsule; $B$, scolex; $C$, germinal layer; $D$, cuticle; $E$, adventitious layer, formed by the host. The three layers bave been separated in the process of sectioning. (Orig.)

The eysts develop slowly in the intermediate host but in man may attain the size of an orange or even of a human head. The thick wall of the cyst is eomposed of an outer adventitious layer formed by connective tissue of the host. Next is a firm lamellated layer called the cuticular membrane. Within this is the thin germinal layer. From the germinal layer and from certain scolices which undergo metamorphosis, there are formed many brood eapsules within which arise numerous larval seolices. Thousands of these potential tapeworms may be present in 
a single hydatid cyst. The brood capsules within which they develop become detached from the germinal layer and float in the fluid as the so-called "daughter cysts."

Examine demonstration specimens of hydatid eysts. Study and make drawings of sections of cysts in liver or lung tissue of the intermediate host and of surface views of the germinal layer with developing scolices. 


\section{CHAPTER VI}

\section{ASCARIS LUMBRICOIDES AS A TYPE OF THE NEMATODA}

\section{TECHNICAL SUGGESTIONS}

Specimens of the pig ascaris are to be obtained from slaughter houses and preserved for dissection in 10 per cent formalin. The larger horse ascaris makes an excellent object for laboratory dissection but is rather difficult to obtain.

Eggs should be removed from the terminal portions of the uteri of fresh specimens and eultured at summer temperature under a shallow layer of 2 per cent formalin to prevent contamination. All stages will be found for study in about two weeks.

Experimental animals - mice, rats, or guinea-pigs-may le fed cultures of infective eggs on lread and the pathologie conditions in the lungs demonstrated a week latel.

The migrating larve can most easily be recovered by ehopping the liver and lungs and placing them in the simplified Baermanm apparatus (p. 107). Then they will migrate out into the warm water and settle to the bottom.

For demonstrating the larva in the liver tissue, a heavily infected animal should be killed about the fourth day after the experimental feeding and small portions of the liver fixed in Zenker's fluid. For stages in the lung, it is better to fix in acetic-alcohol glacial acetic, 1 part; absolute alcohol, 3 parts) some 10 days after infeetion. Paraaffin sections of 10 to $15 \mu$ in thickness should be cut, stained in Delafield's hæmatoxylin, and mounted in the usual manner.

For the infection experiments the dog ascaris, Toxocara canis, or Toxocara mystax from the cat will serve as well. Demonstrations of these common parasites should be shown and their eggs studied in comparison with those of Ascaris lumbricoides.

At this time there should also be demonstrated sperimens of Gordiacea and of Acanthocephala, forms which can harlly be given special attention in an introductory course.

\section{CHARACTERISTICS OF THE ASCAROIDEA}

The class Nematoda contains species of great economic importance to animals and plants. Many of the species parasitic in animals pass part of their cycle free in the soil. The majority of the species of the group are oviparous, although some are viviparous. The larvæ undergo typically two molts before they are in the infective stage. As an introductory type Ascaris 
lumbricoides serves admirably, being large enough for easy dissection and presenting no complicated or highly specialized arrangement of organs.

Ascaris lumbricoides belongs to the superfamily Ascaroidea. In the course of the following study, the student should carefully cheek over the eharaeteristics of this group, as given by Yorke and Maplestone: "Eunematoda; usually fairly large and stout; head bilobed; asophagus frequently more or less enlarged posteriorly, but without a definite spherieal posterior bulb eontaining a valvular apparatus (except in Dujardinia, where there is a small, unarmed bulb), with or without diverticula. Spieules equal or unequal. Females not much larger than the males."

\section{PRACTICAL WORK}

External Features.- Note the general form of the body, which in the Ascaridæ is relatively thiek. The mouth is surrounded by three lips, one dorsal and two ventro-lateral. Running lengthwise of the body are four equidistant lines, a dorsal, a ventral, and two lateral lines. About two millimeters from the anterior end is the minute exeretory pore in the median ventral lime.

Dissection. - The female worm may be distinguished from the male by her greater size and gently curving caudal end. In the male the caudal end is sharply curved to form a hook, and two spieules may be seen at the anal opening. In the female the genital opening is also ventral and situated about one-third the length of the worm from the anterior end. The mouth opens between the three lips at the anterior end. The anal opening is at the caudal end.

Make an enlarged drawing of the ventral anterior end of the body showing the lateral lips and the position of the exeretory pore. Make an outline drawing of the entire worm showing the position of the mouth, anus, exeretory pore, genital opening, and lateral line.

Slit a female worm very carefully longitudinally just laterad of the median dorsal line and pin out the body in a dissecting pan. To prevent the specimen from drying, cover it with $1 / 2$ inch of water. Note the alimentary eanal consisting of a straight tube running from mouth to anus. Three seetions may be distinguished: a short xsophagus, the long flattened mid-intestine, and a short rectum. The lateral line can be seen as an inward projecting ridge separating the longitudinal museles. Loeate the genital 
opening, or vulva, about one-third the length of the worm from the mouth, on the mid-ventral line. Passing in from this is the short vagina, which soon divides into two long tubes which are much convoluted and are filled with eggs, The portion of these tubes nearest the vagina represonts the uterus, the middle portion is the oriduet, and the thinner distal portion the ovary. Enclosed in the ovary is the long central rod, or rechis, around which the eggs are arranged.

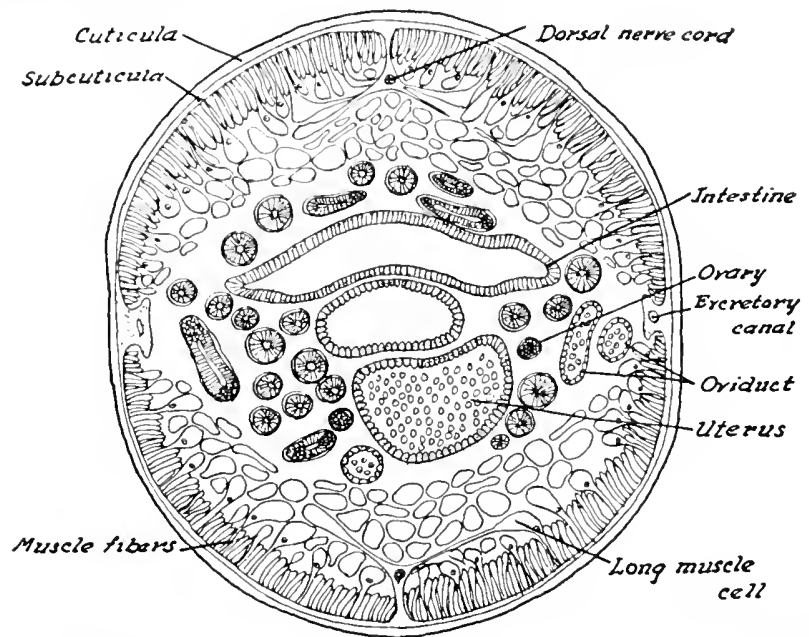

FIG. 13.-C'ross-section through the mid-body region of a female Ascaris meyalocephala. (After Kükenihal.)

Make a drawing showing the alimentary canal, the vagina, the uterus, the oviducts, and the ovary.

In a similar manner prepare a male specimen for study of the internal anatomy. The male reproductive organs are situated posteriorly. A long, single, much-coiled tube opens into the cloaca, a short portion of the alimentary tract between the rectum and anus. This tube is divided into three uneven portions: the testis, the longest portion, which is a thin convoluted tube containing a rachis with the sperm cells arranged around it similarly to the condition in the female; the vas deferens, the part of this tube not containing the rachis; and the seminal vesicle, the central portion, which is much shorter and thicker. The terminal portion is again thimner and quite short, having a musculature of its own. It serves as the ejaculatory duct.

Compare the male and female worms carefully, but drawing of male may be omitterl. 
Cross-sections. - Examine prepared slides of cross-sections of Ascaris lumbricoides or of a related species. Inder low power make a drawing showing the body wall, the alimentary canal, reproductive organs, and the dorsal, ventral, and lateral lines.

Using high power, make a drawing showing the body wall: the cuticle with its various strata, the hypodermal layer from which the cuticle is a derivative, and the single layer of longitudinal

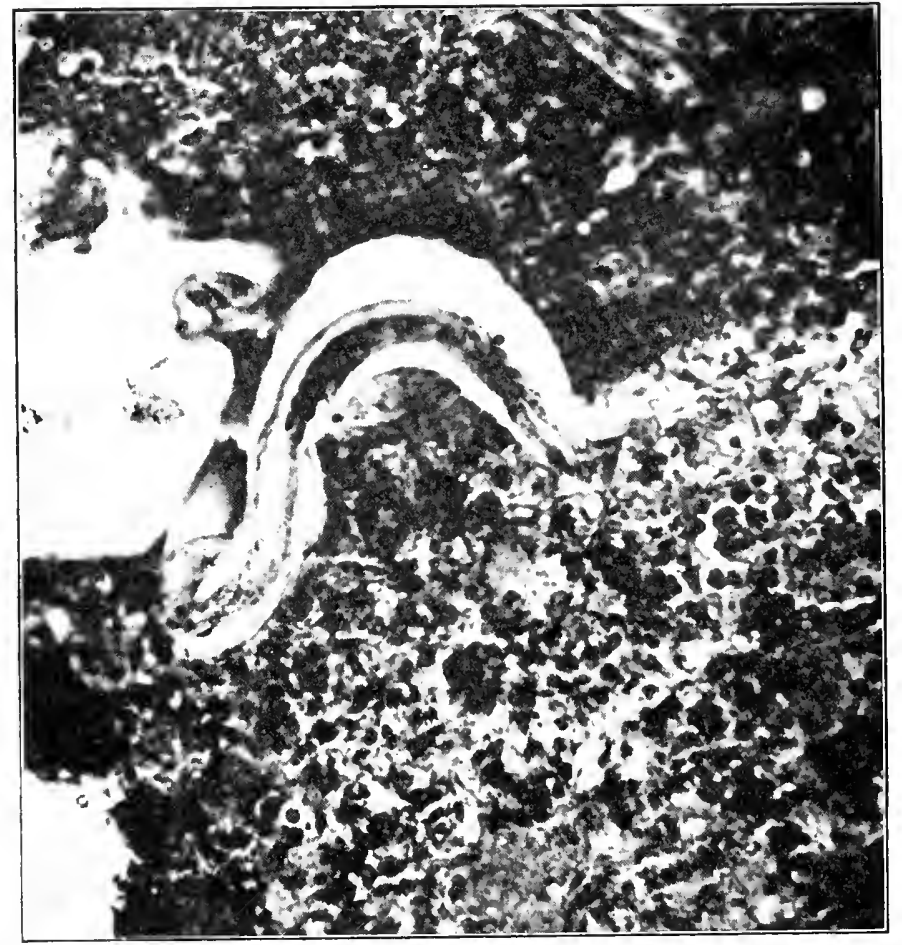

Fig. 14.-Migrating larva of Ascaris lumbricoides in liver of guinea-pig 6 days after feeding. (Orig.)

muscles. Each muscle possesses a protoplasmic core with a nucleus, and a contractile sheath. If possible, find a section cut through the nucleus to include in your drawing. Each muscle cell, or fibril, is enclosed in a thin connective sheath the nuclei of which are often discernable.

Development.-The eggs of Ascaris lumbricoides, as of many Eunematoda, develop directly, without the necessity of an intermediate host. In the course of development the larve undergo a migration through the liver and lungs of their new 
host, increasing in size and finally returning to the intestine to mature.

Using this species or the related Toxocara from the eat or dog, make a series of sketches of first, the unsegmented cggs from the uterus; and second, various segmentation stages from eggs which have been incubated at summer temperature for a few days. The eggs are not infective until they have reached the coiled embryo stage. In both Ascaris lumbricoides and Tororara ranis (Bclascaris marginata) this requires upwards of 2 weeks.

Examine the demonstration specimens of Ascaris larva in the tissues of the liver (Fig. 14) and lungs of experimentally infected rats. If available, note the evidences of "Ascaris pneumonia" in an animal which has been fed infective eggs of the worm about a week previously.

\section{Demonstrations of Gordiacea} and of Acanthocephala.-Compare your specimen of Ascaris, a typical nematode, with the demon. strations of representatives of the Gordiacea and the Acanthocephala.

The Gordiacea are the so-called "hair-snakes." Their bodies are

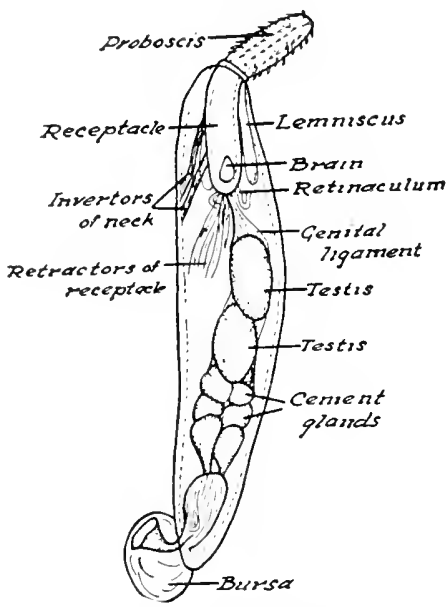

Fini. 15. - Acanthocephalus rana' of frogs and salamanders. (. 1 fter lan Cleave.) slender and wire-like and lack an alimentary camal in the adult stage. In this stage they are free-living, but in the larval stage they are parasitic in insects and less frequently in other invertebrates. As parasites of grasshoppers they often play a part in the natural control of these pests.

The Acanthocephala (Fig. 15) are characterized typically by the presence of a protractile proboscis, armed with numerous hooks, and by the lack of an alimentary canal. The larval stages are found in crustaceans, insects, fish, and small mammals. Adults are especially abundant in birds and fish. The demonstration specimens are of Macrocanthorynchus (Echinorynchus) gigas, a common parasite of hogs. Note also the demonstration of eggs, which are 90 to $100 \mu$ long, nearly cylindrical, with a three-layered shell, the outer layer of which is marked by numerous depressions suggestive of those of an almond shell. 


\section{References}

Martin, H. M., 1926. Studies on the Ascaris lumbricoides. Univ. Nebr. Agr. Exp. Sta., Research Bull. 37, 78 pp.

May, H. G., 1919. Contributions to the life histories of Gordius robustus (Leidy) and Paragordius varius (Leidy). Illinois Biol. Monographs, 5 (2): 127-238.

Ransom, B. H., and IV. D. Foster, 1920. Observations on the life history of Ascaris lumbricoides. U. S. Dept. Agr., Bull. 817, 47 pp.

Van Cleave, H. J., 1919. Aeanthocephala from the Illinois River, with descriptions of speeies and a synopsis of the family Neoechinorhynchidir. Illinois state Natural History Survey Bull., 13 (8): 225-254. 


\section{CHAPTER VII}

\section{THE HOOKWORMS OF MAN AND ANIMALS}

\section{TECHNICAL SUGGESTIONS}

Ancylostoma caninum affords the most satisfactory laboratory type for the study of the hookworms. In ahmost any section of this country a systematic examination of several freshly killed laboratory flogs and cats, or $\operatorname{logs}$ and cats from the eity pound will furnish abundant material. If neessary, speeimens mounted or unmounted ean he purehased from dealers.

The worms should be thoroughly shaken in a vial of elean water to remove mucus and debris from the mouth region, and then killed in hot 70 per eent aleohol plus 5 per eent of glyeerine. When the alcohol has been allowed to evaporate, they may be mounterl in glyeerine jelly and sealed with Noyer's eement. Very satisfactory preparations may be made by passing from plain 70 per cent alcohol to lactophenol mixture in which the speeimens are mounted. For temporary examination either lactophenol or so per cent carbolic acid in absolute aleohol may be used. Such temporary mounts are preferable for small elasses with abundant material sinee they allow manipulating of the speeimen.

Eggs may be obtained in quantity by removing the reetal content of an infeeted dog or eat, sedimenting by several changes of water in a tall bottle, straining through a elose-meshed sieve (e.g., at tea strainer), and preserving in 10 per cent formalin. Random examination of feces of eats and dogs will often yield abundant material.

For larval stages cultures should be made by mixing feeal material containing eggs with equal parts of animal chareoal or heat-sterilized humus moistened with water and stirred to a paste. The moisture content being maintained, they are kept for a week in a warm room or in an incubator maintained at 25 to $30^{\circ} \mathrm{C}$. and then isolated by means of the Baermann apparatus (see Appendix) or by the simple method of White, 1927. The eulture is early placed in a Syracuse wateh glass in a erystallizing dish with water equal to about half the depth of the wateh glass, and the whole is eovered by a lirge watch glass. The larve as they reach the infective stage wander from the eulture into the water and may be recovered in numbers by pouring this off into a test-tube, in which they will settle to the bottom.

An instruetive demonstration of the nematode population of the soil is afforded by placing a pint of rieh garden soil in the Baermann apparatus for a few hours or overnight and draining the sediment in to a large test-tube. A culture of infective hookworm larve should 
be included. Demonstrations of the larvæ in the skin may be purchased.

\section{CHARACTERISTICS OF THE STRONGYLOIDEA}

Among the most important nematode parasites of man and animals are the blood-sucking hookworms and related forms grouped in the superfamily Strongyloidea. They are of moderate size with an elongate, cylindrical, rarely filiform body. The males possess a caudal bell-shaped inflation known as the bursa which is supported by thickened rays and has two equal or subequal spicules. The osophagus is more or less swollen posteriorly but never with a terminal bulb.

We shall study the common dog and cat hookworm, Ancylostoma caninum, as the most available example of the important hookworms.

\section{PRACTICAL WORK}

Ancylostoma caninum.-Compare the general form of the hookworm borly with that of Ascaris lumbricoides. Note that the anterior end is bent dorsad and that it bears the wide mouth or buccal cavity. On the female locate the vaginal opening somewhat more than two-thirds of the length of the worm caudad, and the anal opening near the caudal end. In the male specimen study the characteristic caudal bursa and its supporting rays. How does the caudal end of the male Ascaris differ from this?

Selecting the specimen which shows most nearly a front rather than a profile view of the head capsule (Fig. 16), note the pair of strong, three-pronged teeth on the ventral wall of the capsule (remember that the head is bent dorsad and hence these teeth appear at the anterior end of the worm). Near the base of the capsule are the two broad, triangular, latero-ventral pharyngeal plates with their apices projecting into the pharynx. Between them is the dorsal pharyngeal tooth, a narrow elongate structure which appears rod-like in this view. Following the short bulbous pharynx is the elongate, cross-striated cesophageal bulb. The intestine passing from this point to the tip of the body is almost concealed by the coils of the reproductive organs. These in the female are the ovarian and the uterine tubes, the latter discharging the eggs through the vaginal opening in the posterior third of the worm. in the male the long coiled testes lying at the side of the intestine open into a broad sac, the seminal 
vesicle, about the middle of the body. From this the ejaculatory duct passes to the ventral side of the tip of the tail within the bursa. From this point extent the wo long, threadlike spicules.
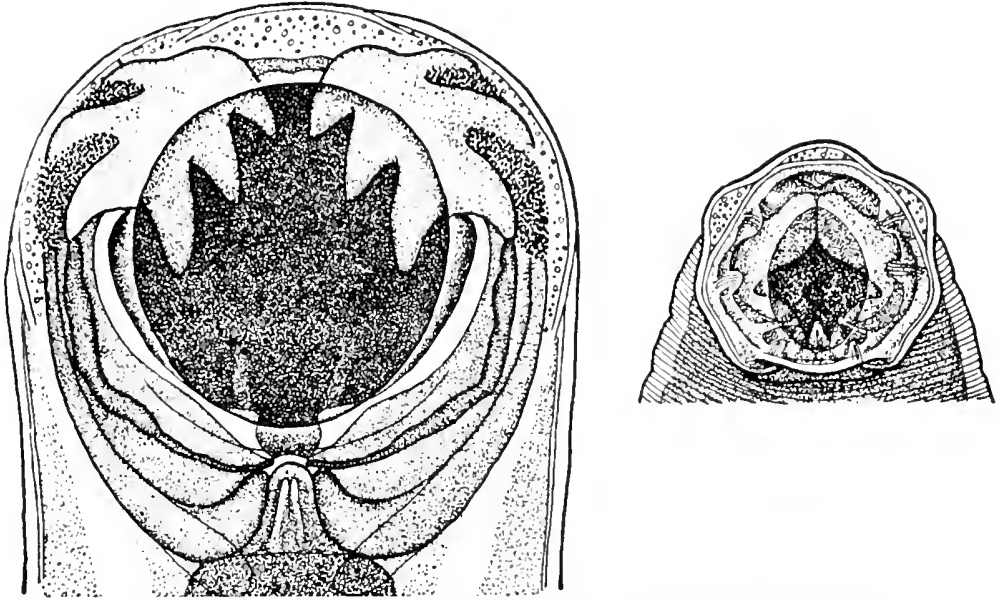

Fig. 16.- Head end of Ancylostoma caninum and of Secator americanus drawn to the same scale. (Adaptcd from Looss, that of Necator reduced.)

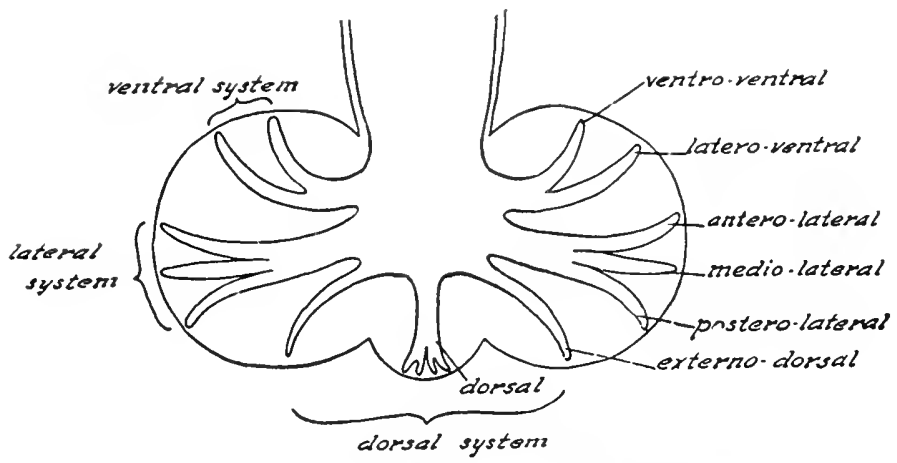

Fig. 17.-Diagram of the caudal bursa of the male Strongyloidea. (After Baylis.)

The bursa of the male is a bell-shaped expansion of the cuticle supported by thickened rays which branch in a manner characteristic of the species. Compare carefully with the diagram (Fig. 17), identifying the various systems of rays.

Make a large drawing showing the general features above described. 
Compare with the demonstration of the head capsule of $A n c y$ lostoma duodenale of man, noting especially differences in the paired teeth.

Study also the demonstration of the buccal capsule of Necator americams (Fig. 16) and note the two chitinous plates which replace the ventral teeth found in the genus Ancylostoma. The latero-ventral pharyngeal plates and the dorsal pharyngeal tooth also differ in this genus.

Development.-Make drawings of various segmentation stages of the hookworm eggs from feces.

Make a careful study of the sheathed infective larva. If living material is available, note the movements and combine study of the living and the mounted worms. Make a drawing showing the buccal cavity, osophagus, intestine, genital pore, genital rudiment, and anal opening of the larva.

Penetration of the Skin by Hookworm Larvæ.-Examine the demonstration showing a section of skin and of a larval hookworm which has penetrated its outer layers.

Soil Nematodes.-Examine a preparation of living nematodes, isolated from garden soil by the use of the Baermann apparatus, and distinguish the hookworm larvæ.

\section{References}

The standard textbooks on parasitology-Braum, Brumpt, Chandler, Faust-and such sources as the "Reference Handbook of Medieal Seience" afford easily accessible discussion of the morphology and biology of the hookworms of man. For referenees to more special papers, see the "Bibliography of Hookworm Diseases" issued by the International Health Board, 1922 . 


\section{('HAPTER VIII}

\section{TRICHINELLA SPIRALIS AND RELATED FORMS}

\section{TECHNICAL SUGGESTIONS}

The importance of Trichinclla spiralis as a parasite of man and animals and the ease with which all stages of its life history may be demonstrated make it especially desirable for lahoratory study. Other representatives of the group may be demonstrated. The characteristic eggs of Trichuris should be stulied.

The most convenient sources of Trichinella for feeding experiments are wild rats from slaughter houses, particularly from local establishments. Here the infeetion may run as high as 75 per cent, though such high incidence is exceptional. Another convenient reservoir is the vagrant cat. Pork samples are not to be relied on unless a considerable number, from different sources, are available.

The presence of the parasite is best determined by the microscopic examination of thin fragments of muscle from the diaphragm or from the base of the tongue, cut parallel with the fibers and examined under pressure. In the absence of a regular "trichina compressor" a very satisfactory substitute is furnished by two slides clipped together by spring clothes-pins. When an infection is located, hits of the musele should be fed to white rats or mice, and one of these should be killed within 2 or 3 days for the study of the mature sexes isolated by the method described on page 10s. A seeond should be examined 2 or 3 weeks later for wandering larva, and a third after 3 weeks for eneapsuled larve. Calcified eysts will be present in musele which has been infected for 6 months or longer.

Permanent mounts of these various stages should be made. Adult worms should be killed in hot 70 per cent alcohol, and gradually dehydrated and, after clearing in xylol, hrought into thin lalsam; or they may be mounted in glycerine gelatine and sealed, as describer on page 105. Muscle containing the migratory stages may be macerated for 24 to 48 hours in 0.1 per cent chromic acid or 2 per cent acetic acid, teased, dehydrated, and mounted in balsam. For the cyst stages compressed muscle maty he dehydrated and mounted in balsam; or it may be fixed, imbedded in paraffin, and sectioned. For ordinary study it is undesirable to stain the material.

To show the female worms in situ, the small intestine of a heavily infected rat should be removed a week or more after the experimental feerting, fixed in Bouin's fluid, sectioned, stainet, and mounter by the usual methods. 
While free larval stages are readily obtained by teasing infected muscle, an instructive demonstration is that of the action of the digestive juices on the cysts. For this purpose pieces of infected muscle the size of a pea are kept for a day or so at 38 to $40^{\circ} \mathrm{C}$. in an artificial gastric juice consisting of : seale pepsin (U.S.P.), 0.25 gram; sodium chloride, 0.2 gram; hydrochloric acid (sp. gr. 1.19), 1 ce.; water, 100. If an incubator is not available the experiment may be carried out in a warm room.

For maintaining a supply of trichina, rabbits forcibly fed are preferable to rats. They are more resistant to the infection and are often more readily kept than are rats.

\section{CHARACTERISTICS OF THE TRICHUROIDEA}

To the superfamily Trichuroidea belong the famous trichina worm and the whipworm of man, several important species affecting the respiratory passages of carnivores, and a number of less important forms.

The group is characterized by the fact that the anterior end of the long body is prolonged into a slender, more or less whiplike portion, while the posterior end is more or less swollen and contains the genital organs. The osophagus is very long and traverses a chain of large, single cells; there is no oesophageal bulb, and the anus is terminal. The ovary is single and the vulva is at the origin of the swollen part of the body.

We shall use as a type the trichina worm, Trichinella spiralis.

\section{PRACTICAL WORK}

Encysted Larvæ.-You will be furnished with a portion of infected muscle or with prepared slides showing the larval or cystic stages of trichina. If the former, snip with the scissors very thin sections of the muscle, lengthwise of the fibers, and mount under pressure between two slides held together by rubber bands or by elips. Search for the lemon-shaped cysts showing the coiled larva. Can you find eysts containing more than a single larva? More than two? It should be recalled that the cyst is formed from connective tissue elements of the host and not by the worms. If you have had the fresh material, supplement your study by examination of prepared slides. Make drawings illustrating the cysts and larva and their relation to the muscle tissue.

Some months after the formation of eysts in a host, their ealcification sets in. This is the stage in which they were early noted as gritty particles in the flesh of eadavers in the 
medical schools of London. When examined with reflected light rather than by transmitted light, they appear chalky white. Study the demonstration specimens if you do not have a slide showing this stige.

Adults. - When trichinous flesh is ingested by man or other appropriate host, the capsules are dissolved by the gastric juice and the larvæ are liberated. If you have infected meat for study, some of it should be subjected to the action of an artificial gastric juice and kept at body temperature for a day or so, in order to obtain the free larve. Other portions should be fed to white rats or mice for study of the mature stages and the migratory larvæ. If such trichinous flesh is not at hand and not procurable, use the prepared slides which will be furnished.

Within 48 hours after being ingested the larvæ have developed into mature sexual individuals. Examine fresh or mounted preparations and observe the division of the body into the slender, elongate anterior end and the posterior swollen portion. Note the large cells making up the anterior portion and the delicate cesophagus piercing them. The more conspicuous alimentary tract of the swollen section opens by a terminal anus.

In the female worms the eggs may be seen in progressive development as they are traced forward from the posterior region to the vulva in the anterior fourth of the worm, through which the fully formed larvæ escape.

The males are only about half the size of the mature females and are readily distinguished by the presence of two caudal, hemispherical copulatory lobes. Between them are four minute papillæ.

Make drawings illustrating the structure of the male and female worms.

Migrating Larvæ.-By the end of the first week, larvæ are escaping in large numbers and are being carried by the blood stream and, to some extent, actively migrating to the muscular tissue. Tease parallel with the fibers small fragments of muscle from an animal which has been infected 2 to 3 weeks previously. Thus the still unencapsuled larvæ ean be obtained in numbers. By the end of the third week cysts are being formed and the flesh is infective for new hosts.

Trichuris trichiura.-Examine the demonstration specimens of the whipworm of man ( $T$. trichiura) or of the related species 
from the dog. In these forms the anterior portion of the body is excessively long and slender, suggesting a whiplash. Study and make drawings of the peculiar lemon-shaped brown eggs with pluglike clear sections at each pole.

\section{References}

(iood general accounts of the structure and life history of Trichinella spiralis and of trichinosis, the disease which it causes, are to be found in present-day textbooks of zoology and of parasitology. Of the enormous literature on the subject, the following modern researches are of special interest and availahility to American students:

Ranson, B. H., 1916. Effects of refrigeration upon larva of Trichinella spiralis. Jour. Agr. Rescarch, 5 (18): 819-854.

Ransom, B. H., and B. Schwartz, 1919. Effects of heat on trichinas. Jour. Agr. Research, 17 (5): 201-221.

Ransom, B. H., B. Schwartz, and H. B. Raffensperger, 1920. Effects of pork-curing processes on trichina. $U^{r}$. S. Dept. Agr., Bull. \$so, $37 \mathrm{pp}$. 


\section{CHAPTER IX}

\section{THE DETERMINATION OF HELMINTH INFECTIONS THROUGH FECAL EXAMINATIONS}

\section{TECHNICAL SUGGESTIONS}

As an introduction to the methods of determination of parasites in the living host, this practicum is confined to the microscopic examination of fecal samples for helninth infertions. Most of the eggs to be eonsidered have already been seen in the course of the practicums, but it is essential that the student learn to identify them and to distinguish them from the miscellaneons debris of feral samples.

If time and the size of the class permit, the entire preparation and exanination should be carried out by each student. For this purpose fresh feces of eats amd dogs, preferably of young animals, may be used.

Ordinarily it is necessary to rely on formalin-preserved material, and such may often he from human sources. Samples from infected patients can be secured through the aid of physicians and hospital technicians, sedimented, and preserved in a liberal quantity of 10 per cent formalin. If there is considerable coarse debris, the sample should be passed through a fine-meshed sieve. (The tea-strainers arailable at the five-and-ten-cent stores make a convenient tool for this purpose.) After each using they should be flamed or thoroughly washed to avoid contanination of subsequent samples.

Eggs of a number of species of helminths affecting man, or of very closely related species, may be obtained from the parasites of various animals and should be stored in formalin as individual samples. In order to obtain quantities of eggs for class work the samples may be increased by adding the teased uteri of mature specimens. Inknowns may be prepared by combining several speeies after the study of the separate simples.

As illustrations of useful forms from animals may be cited the ascaris of the pig, asearids, hookworms, and trichurids of eats and dogs; Tienia and Dipylidium eggs from eats and dogs; Hymenolepis eggs from rats and mice, or, for more general study, from chickens. The sheep liver fluke affords a typical fluke egg, but even the ever available frog flukes may be used. The oöcysts of rabbit coccidia should be studied as illustrations of forms that may be confused with helminth eggs.

One or more of the important schistosomes of man should be available. Formalin-preserved material or prepared slides of eggs of these are ohtuinahle from dealers. 
Permanent mounts of the various eggs used in this practicum may be prepared by Looss' method (p. 109) and sealed with Noyer's cement.

\section{METHOD OF FECES EXAMINATION}

The determination of parasitism in the living host can rarely be made on the basis of clinical symptoms. It requires usually the microscopic examination of the various excreta, of the blood, and even of bits of living tissue. A large number of endoparasites inhabit the alimentary canal or glands, such as the liver, of their host and discharge their eggs or larvæ or segments in the feces. To some extent in man and commonly in animals, eggs of lung parasites are likewise swallowed and pass through the intestine. Their presence in the living host is then revealed by the examination of the feces. This examination may be both macroscopic and microscopic. The parasites concerned may be protozoal, helminth, or arthropod. In this practicum we shall restrict our attention largely to the helminths, and particularly to the recognition of the eggs of these forms.

Macroscopic examination of normal stools is very superficial and to be trusted only when it is positive. More definite information can be obtained by giving the patient a vermifuge and examining all of the stools for a period of at least 48 hours. The fecal material is broken up in a large quantity of water in a flask and as rapidly as it settles the supernatent fluid is decanted; or the stool is washed repeatedly through a fine-meshed sieve. The sediment is poured into a tray and examined for segments of tapeworm, small nematodes, and flukes. A black photographic tray is useful for this examination.

Microscopic Examination.-The simplest method of microscopic examination is to remove several samples of the stool, about the size of a pinhead, emulsify on a slicle in clean water, and cover with an $18-\mathrm{mm}$. square cover glass. If the stool is quite fluid, it may not need dilution. Care should be taken not to have the preparation too opaque, for eggs and cysts may be overlooked. On the other hand, if it is too thin, time is wasted in search. A good rule is to have it thin enough for ordinary print to be read through the preparation.

Simple Sedimentation.-The search for microscopic evidences of parasitism may be considerably lightened by thorough and repeated sedimentation of stool samples. Finally small quantities of the sediment are mounted for examination. 
Centrifuging.-An improvement on the method of simple sedimentation is thoroughly to emulsify in water a sample the size of a walnut, strain out the coarse particles, and then centrifuge for the purpose of giving a rapid and certain concentration.

Treatment with Dense Liquids.-Advantage may be taken of the fact that parasite eggs are of specific gravity different from that of the other constituents of the material to be examined. In hookworm work a small quantity of feces is placed in a vial three-fourths full of saturated solution of salt $(\mathrm{NaCl})$, thoroughly shaken, and allowed to stand for an hour; then a drop from the surface of the fluid is examined. If the concentration is correct all of the eggs rise to the surface and large numbers may be found in a single drop. The process is much facilitated by forcing the coarse float below the surface with a disk of No. 0 steel wool.

The so-called Willis method is now widely used in hookworm campaigns. A saturated solution of $\mathrm{NaCl}$ is prepared in boiling water and allowed to cool. One or two grams of the fecal sample are then thoroughly mixed with this concentrated salt solution and the container then filled to the brim with it. A clean glass slide is placed in contact with the film and allowed to stand for 15 minutes. It is then earefully removed, inverted, and examined under the low power of the microscope for adhering eggs.

The various methods of treatment with dense liquids will not reveal the presence of operculate eggs such as those of most flukes and of the fish tapeworm of man.

\section{PRACTICAL WORK}

Prepare an emulsified sample as above described or mount under a square cover glass a small drop of sedimented fecal sample preserved in 10 per cent formalin solution.

Beginning at one corner of the preparation pass systematically from end to end under the microscope until the whole field has been eovered. Distinguish carefully between fragments of plant tissue, partially digested muscle and other food, plant spores (see Fig. 18), and the eggs, larvæ and eysts of parasites. Vary the lighting of your preparation by the use of the iris diaphragm and note the great role which this procedure plays in the detection and identification of significant objects. 
Using the following key, as explained by the instruetor, determine the eggs found. Do this for each of the samples supplied for laboratory work. Note earefully the relative size of the eggs and draw them to seale.

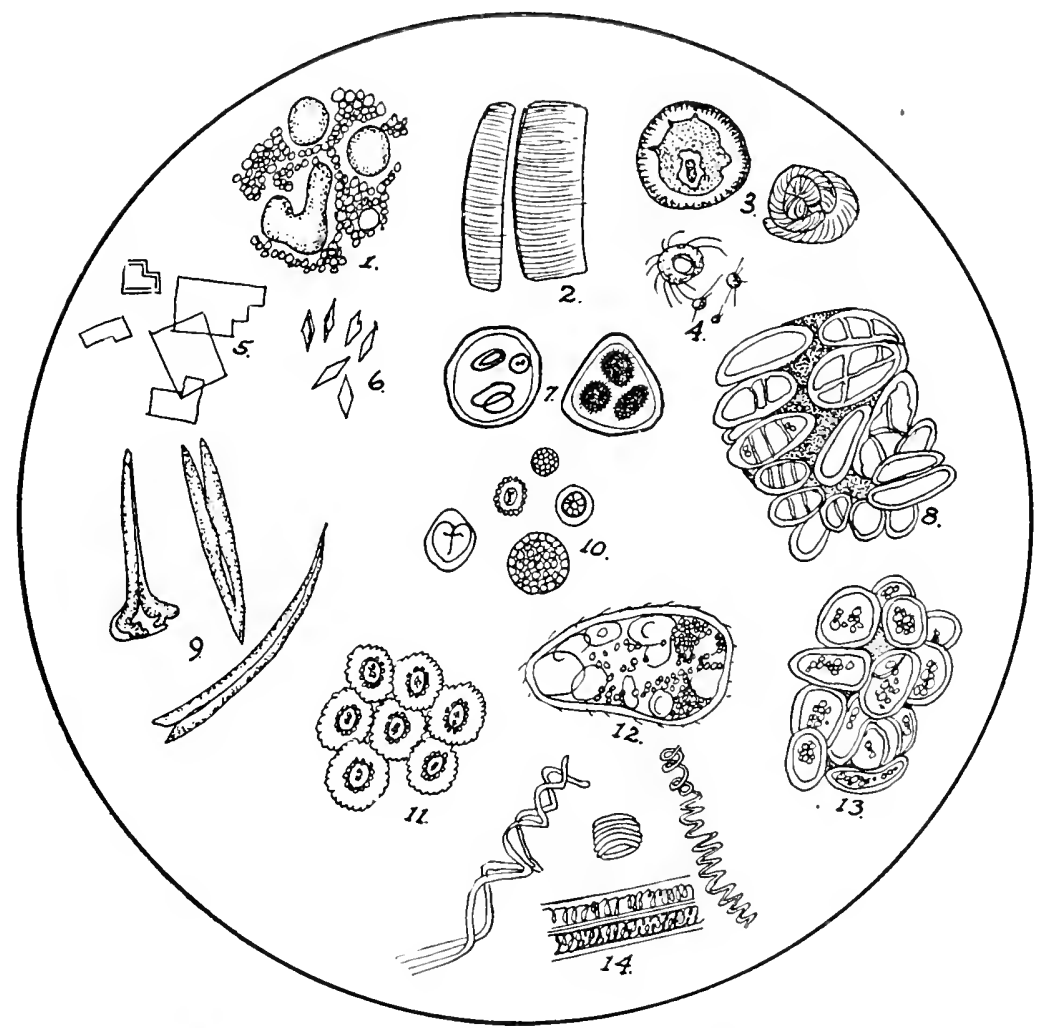

FIG. 18.-- Microscopjc appearance of common objects in the feces. 1, casein and fat droplets; 2 , muscle fibers; 3 , soap crystals; 4 , crystalline fatty needles; 5, cholesterin erystals; 6 , Charcot-Leyden crystals; 7 , truffle spores; 8 , portions of husks of cercals; 9 , hairs of wheat grains; 10 , spores of fungi; 11 , cells from pericarp of peas; 12, parenchyma of beans; 13 , endospern of rice: 14, vegetable spirals. (After Manson-Bahr.)

Remember that an important part of this work. is the reeognition of plant cells, starch grains, and other food debris, pollen grains, spores of fungi, and the like, which are readily confused with eggs of parasites. Plant hairs and spiral plant tracheids should also be noted earefully as they are not infrequently mistaken for nematode worms. 


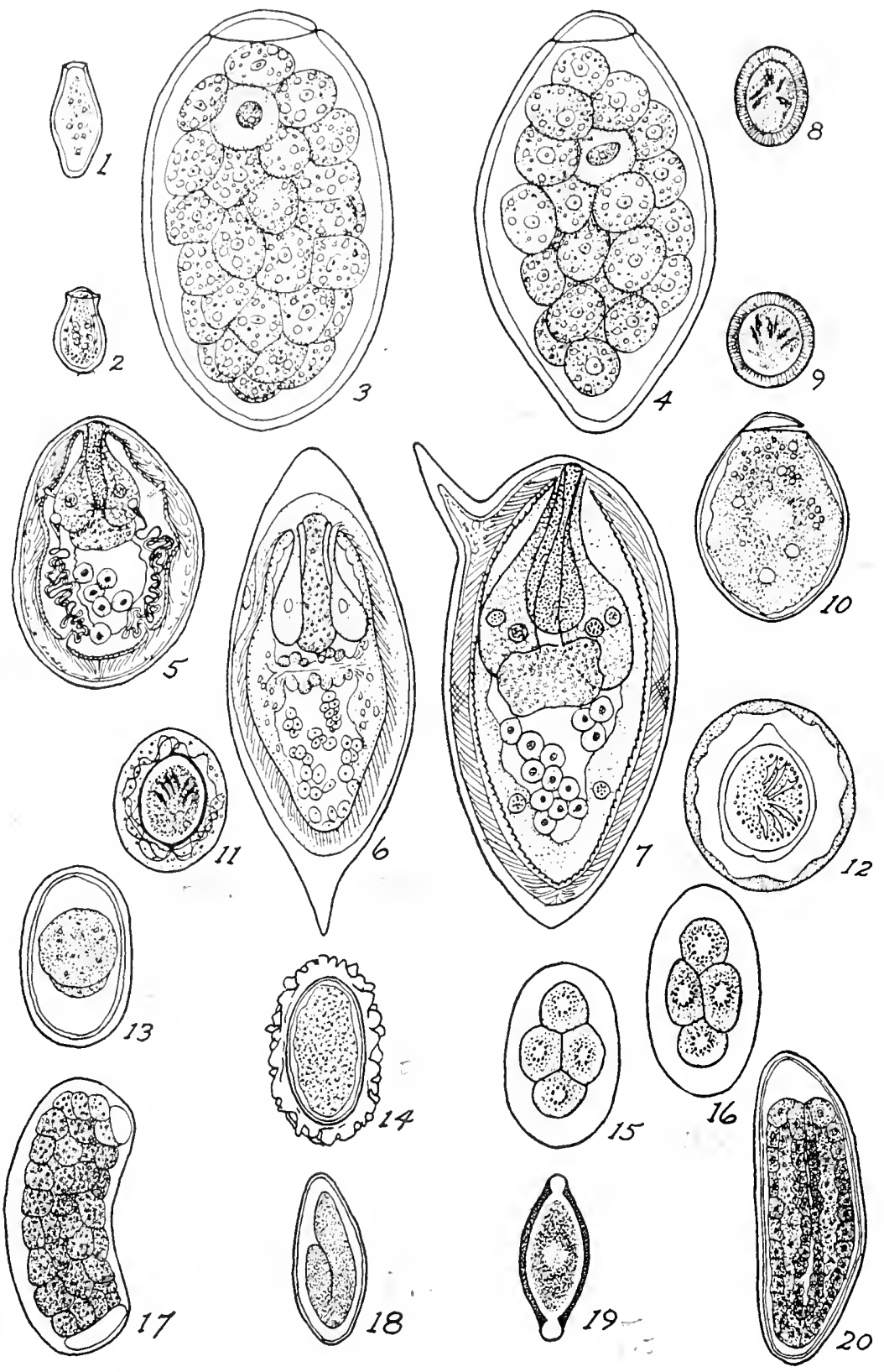

Fro. 19.-Fggs of parasitic worms of man. 1, Opisthorchis felineus; 2, Clonorchis sinensis; 3, Fasciola hepatica; 4, Fasciolopsis buski: 5, Schistosoma japonicum; 


\section{Key to Parasite Eggs in Human Feces}

A. Eggs are round or slightly oval.

B. Slightly oval with finely honeycombed surface; 65 to $75 \mu$ in diameter. Common in eat, very rare in man.

Toxocara myslax

BB. Surface of egg not honeycombed; contains a six-hooked embryo. C. Eggs isolated.

D. Brown or brownish in color with thick, radially striated capsule or embryophore; 30 to $40 \mu$ in diameter...................Tenia solium

Tenia saginata

DD. Colorless with thin membranous inner shell, unstriated, separated from very thin outer membrane by a transparent, semifluid elear substance.

E. 30 to $60 \mu$ in diameter. ..... Hymenole pis nana

EE. 54 to $86 \mu$ in diameter...... Hymenolepis diminuta CC. Eggs in rusty red packets of 12 or more.

AA. Eggs not round, though they may be broadly oval.

Dipylidium canimum

B. Broadly oval, long axis less than twice that of shortest axis.

C. With mammellated, thick, glutinous eapsule, size 50 to $80 \mu$

long, 45 to $55 \mu$ broad............Ascaris lumbricoides

CC. Without such eapsule.

D. With thiek, smooth shell, size 75 to $85 \mu$, contents undivided or in early segmentation stage. Common parasite of dog, rare in man..... Toxascaris limbata

DD. With delicate lid or operculum at one end.

E. Eggs large, exceeding $100 \mu$ in length, rounded at both ends............Fasciolopsis buski

EE. Eggs less than $100 \mu$ in length.

F. Eggs exceeding $80 \mu$ in length, broadly truneate at opercular end. Found in sputum as well as in feces.

Paragonimus westermani

FF. Eggs less than $80 \mu$ in length, evenly rounded at ends, eontents eoarsely granular, mulberry-like, shell thin and light straw eolored......... Diphyllobothrium latum

BB. Eggs not broadly oval, longest axis approximately twice the length of the shortest one.

C. Eggs more or less truncate.

6. Schistosoma hacmatobium; 7, Schistosoma mansoni; \&, Tania saginata; 9, Tania solium; 10, Diphyllobothrium latum; 11, Hymenolepis nana; 12, Hymenolepis diminuta; 13, Ascaris lumbricoides, without shell; 14, Ascaris lumbricoides, normal; 15, Ancylostoma duodenale; 16, Necator americanus; 17, Heterodera radicicola (Oxyuris incognita); 18, Enterobius vermicularis; 19, Trichuris trichiura: 20, Syphacia obvelata. (Figures 1, 3, 4, 6, 15, 16 from Looss; 8, 9, 13, 14, Nellmann and Mayer; 5, 7, 18, Cort; 2, Ward; 12, Grassi, 10 Brumpt; 11, Augustine; 17, Sandyround; 20, Riley.) 
D. Slightly truncate at one end and the delicate opereulum with shell projecting slightly behind its edge.

E. Lgg relatively narrow, average size $30 \mu$ by $11 \mu$. Opisthorchis felineus

EW. Eggr broader, $26 \mu$ to $30 \mu$ by $13 \mu$ to $16 \mu$.

Clonorchis sinensis:

DD. Truncate at hoth ends with dark brown shell, 50 $\mu$ long, slightly pointed and tipped with a little shiny elear plug, content unsegmented..... . Trichuris trichiura CC. Not trunciste.

D. Large eggrs, 120 to $160 \mu$ long, bearing a sharp spine.

E. spine terminal, eggs found in urine and more rarely in feres........ Schistosoma hematobium EE. Spine lateral, eggs found in feees.

Schistosoma mansoni

DD. Eggs not spined.

E. Containing a miracidium, or ciliated embryo; size averaging $\$ 3 \mu$ by $62 \mu$, sometimes with slight knob-like lateral thickening.

Schistosoma japonicum

EE. Miracidium not present; embryo tadpole-like or vermiform, or egg content in early segmentation stages.

F. Very delicate, transparent, asymmetrical shell with double contour, $50 \mu$ by $80 \mu$ containing well developed embryo.

Enterobius vermicularis (Oxyuris)

FF. Delicate, single-contoured shell, symmetrical, and with broadly rounded ends. A broad clear zone between the shell and the content; normally showing early segmentation stages, but never larvie in fresh stools.

G. Ends somewhat pointed, size 75 to $90 \mu$ by 39 to $47 \mu$.

Trichostrongylus orientalis GG. Ends more broadly rounded, size 58 to $80 \mu$ by 35 to $52 \mu$.

Necator americanus Size 56 to $61 \mu$ by 34 to $38 \mu$.

Ancylostoma duodenalc

\section{References}

Brug, S. L., and G. H. Kloevenorn, 1926. "Die parasitologische Diagnostik der mensehlichen Faezes," 64 pp., 8 plates. Barth, Leipzig.

HALL, M. C., 1912. A eomparative study of methods of examining feces for evidences of parasitism. U. S. Dept. Agr., Bur. An. Ind., Bull. 135, $42 \mathrm{pp}$.

Hall, M. C., 1922. The eggs of dog, eat, and fox parasites. Veterinary Mel., Apr., 1922. 
Hausheer, W. C., C. A. Herrick, and A. S. Pearse, 1926. Evaluation of the methods of Stoll and Lane in light hookworm infections and aceuracy in diagnosis of the Willis floatation method. Am. Jour. Hyg., $6: 118-135$.

Langeron, M., and M. Rondeau du Norer, 1926. "Coprologie microscopique," ii + 132 pp. Masson et cie, Paris.

Luger, A., 1928. "Grundriss der klinischen Stuhluntersuchung," x + 341 pp., 24 plates. Springer, Wien.

Stoll, N. R., 1929. Laboratory methods in the Panima studless. Am. Jour. Hyg., Monographic series 9, 30-44. 


\section{CHAPTER X \\ THE EXAMINATION OF SMALL MAMMALS FOR ANIMAL PARASITES}

\section{TECHNICAL SUGGESTIONS}

Few students nowadiys hatve any experience in the disseetion of mammals in their course in general zoölogy. Even those who do dissect a type form, such as the eat, rabhit, or rat, have little idea as to its parasitic fanma. Not only for these reasons but also beeause it adkls zest and value to the work, it is desirable that the members of the chass get supervised experience in the examination of animals for parasites. This work may well follow the detailed study of the various helminths.

While the eat has been selected as probably the most suitable form for this work, the directions are of general applicability. If opportunity affords, various small mammals, such as the dog, rat, and rabbit, may be used at this time. They should be killed before the laboratory period.

Stretching boards, thumb tacks, sponges, and one or more bone foreeps should be at hand. If the students do not have their own dissecting sets, there should be provided at least a sharp sealpel, scissors, dissecting needles, and foreps for each group.

Facilities for the preservation of material should he provided and the details of the work assigned to the two or four students who will be working on each speeimen. Emphasis should le placed on the importance of proper labeling and of keeping aceurate data as to the source and number of the parasites and possible evidence of pathological conditions.

\section{THE INCIDENCE OF PARASITIC INFECTIONS}

The current opinion, even among zoölogists, as to the rarity of many parasitic forms is largely due to lack of a systematic examination of animal hosts. Particularly has this been true in this country, although there is a growing realization of the value of such studies from the viewpoint of both pure and applied science. Even now there are few sections of this country for which we have accurate data as to the incidence and variety of parasitism of even such ubiquitous animals as the dog and cat, this in spite of the fact that both of these animals play roles in 
the maintainence of some of the most important parasites of man and domestic animals.

We have seen the extent and variety of parasitic infection of the common frog. Of the mammals, the domestic cat serves as a convenient subject for similar examination. Over a hundred species of parasities have been listed for this animal, though of course in a given locality an individual animal might harbor very few representatives. The present practicum will illustrate a simple routine for the examination of any small mammal.

\section{PRACTICAL WORK}

Preliminary Examination.-Search the fur carefully for ectoparasites such as ticks, lice, and fleas. Place any of these in the bottles of 70 per cent alcohol provided, and record their presence. It should be recalled that lice and fleas serve as intermediate hosts of the double-pored tapeworm of cats, and hence if your animal harbors this worm a percentage of the insects would probably be infected.

Examine for evidence of mange, such as falling hair and wrinkled, crusty skin particularly about the ears and upper part of the neck. If these conditions are encountered, make scrapings of the crusts and search with the microscope for the causative mite, Notoëdres cati. Examine scrapings from the auditory canal for the ear mite, Otodectes cynotis. Mounting the scrapings in 5 per cent caustic potash will render the parasites more distinct.

Preparation for Dissection.- Stretch the animal on its back on a broad dissecting board or tray and tie its extended legs. Wet the fur of the abdomen and part it along the midline. Then insert a scalpel just under the skin in the midline of the throat and slit the skin to the anus. Loosen the skin and pin it down on either side. Being careful to a void piercing the intestines, make a longitudinal cut through the abdominal muscles from the sternum to the pubis and a lateral cut along the last ribs, and pin out these flaps with the skin. With bone cutters (not with scissors) cut through the ribs of both sides and, completing the euts with a scalpel, lift off the sternum and attached stumps of ribs.

Before proceeding further, examine the abdominal and pleural eavities for larval tapeworms or other parasites. An elongated plerocercoid 2 to $3 \mathrm{~cm}$. long by 2 to $3 \mathrm{~mm}$. broad has 
been deseribed for the serous cavities of the cat under the generie name Dithyridium.

Examination of Special Organs.-In the following outline there will be mentioned only the more common or important. species of parasites of the eat. Additional species and referenees to descriptions are listed in the Appendix, page 114.

Lungs and Bronchi.-Remove the lungs to a dish of water and examine for any abnomal conditions. Serapings of the mueosa and bronchi should be examined mieroseopieally for eggs of the fluke Paragonimus and the nematode lungworm C'apillaria arophila. The former are typical opereulate eggs of flukes; the latter are very similar to the brown oval eggs with a clear stopper-like phig at each end which you have seen in the whipworm, Trichuris trichiura. Rarely, minute larval nematodes are to be found in these serapings. They are immature forms of another nematode, Elurostrongylus abstrusus, whose eggs are laid in the alveoli of the lung. The adults which are to be found in the smallest bronchi, measure 5 to $10 \mathrm{~mm}$. Cut the lungs into fragments and search for adult worms of any of these species.

Heart.-The senior author has recorded one case of the presence of the filarial worm Dirofilaria immitis in the ventricles of the heart of a cat. It is quite possible that such cases are to be found in the South.

Stomach.--Slit open and spread out the stomach on a dissecting board and examine with the naked eye for any macroscopic forms. Not infrequently the cat asearid Toxocara mystax will be found in this organ. Examine microscopically scrapings of the stomach nucosa for the interesting nematode Ollulanus tricuspis, a minute form measuring $1 \mathrm{~mm}$. or less in length.

Intestine.-Cut the intestine into sections, slit them lengthwise, and pin down. In slitting, eare must be taken to avoid injury to worms in the lumen. Collect and preserve the grosser forms such as asearids and tapeworms. Then exanine elosely for threadlike hookworms and minute flukes. If tapeworms are present, note the isolated segments, particularly those of IDipylidium which are large, brick-red, and cueumber-seed shaped in the ripe condition.

Examine under the mieroscope samples of the content of the small intestine for eggs or early stages of helminths.

Gall Bladder and Liver.-Remove the gall-bladder to a dish, open, and mount some of the content, diluting with water. 
Search microscopically for eggs of trematodes. Cut the liver in slices about a centimeter in thickness and press lightly so as to force any parasites out of the smaller branches of the gall ducts. The most probable find is the fluke Amphimerus pseudofelineus, an elongate, tapering form, measuring up to $20 \mathrm{~mm}$. Remove any found and then place the slices in a large dish of water or physiological salt solution and examine from time to time for any parasites that have emerged. The process is hastened if the fluid is at blood heat.

Kidneys and Bladder.-The kidneys should be included in the examination, for important parasites occur in these organs in some species of animals. We are not aware that any have been reported for cats in this eountry. A species of Capillaria, long and slender like that from the lungs, is reported as occurring in the bladder.

Muscle.-Minute samples of muscle, especially from near the tendon of the diaphragm, should be compressed between two slides and examined for the cysts of Trichinella spiralis. The food habits of eats are such that they have frequent opportunities to become infected by this dangerous parasite and thus to play a rôle in its maintenance.

Summary of Results. - Toward the end of the period the results of the various examinations will be collected and summarized. Such records earefully obtained and ehecked will ultimately afford important data on the distribution and ineidence of parasites of economic importance. 


\section{('HAP'TER XI}

\section{THE AMCEBA OF MAN}

\section{TECHNICAL SUGGESTIONS}

On account of the difficulty of obtaining living material illustrating the endomobie of man, and the necessity of using oil immersion lenses for the study of details, a survey course such as this must rely chiefly on demonstrations. Fortunately, well-prepared slicles stamed in iron hamatoxylin are now available through several of the biological supply louses listed in the Appendix.

Through such sourees, if not through some hospital clinic, it is usually possible to obtain fecal material in formalin, containing trophozoites and eysts of Endamoba histolytica and Endamobe coli. By adding a drop of iodine solution to the slide, much may he gained from the study of this material under the high power dry lens.

For study of Endamaba histolytica in the tissues, the most favorable materials are sections through the rectum of experimentally infected kittens. Such preparations are offered by several of the supply houses listed. For aid in the laboratory examination a blackboard sketch or chart showing the structure of the normal organ should be before the student.

In most sections of the country rats and mice and, to a less extent, frogs, are infected with intestinal amobe very similar to E. histolytica. Our large native cockroach, Periplancta americana, frequently harbors Endamaba blatto, the type of the genus. These species ean be used to advantage for the study of motile stages. While it is assumed that the student has made a careful study of living specimens of nonparasitic amobe in his course in gencral zoölogy, it is nevertheless well to review this material.

\section{CHARACTERISTICS OF THE RHIZOPODA}

Within recent years it has become known that some of the most devastating diseases of man and animals are due to Protozoa. All of the classes of the phylum contribute important illustrations of parasitic forms. They inhabit organs, tissues, and cells, and even the nuclei of cells of their various hosts.

The phylum is usually divided on the basis of the development of locomotary organelles into four classes: the Rhizopoda, the Mastigophora, the Infusoria, and the Sporozoa. Many students of animal parasitology include as a fifth class the Spirochrta, 
an important group of exceedingly tenuous, spiral organisms regarded by some authorities as bacteria.

As typical of the Rhizopoda, or "root-footed" organisms, you have already studied the free-living Amøba proteus. It should be reealled that this organism is an irregular mass of protoplasm, constantly ehanging its shape during life by the pushing out of lobe-like pseudopodia which constitute the locomotary organelles. The body consists of a elear outer layer, the ectosarc, and a granular inner layer, the endosarc. Within the endosarc lie the nucleus, a contractile vacuole, and food vacuoles of varying size.

Of the numerous speeies of amoba which have been described as infesting man, three are of special significanee: Endamœba histolytica as the cause of bloody dysentery, and Endamoba coli and Endolimax nana as common species which are often mistaken for the pathogenic form.

\section{PRACTICAL WORK}

Endamœba histolytica.-Amaboid Forms.-Examine under high power prepared stained slides showing the amoboid forms, or trophozoites, of this amœeba. Note the size as estimated by that of red blood eells under the same magnification. If a micromcter eye piece is available, make more exact measurements. The specimens are usually rounded in stained material and show only slight differentiation into ectoplasm and endoplasm. The culoplasm is free from ingested bacteria but in acute cases may contain red blood corpuseles. As compared with that of $E$. coli, the cytoplasm is relatively homogeneous and without prominent vacuoles. In normal, well-stained specimens the nucleus appears as a ring-like strueture approximately the size of a red blood corpuscle $(7.5 \mu)$ or somewhat smaller, representing the very delieate nuelear membrane covered on the inner surface by a layer of very minute chromatin granules. At the center is a minute deeply staining granule known as the karyosome.

A moboid Forms in Host Tissues.-A section of the large intestine showing amobic infeetion will be furnished. Under low power loeate the following layers of the intestinal wall: (1) an inner glandular layer with closely erowded, deeply staining nuclei, which is about one-fourth of the entire thickness of the wall; (2) a narrow band of museles constituting the muscularis murose; (3) a light-staining middle portion, the submucosa; and 
(4) a thick outer, deeply staining layer of muscles. Examining the base of the glandular portion under high power note the numerous rounded, vacuolated amœba. The structure of their nuclei is not typical as they are rarely fixed in a favorable manner.

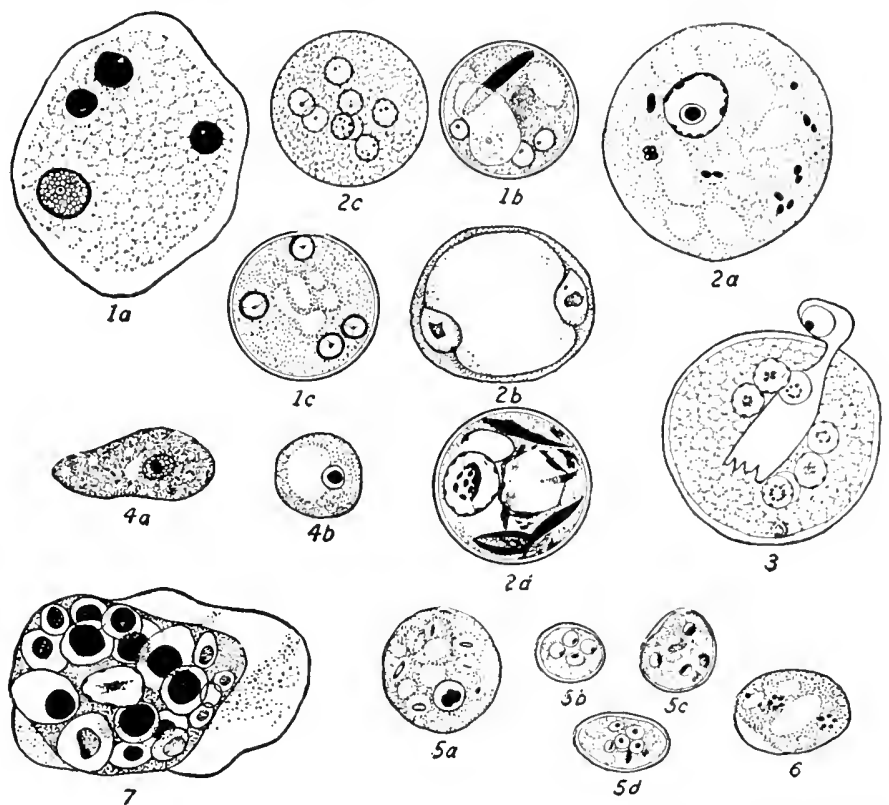

FIG. 20.-Amoebæ of man. 1a-1c, Endamoba histolytica; $2 a-2 d$, Endamaba coli; 3, Councilmania lafeuri cyst with "bud;" $4 a-4 b$, Iodamaba williamsi; $5 a-5 d$, Endolimax nana; 6, Dientamaba fragilis; 7, Endamaba gingivalis. (Afler Kofoid, except $1 a$ and 5 after Bocck, $2 b, 2 c$ and 4 after Wenyon.)

Cysts.-Search the prepared slides under high power for the round, four-nucleate mature cysts of Endameba histolytica. They are sharply contoured, spherical bodies measuring from 5 to $20 \mu$ in diameter, whose nuclei show the typical delicate peripheral layer of chromatin and the central karyosome. In addition, about half of the cysts show one or more conspicuous black, rod-like bodies with rounded ends, which, like the chromatin of nuclei, stain black with the iron-hæmatoxylin stain. On account of this reaction they are called chromatoid bodies. In the same preparation will be found uninucleate and binucleate cysts. These contain one or more large glycogen masses which in fresh cysts stain a deep mahogany color in iodine. Make careful drawings of the various stages of cysts found. 
For the examination of unstained cysts, formalin-preserved fecal material showing those of Endamoba coli will be used, since this species is more readily available than is $E$. histolytica. Mount a small drop of the sedimented material under a cover glass. Care should be taken not to use so much as to render the mount opaque. (A satisfactory preparation should be so transparent that ordinary print can be read through it.) Search for round, sharply contoured clear bodies, usually about twice the

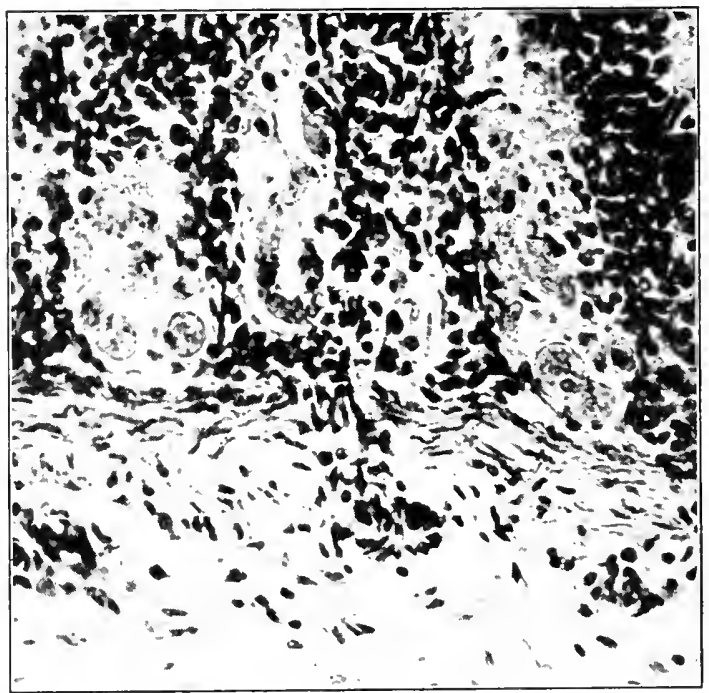

Fia. 20a. - Section of rectum of kitten infected by Endamaba histolytica, showing groups of the rounded parasites at the base of the crypts. (Orig.)

diameter of a red blood corpuscle. Add a drop of iodine solution and study under high power. The nuclei are brought out by the iodine and it will be seen that they are eight in number in the mature cysts as contrasted with four for those of E. histolytica. The karyosome is large and excentric and the peripheral chromatin, along the nuclear membrane, is thicker.

Preparations stained in iron hæmatoxylin frequently show splinter-like chromatoid bodies, in contrast to the rounded ones of E. histolytica.

Endamœba coli. Amoboid Forms.-Study the prepared slide of Endamoba coli and note that the peripheral chromatin of the nucleus is in a thicker layer and its granules coarser than in $E$. histolytica. The karyosome is coarser and excentric in position. 
Of special significanee is the fact that the endoplasm is much more gramular and contains ingested bacteria, spores, and cellular debris.

Demonstrations.- Study the demonstration specimens of the trophozoites and cysts of the two species described above. Contrast with the trophozoites those of the common intestinal Endolimax nana. In this species the nuclear membrane is very delicate and the chromatin material is concentrated very largely in a central mass. The organism is small, the diameter averaging that of a red corpuscle.

\section{References}

Boeck, W. C., and C. W. Strles, 1923. Studies on the various intestinal parasites (especially amobse) of man. Hyg. Lab., Washington, Bull. 133, xxvi +202 pp.

Clraig, C. F., 1926. "A manual of the parasitic protozoa of man," viii + 569 pp. J. B. Lippincott Company, Philadelphia.

Dobele, C., 1918. Are Entameba histolytica and Entameba ranarum the same species? Parasitology (London), 10: 294-310.

Hegneli, R. W., and W. H. Tallaferro, 1925. "Human Protozoölogy," xix +597 pp. The Macmillan Company, New York.

Kessel, J. F., 1924. The distinguishing characteristies of the parasitic amober of culture rats and mice. Univ. Calif. Pub. Zoology, 20 (23): $489-544$.

Kofold, C. A., 1923. Amoeba and man. Univ. Calif. Chron., 25: 149-310.

Kofold, C. A., S. I. Kornhaderer, and Olive Swezy, 1919. Criterions for distinguishing the endamoxare of amehiasis from other organisms. Arch. Internal Med., 24:35-50. 


\section{CHAPTER XII \\ TRYPANOSOMES AND ALLIED FORMS}

\section{TECHNICAL SUGGESTIONS}

The most readily available trypanosome for laboratory work is Trypanosoma lewisi from the wild rat. A drop of fresh blood from the tail should be examined under the $4-\mathrm{mm}$. lens of the microscope, with the diaphragm almost closed. If a considerable number of freshly killed rats is available, transfer 5 to $10 \mathrm{ec}$ of blood to small vials, defibrinate, and examine promptly on return to the laboratory. In such blood, or in the livers of infected rats kept in a refrigerator, the trypanosomes will persist and be infective for a week or more.

If an infection is found, inoculate 3 to $5 \mathrm{cc}$. of the blood into the body cavity of a young white rat, by means of an ordinary lrypodermic syringe or even by means of a fine-pointed pipette. The parasites appear in the circulating blood in a day or two and persist for upwards of a month. In order to be sure of maintaining the supply, other young rats should be inoculated at least once a month.

Detailed technique for the study of the life cycle of Trypanosoma lewisi in the rat flea may be found in the monograph by Minchin and Thompson, 1915.

Permanent mounts of trypanosomes may be prepared by the dryfilm method, staining with Wright's stain. A preferable method is to fix the moist films in hot Schaudinn's fluid and stain in iron hematoxylin.

Prepared slides of Trypanosoma gambiense are on sale but offer no advantage over those of $T$. leuisi for general laboratory study.

Our native frogs are not uncommonly infected by $T$. rotatorium, but the parasites are rarely abundant. Hegner has called attention to the value of aquatic specimens of the salamander, Diemyctylus viridescens, as a source of $T$. diemyctyli.

Demonstration slides showing the intracellular phases of Trypanosoma cruzi are to be purchased, as are also those of Leishmania. As a representative of species having only an invertehrate host, Herpetomonas musco-domestica is readily obtainable from the intestine of houseflies and various blowflies.

\section{CHARACTERISTICS OF THE MASTIGOPHORA}

The Mastigophora or Flagellata are Protozoa which are provided with one or several whiplike flagella. The group is a large one and contains many free-living forms as well as numerous 
speeies parasitic in animals and plants. Of those infesting animals an important group of blood-inhabiting speeies and elosely related forms belongs to the family Trypanosomidæ.

The Trypanosomidæ are charicterized by a more or less spindle-shaped body, a central nucleus, and by the kinctoplast, from which arises the single flagellum. As a type we shall first study Trypanosoma lowisi, (Fig. 21) a cosmopolitan species found in the blood of the rat.
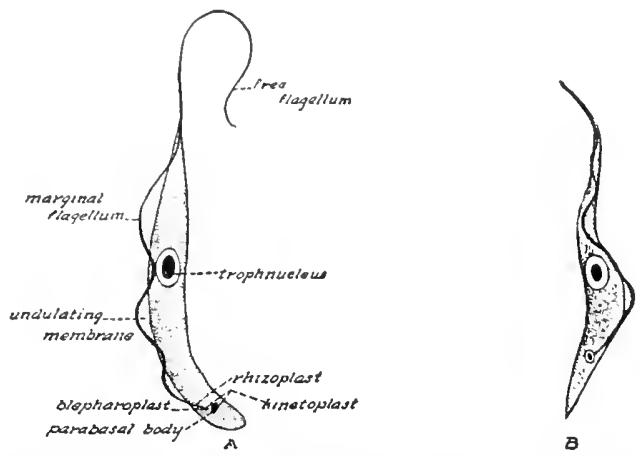

Fig. 21.-A, diagram of the structure of a trypanosome. (Modificd from

Hartmann. B, Trypanosoma levisi. (After Hartmann.)

\section{PRACTICAL WORK}

Trypanosoma lewisi.-Examine under high power the prepared slide of rat's blood containing Trypanosoma lewisi. Do not restrict your study to a single specimen but choose the better examples. Note the general form of the body, and, using the red blood cells as an index, measure several specimens (the red cells of the rat average $6.2 \mu$ in diameter). The true nucleus is the larger, centrally placed, deeply stained body. Posterior to this, at the blunter end of the organism, is another nucleus-like body known collectively as the kinetoplast. Under high magnification it is seen to be made up of a larger, somewhat rod-shaped body known as the parabasal body and a minute, highly refractile granule, the blepharoplast. From this blepharoplast there arises the single flagellum, which is attached to the body by a characteristic undulating membrane as it runs forward to projeet as the free whiplike motile organelle.

Examine mounts of the fresh blood of an infected rat and study the movements of the numerous trypanosomes present. 
Since trypanosomes occur in the blood of their host, the transmission to a new host involves a developmental cycle. In the case of $T$. lewisi it is undergone in the rat flea. It is not feasible to demonstrate this cycle in the present course, but it will be discussed in the lecture.

Demonstration Specimens.-Examine the demonstration slides of Trypanosoma gambiense, the organism of African sleeping sickness of man, and Trypanosoma cruzi, the cause of South American trypanosomiasis. In this latter species the parasites multiply not in the circulating blood but in the muscles and other tissue cells of the human host. Here they round up, lose their flagella, and by repeated division produce large numbers of forms resembling, in the possession of a nucleus and a parabasal body, the Leishmania organisms of kala-azar.

Leishmania.-Parasites belonging to this genus, often called the Leishman bodies, are minute Protozoa which are the cause of two types of disease in man: the one a generalized disease, kala-azar, and the other a cutaneous type known as oriental sore. The organisms as seen in the vertebrate host are very minute, oval bodies measuring 1 to $2 \mu$ in length and crowding endothelial or macrophage cells. In spite of their small size and their intracellular position they show their relationship to the trypanosomes by the presence of a distinct nucleus, a very distinct parabasal body, and a very slender rhizoplast which represents the basal portion of a flagellum. Study the demonstration slide of Leishmania donovani, the organism of kala-azar.

Trypanosomidæ from Invertebrates.- Since the blood-inhabiting trypanosomes of mammals typically undergo a cycle of development in an invertebrate host, different stages of the protozoan may be found on examination of these forms. In addition, however, insects and other invertebrates may harbor flagellates which, while showing relationship to trypanosomes, are apparently restricted to the one host. They are significant not only because of their resemblance to trypanosomes morphologically, and in their behavior in artificial cultures, but because of the probability that they represent the groups through which the blood-inhabiting species have developed.

These intestinal flagellates of invertebrates belong to the genera Leptomonas, Herpetomonas, and Crithidia. Like trypanosomes, they possess a more or less centrally placed nucleus and a single 
flagellum arising from a composite kinetoplast, which in these genera, lies anterior to the nuclens.

These will be illustrated by the widely distributed IIerpetomonas musca-domestica from the intestine of house flies and related species. It is transmitted from fly to fly in the form of rysts in the feces. A much-studied Leptomonas is found in fleas, while the genus Crithidia, eharacterized by a rudimentary undulating membrane, is readily obtained from the intestine of the alpuatic bugs commonly known as "water-striders."

\section{References}

Execlient diseussions of the trypanosomes and related flagellates are to be found in the texts of Craig; Hegner and Taliaferro; Hegner, Augustine, and Root; Thompson and Robertson; and especially of Wenyon. The following references indicate some of the sourees of material for study.

Becker, E. R., 1923. Olservations on the morphology and life cyele of Crithidia gerridis Patton in the water-strider, Gerris remigis say. Jour. Parasitology, 9: 141-152.

Becker, E. R., 1923 b. Olservations on the morphology and life-history of Herpetomonas musca-domestice in North Ancriean muscoid flies. Jour. Parasitology, 9 : 199-213.

Crawler, H., 1912. Trypanosoma americanum, a common blood parasite of Ameriean cattle. U.s. Dept. Agr., Bu. An. Ind., Bull. 145: 5-39.

Drbohrav, J. J., 1925. Stutlies on the relation of insect flagellates to leishmaniasis. Am. Jour. Hyg., 5 (5): 580-621.

Hegner, R. W., 1921. Measurements of Trypanosoma diemyctyli from different hosts and their relation to speeifie identifieation, heredity, and environment. Jour. Parasitology, $7: 105-113$.

Hoare, C. A., 1923. An experimental study of the sheep trypanosome ( $T$. melophagium Flu 190S) and its transmission by the sheep ked (Mclophagus ovinus L.). Parasitology, 15: 365-424.

Minchin, E. A., and J. D. Thompion, 1915. The rat trypanosome, Trypanosoma lewisi, in its relation to the rat flea, Ceratophyllus fasciatus. Quart. Jour. Micro. Sci., $60: 463-692$. 


\section{CHAPTER XIII}

\section{INTESTINAL FLAGELLATES OF VERTEBRATES}

\section{TECHNICAL SUGGESTIONS}

Where hospital facilities permit the examination of considerable numbers of fresh stools, the species of intestinal flagellates infecting man may be used for this study. The more dependable sources are domesticated and laboratory animals.

Frogs commonly harbor in the rectum and at the junetion of the large and small intestine Eutrichomastix batrachorum, Trichomonas batrachorum, and T'richomonas augusta. Kofoid and Swezy found the last-mentioned speeies abundantly in the salamander Diemyctylus torosus as well as in Rana pipiens, R. boylei, R. Lraytoni, and Hyla regilla, at Berkeley. They kept speeimens alive for several months by diluting the intestinal smear with physiologieal salt solution and sealing the cover glass with raseline. Cultures of various Trichomonads were made lyy placing a bit of the intestinal content in a hollow-ground "ulture slide, filling the eavity with physiologieal salt solution, and sealing the cover glass with raseline.

Laboratory white mice and rats are frecuently infected with Trichomonas muris. Less frequently it is found in house and field mice. Trichomonas cavite is oecasionally harbored by guinea-pigs.

An important source of material is the domestic chicken, whose exea may yield the four species: Chilomastix gallinarum, Trichomonas gallinarum, 'T' eberthi, and Eutrichomastix gallinarum. Becker, 1926 , reports on seven speeies of flagellates from the striped ground squirrel, Citellus tridecemlineatus.

Chilomastix species are reported from mumerous other animals including rabbits and rats. They are eommonly present in human dejeetions following the use of saline purgatives.

Giardia lamblia is a widely prevalent species affecting man. It is cspecially peralent among young children, and the examination of an institutional group is a ready method of obtaining eysts. Motile and eystic stages of "losely related species are very eommonly found in rats, mice, guinea-pigs, and various other mammals. An interesting species is found in tafpoles.

In atdition to the material from various animals used in the laboratory work, slides of Trichomonas hominis, Chilomastix mosnili, and Giardia lamblia should be available for demonstrat ion. As opportunity presents, fecal material containing 'y'sts of Chilomastix and Giardin should be preserved in $10 \mathrm{per}$ eent formalin for diagnosis. 
Unfortunately, the Giardia eysts break down in this fluid after a few nonths.

Permanent slides of any of the species to be used in this exereise should be made by fixing moist smears in hot Sehandinn's fluid and staining in iron hamatoxylin (see p. 99). When possible, smears shoukl be made from a fragment of the infected intestinal wall als well as from the intestinal content. Special care should be observed in differentiating the stain.

\section{CHARACTERISTICS OF INTESTINAL MASTIGOPHORA}

Of the many forms of intestinal flagellates we shall give special attention to three genera-Chilomastix, Trichomonas, and Giardia - not only as widely distributed forms, but also as genera represented by parasites of man. The consideration of them together is only a matter of convenience for, from a systematic viewpoint they represent distinct families. One of them, Giardia, is a nember of a special order of Mastigophora, the Diplomonadida, or "double monads," characterized by a bilateral symmetry of the body, with two nuclei, eight flagella, and all of the organelles paired. The distinguishing characteristics of this and of the Chilomastigidæ and Trichomonadidæ will be brought out in the laboratory work.

\section{PRACTICAL WORK}

Examine, when possible, both living and stained specimens of the following representative parasites or related species from animals. Note the size, movements, structures, features, and the characteristics of the cysts when present.

Chilomastix mesnili is a fairly common parasite of the small intestine of man which has often been confused with Trichomonas intestinalis. It is pear-shaped with a rounded anterior end and a pointed posterior end. It has a characteristic jerky, spiral movement. The size varies greatly, the average being about $14 \mu$ in length by $6 \mu$ in breadth. The relatively large, round nucleus is at the very anterior end, dorsal to the cytostone ("mouth"). The three anteriorly projecting flagella should be examined in favorable specimens, with careful adjustment of the iris diaphragm of the microscope. In properly stained specimens under high magnification it may be seen that they arise from minute, dotlike blepheroplasts. A fourth flagellum lies within the large elongate cytostome and probably functions 
chiefly in obtaining food, as suggested by Boeck. The cytoplasm contains bacteria and other food inclusions.

The cysts are small, refringent, and pear shaped, with a transparent wall which is thicker at the anterior end. They measure from 7 to $9 \mu$ in length by 4.5 to $6 \mu$ in width. In the

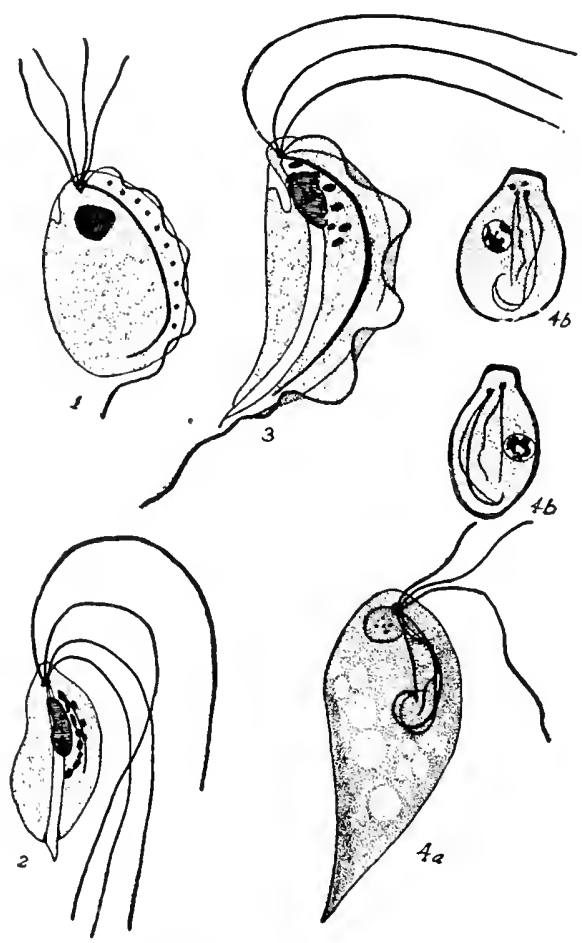

Fut. 22.- Intestinal flagellates of the chicken. 1, Eutrichomastix gallinarum; 2, Trichomonas gallinarum; 3, Trichomonas eberthi; 4, Chilomastix gallinarum, motile and eyst stages. (Figures 1-3 from Martin and Robertson, Figs. ta and 4h from Boeck and Tanabe.)

granular cytoplasm may be seen the large rounded or oval nucleus and the outlines of the cytostome with its fibrillar apparatus.

Trichomonas hominis is said to be the most common flagellate affecting man. Statistics are not altogether reliable on account of the above-mentioned confusion in many cases with Chilomastix mesnili. More available species for study are Trichomonas augusta and Trichomonas batrachorum from the frog. Mount in a drop of water the intestinal content from the juncture of the small and the large intestine. The trichomonads may be seen als 
actively moving, tadpole-shaped organisms. Under high power, study a less active specimen. Cut down the light and note the three anteriorly projecting flagella and the posteriorly directed flagellum attached to the body of the organism by an undulating membrane. A wave of movement from the anterior to the posterior end of the flagellum and membrane simulates a series of minute projecting legs. At the anterior end, near the base of the flagellat, is a small cytostomr; while through the center of the body there runs a hyaline rodlike strueture, the axostyle.
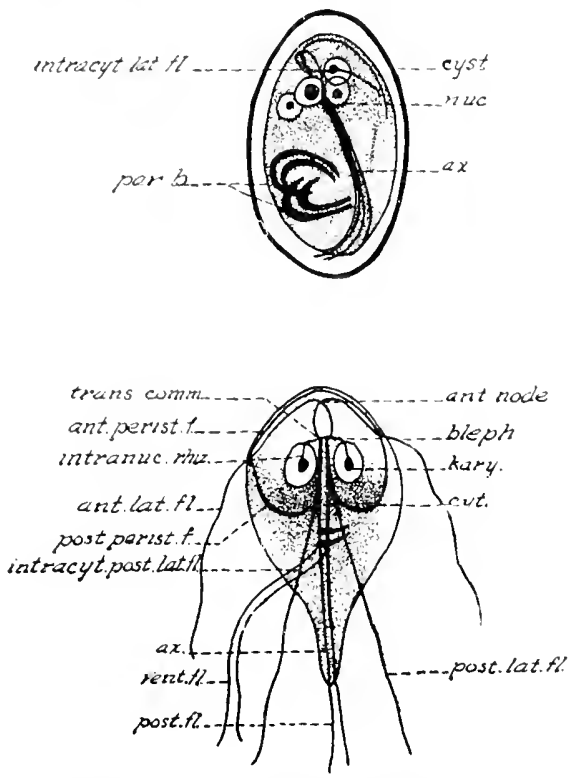

Fig. 23.-Ventral view and eyst of Giardia lamblia. (After Kofoid and Suczy.)

In stained specimens note the above-described structures and, particularly, the blepheroplast from which the flagella originate, the chromatic basal rod, and the nucleus. (Cf. Fig. 22.) The oval cysts with remains of the fibrillar apparatus will be demonstrated. Those of the species infecting man have not been found and it is generally believed that this species is transferred in the trophozoite stage.

Giardia lamblia (Fig. 23) is a remarkable parasite infecting man. In the older literature it is known as Lamblia intestinalis and hence the term lambliasis, as well as giardiasis, is applied to the infection. Occasionally it is transferred from man to 
rats, but the very closely related species commonly infesting rats is Giardia muris. Other related species are found in rabbits, guinea-pigs, and numerous other animals. The organisms are the shape of a longitudinally cut half of a pear with a large eoncavity, or sueking disk, at the anterior end. They move in a characteristic manner, rotating on their long axis in a jerky manner. The size and relative breadth vary with the species, though considerable variations oecur in the same species. A striking peculiarity of representatives of the genus is the duplication of organelles. There are four pairs of posteriorly directed flagella, two prominent nuclei, and two rodlike longitudinal axostyles. Just posterior to the sucker is an obliquely placed, deeply staining mass which represents a pair of more or less fused parabasal bodies.

The cysts are hyaline, oval bodies with a well-marked refractile membrane and exhibit two or more nuelei and traces of the fibrillar apparatus in the living condition. Speeimens well stained in iron hæmatoxylin show the basal portions of the flagella and the axostyles in the younger eysts. There are usually four nuclei in the older ones, and in some cases eight and even more have been noted. Near the posterior part of the cyst are paired, coarser, deeply staining fibrils whose significance is still in dispute.

\section{References}

Becker, E. R., 1926. The flagellate fauma of the exeum of the striped ground squirrel, Citellus tridecemlineatus, with speeial reference to Chilomastix magna sp. nov. Biol. Bull., 51(5): 287-295.

Вовск, W. C., 1921. Chilomastix mesnili and a method for its eulture. Jour. Exptl. Ned., 33(2): 147-175.

Dobell, C. C., 1909. Researebes on the intestinal protozoa of frogs and toads. Quart. Jour. Micro. Sci., 53 (2): 201-277, plates 2-5.

Hegner, R. W., 1923. Giardias from wild rats and mice and Ciardia cavia sp. nov, from the guinea-pig. Am. Jour. Hyg., 3 (3):345-349.

Kofon, C. A., and Olive Swezr, 1915. Mitosis and multiple fission in trichomonad flagellates. Proc. Am. Acad. Arts Sci., 51 (6): 289-378, plates 1-8.

Kofon, C. A., and Olive Swezy, 1922. Mitosis and fission in the active and eneysted phases of Giardia cnterica (Crassi) of man. Univ. Calif. I'ub. Zoölogy, 20 (8): 199-234, plates 23-26.

Martin, C H., and Muriel Robertson, 1912. Further oloservations on the eacal parasites of fowls, with some reference to the rectal fatuna of other vertobrates. Quart. Jour. Micro sisi., 57 (1): 53-\$2, plates 10-14. 
Potter, L. A., 192s. Two species of cialrdia from the rat. Alm. Jour. $1 / \mu g ., 8(1): 77-84$.

Stmon, C. E., 1922. A critigue of the supposed rodent origin of human (iiardiasis. Am, Jour. Hyg., 2 (4): 406-434. ('f. Potter, 192s).

Wennern, 1). II., 1921. The structure and division of Trichomomes muris (IIartmann). Jour. Worphology, 36 (1): 119 15t, plates 14. 


\title{
CHAPTER XIV
}

\section{A SIMPLE LIFE CYCLE OF A SPOROZOAN}

\author{
TECHNICAL SUGGESTIONS
}

The speeies of Monocystis from the seminal vesicles of the earthworm, on aceount of their a valiability and the readiness with which the various stages can he foume, afford a most satisfactory introduction to the study of the sporozoa.

In most localities the great majority of the large Lumbricus terrestris will be found infected. In regions where this worm is not established, it is desirable to purchase living speeimens from some Eastern collector or through supply houses. In case this speecies is not obtained, local specjes will usually be found to harbor related parasites, as shown by Mickel, 1925, who fomm Helodrilus caliginosus in Minnesota heavily infesterl by Zygocystis cometa.

For supplementing the sturly of fresh materials, sections and smear preparations should be prepared from heavily infected specimens.

Cirasshoppers, cockroaches, ant the mueh-used mealworms (larve of Tenebrio molitor) are certain sourees of cephaline gregarines. The mealworms ean be purchased from lird dealers if a supply is not kept in the laboratory.

\section{CHARACTERISTICS OF THE GREGARINIDA}

The class Sporozoa is a somewhat hetcrogeneous group of Protozoa, made up of forms exclusively parasitic, which lack definite locomotory organs, mouth, anus, and contractile vacuoles. They produce at some stage in their life history resistant spores which, however, are not directly infective but give rise to sporozoites which are the forms infecting new hosts.

The order Gregarinida includes celom-inbabiting Sporozoa which reproduce typically by spore formation after the fertilizing union of similar gametes. They are very common as parusites of invertebrates, chiefly insects, hut the majority of the species are probably harmless to their losts. Dissemination is usually passive, infection being by way of the alimentary canal.

In spite of their relativo unimportance as parasites, the generalized life cycle of the Cregarinida and their close relationship to important groups of mammalian and human parasites 
make them important objects of study. Among the most widely distributed and best known forms are Monoeystis agilis and rolated species from the seminal vesicles of carthworms. In many localitios practically every worn is infested and all stages may be found.

\section{PRACTICAL WORK}

Directions for Dissection.-A fresh specimen of Lumbricus terrestris or related species of earthworm will be supplied. Place the worm in a flat-bottomed tray with the dorsal surface upward, stretching with a pin through the fifth segment and in the neighborhood of the thickened clitellum. Very carefully slit through the skin along the mid-dorsal line, avoiding piercing the alinentary canal or other organs. The conspicuous creamcolored bodies at the side of the asophagus, and overlying it in the ninth, tenth, and eleventh scgments are the seminal vesicles.

Remove with forceps a bit of one of the seminal vesicles and tap it in a drop of physiological salt solution (or water) on a slide. Cover the preparation and observe and make careful drawings of the following:

Normal Tissues-Preparatory to study of the parasitic organisms, distinguish and make drawings of the following normal tissues of the seminal vesicle: (1) the sperm morula, spherical masses of small rounded cells which should be studied both in surface view and in optical section; (2) mature spermatozoa in brush-like clusters attached to a central core of protoplasm; (3) epithelial cells, flattened, angular, and homogeneous.

Monocystis sp.-Having distinguished the normal tissues in your preparation, scarch out various stages of the gregarine parasites. Study and figure the stages as you find them, but arrange your drawings in the following order:

1. The young trophozoite, or feeding stage, is a minute nucleated body in the midst of a sperm morula. As it develops at the expense of the sperm colls it becomes clongated and finally appears as a spindle-shaped organism with a cilia-like covering of short, abortive spermatozoa.

2. Motile trophozoites, extended and contracted, may be found in the seminal fluid. The living organism exhibits slow. flowing movements. Note the clear ectosare, granular endosare, and nucleus. 
3. Gametocytes.-Two similar individuals become associated, and though remaining perfectly distinct from one another, secrete about themselves a common envelope, or cyst.

4. Gametes. - The nuckes of each gametoeyte breaks up into a large number of nuelei. These beeome arranged around the periphery of the gametocytes, and about each nueleus there is cut off a little of the protoplasm of the mother cell. This
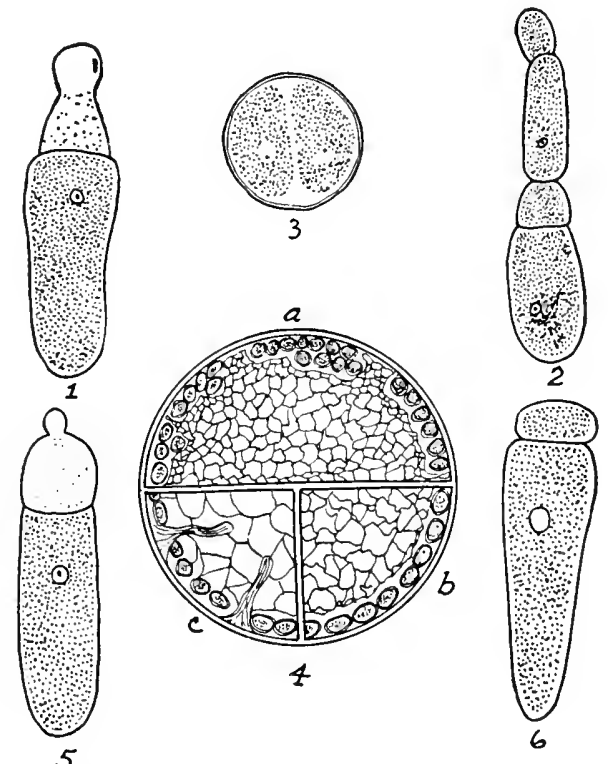

FIG. 24.-The gregarine parasites of the meal worm, Tenebrio molitor. 1-4, Gregarina cuncata; 2, conjugating individuals; 3 , gametoeytes eneysted; 4 , diagram of spore formation. In $a$, the gametes formed by the gametocytes are fusing to form sporoblasts, in $b$ and $c$, the spores are maturing. 5, Gregarina polymorpha; 6, Gregarina steini. (After Berndt.)

nueleated mass of protoplasm is now known as a gamete, or sexual element. A large number of these gametes are formed, but a portion of the original cell remains as residual protoplasm, or "Restkörper." Study these points in prepared seetions through infested seminal vesieles.

5. Sporoblasts.-The gametes now pass from one cell to the other and eonjugate in pairs to form rounded sporoblasts. The nuclei fuse and the sporoblasts become oval and form a spore. 
6. The spore in Monocystis is boat shaped and is of ten known as a preudonavicula. As in the Sporozoa in general, this is not the infective stage; but the nucleus divides and the protoplasm forms sporozoites.

7. The sporozoites vary in number, depending upon the genus. In Monoeystis the longitudinal division of the spore content into sporozoites can be indistinctly seen in the living spore if the light is properly adjusted. After studying it in this manner, examine sections of the seminal vesicles showing spores in cross and longitudinal sections. Make drawings showing the sporozoites and the granular "residual protoplasm."

Other species of Monocystis may occur and should be figured if found. A related genus, Zygorystis, has the adult trophozoites more or less pearshaped, with frayed ends, and always united in twos and threes. Very many species of Gregarinida are known, of which the majority are parasitic in insects.

Nematodes.-In the course of these studies roundworms are occasionally to be found in the seminal vesicles of the earthworm. These are Discelis filaria of Dujardin, 1845, or closely related species.

\section{References}

Cuenot, 1901. Recherehes sur l'évolution et la conjugaison des grégarines. Arch. biol., 17 (4): 581-652.

Hense, E., 1909. Contribution a l'étude des Monocystidées des oligochètes. Arch. Zool. exper. (ser. 5), 3: 27-301.

Mickel, C. E., 1925. Notes on Zygocystis comcta Stein, a gregarine parasite of earthworms. Jour. Parasitology, 11: 135-139.

Minchin, E. A., 1903. Seetion, Sporozoa. In Lankester, "Treatise on Zoölogy," Part I, fascicle 2, pp. 154-164.

Watson, Minnie E., 1916. Studies on gregarines, inchuding twenty-one new species and a synopsis of the Eugregarine records from the Myriapoda, Coleoptera and Orthoptera of the World. Illinois Biol. Monographs, 2 (3), 258 pp. 


\section{CHAPTER XV \\ THE LIFE CYCLE OF THE COCCIDIA}

\section{TECHNICAL SUGGESTIONS}

The most readily available species for the study of the life cycle of a coecidian are Eimeria stiede and E. perforans from the rabbit, the former from the liver and the latter from the intestine. By some writers the two are eonsidered identical and the following laboratory outline is applicable to either.

Infections may be detected by examining the feces of laboratory rabbits, even if acute cases are not available. The oöcysts maty be concentrated by breaking up the feces in water, sedimenting repeatedly, and straining out the coasser particles. They are then cultured to the infective stage in Petri lishes under a thin layer of 4 per cent potassium hichromate solution to prevent mold. Andrews, 1926, eomminuted heavily infected feees in 1 per cent chromie ardid, cultured for a week or so, strained out the consest particles of feeres through eheesecloth and them through batiste, and finally floated up the oöcysts by saturation with sodium chloride. If acute cases are available the animal may be killed and the oöeysts recovered by seraping the infected mucosa, thoronghly shaking the scrapings to remove the oöcrsts, and then centrifuging gently for one or two minutes so that the oöeysts are thrown down while the cell dehris remains suspended. Freshly recovered oöeysts as well as those which have undergone development to the infective stage shoull be preserved in 10 per cent formalin for elass study.

Others should be arministered, in food or by drenching, to young rabbits, in which acute cases of coceidiosis may be induced for further study. For eritical work Andrews administered known numbers of the oöcysts by means of a stomach tube. Portions of the diseased liver or intestine, dependent upon the speeies of parasite, should be fixed in saturated corrosive sublimate solution and in picro-formol, sectioned, and stained in hemotoxylin and eosin.

In lieu of rabbit material young chickens often afford an abundint supply of Eimeria atium. Myriapods of the genus Lithobius commonly harbor Eimerin schubergi, but it is generally associated with other forms which may confuse the sturly of it. English sparrows commonly yield a species of Isospora and others of this genus are readily obtainable from cats, dogs, foxes, and various other mammals.

\section{CHARACTERISTICS OF THE COCCIDIA}

The Coccidia are cell-infesting Sporozoa which typically reproduce intracellularly by asexual spore formation (schizogony) 
as well as by true sporogony, thus having a life cycle with alternation of asexual and sexual generations. The former provides for the multiplication of the parasite within the host, while it is through sporogony that infection of new hosts is brought about. After fertilization the oösphere forms sporoblasts which may or may not be covered by a sporocyst membrane, and which may each become transformed into one or several sporozoites.

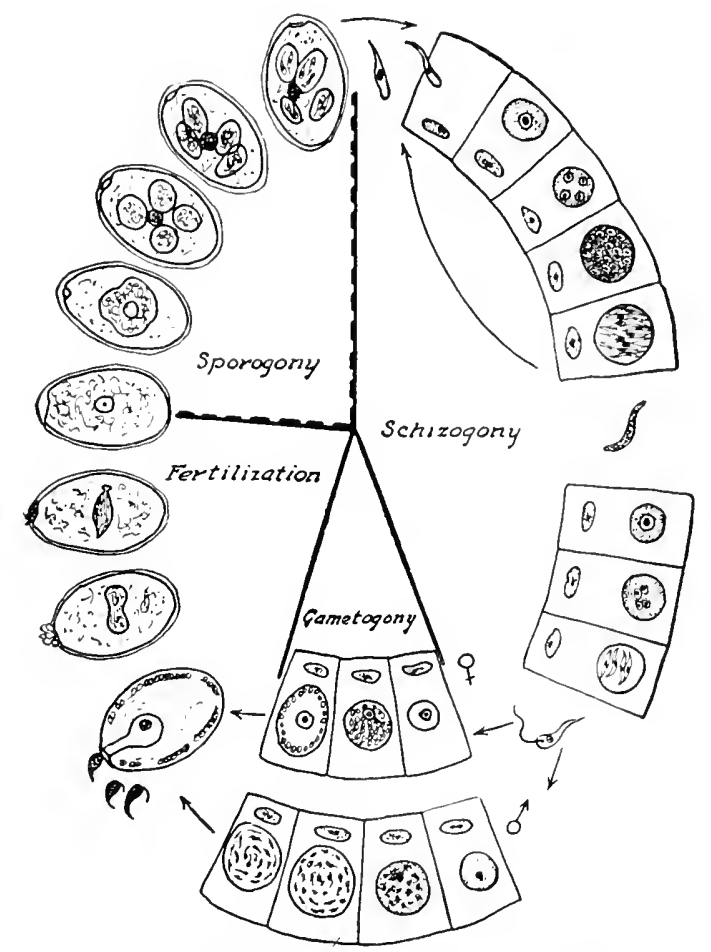

F1G. 25.- Diagram of the development cycle of a Coceidian. (After Reirh.)

The chief difference between the Coccidia and the Gregarinida, as typified by Monocystis, is then, the intracellular habitat of the parasites and the interpolation of an asexual cycle.

There are many species of Coccidia infesting both invertebrates and vertebrates, including man. We shall use as a type Eimeria stiedce, a species which commonly infests rabbits and is the cause of much mortality, particularly among the young animals. Related species cause serious disease of cattle, dogs, 
birds, and other animals. Several species are reported for man but infections are rare.

\section{PRACTICAL WORK}

Oöcysts.-Coceidial infections are conveyed from animal to animal by oöcysts whieh pass out with the dung. We shall begin our study with these bodies as they appear when first discharged. Note their oval form, the size, the sharply contoured envelope, and the minute pore, or micropyle, at one encl. The protoplasmic content may fill the cyst in the early stages or may be later clumped into a spherical mass.

Development outside the Host.-The oöcysts are ineapable of further development until they have been discharged from the body of their host. In the presenee of oxygen and under favorable conditions of temperature and moisture the protoplasm divides into four sporoblasts. These secrete cyst walls and become spores, each of which produces two sporozoites. The infective oöcyst thus contains four spores and eight sporozoites. Make drawings illustrating the various stages.

Development within the Host. - When ripe oöeysts are ingested by a rabbit, the sporozoites are liberated by the action of the gastrie and panereatie juices and bore into the intestinal or gall-duct epithelium. Here they undergo asexual multiplication, or schizogony, and the early stages of their sexual reproduction, or sporogony.

In prepared slides of infected intestine study the following:

Schizogony. - When the sporozoites enter the epithelial cell, they become rounded schizonts and begin to increase in size. In unstained preparations they are readily distinguished from the host cell by their greater refractivity. As the schizont develops, the nueleus divides repeatedly and finally the sehizont breaks up into a number of nucleated merozoites. These merozoites are aetively motile and enter new epithelial cells, beeome schizonts, and continue the cyele. The infection may be so extreme that large areas of tissue of the host are destroyed.

Sporogony.-The infection of new hosts is made possible by the sexual eyele, or sporogony. Certain merozoites instead of developing into asexual sehizonts develop as male or female gamctocytes. Unlike those of the Gregarinida, there is a marked difference in the gametes and hence the cells producing the male 
elements are known as microgametocytes, those producing thr female gametes are designated macrogametocytes.

Microgametocytes. - The microgametocytes present a clear, finely vacuolate protoplasm and reach a much greater size than either schizonts or macrogametoeytes. From each there arises a great number of microgametes analogous to the spermatozoa of the higher animils. A voluminous mass of residual protoplasm remains unchanged.

Macrogametocytcs. - The female gametocytes possess a coarscly granular, dense protoplasm, rich in nutrient substances. In sections the granules, arranged around the periphery, are so large as to resemble nuclei. The true nucleus is, however, clearly evident as a large central body. The young macrogametocytes are spherical, but they become oval as they mature. They undergo a process of maturation, after which they are known as macrogametes.

Oöcysts.-The mature maerogamete is fertilized by a mierogamete and through the fusion of their nuclei, the oöcyst is formed, ready to continue its development when it passes from the host.

\section{References}

Andrews, J. M., 1926. Coccidiosis in mammals. Am. Jour. Hyg., 6 (6): 784-798.

Bruce, E. A., 1920. Bovine coccidiosis in British Columbia. Jour, Am. l'et. Werl. Assoc., 58 (1): 638-662.

Johnson, IV. T., 1924. Eimeria avium and the diagnosis of avian coceidiosis. Poultry Sci., 3 (2): 41-57.

Johnson, W. T., 1928. Coccidiosis of the chicken. Oregon Agr. Exp. Sta., Bull. 238: 1-16.

Pérard, Chi, 1924-25. Recherches sur tes cocerilies et les coceidioses du lapin. Ann. inst. Pasteur., 38 : 953-976; 39: 505-542.

Rerch, F, 1912. Das Kaninchencoceid Eimeria stiedce. Arch. Protistent., $28: 1-42$. 


\section{CHAP'TER XVI}

\section{THE HAMOSPORIDIA}

\section{TECHNICAL SUGGESTIONS}

For most classes it is necessary to precede the study of malarial parasites and related forms by a study of the morphology of the blood, with particular attention to the types of leucocytes. Otherwise, the student is very apt to confuse the nuclei of these cells with the parasites for which he is searehing.

In this country it is rarely possible to demonstrate the living malarial parasites of man. If such an opportunity presents itself, a preparation should be sealed with vaseline and movements of the organism and pigment granules demonstrated. Mature parasites if kept on a warm stage may be seen to sporulate.

Stained preparations of Plasmodium vivax and P. falciparum are widely ohtainable from dealers. Less frequently, demonstration speeimens of $I$. malario may be purehased. In some parts of the country cndemic malaria still oecurs, and even in malaria-free sections the widespread use of induced malaria in treatment of paresis affords occasional opportunities for obtaining material from hospitals and dinies. In such eases smears should be made at 12 -hour intervals heginning immediately after a chill and continuing through the eyele. Stain with Wright's stain (p. 110).

Plasmolium procox and related species are found in English sparrows in this country, although natural infections do not secm common. Laboratory strains have long been maintained in canaries in various labomtories and infeeted birds may be obtained from some of the dealers listed on page 124. The parasites are abundant only during the acute stages of the infection and henee fresh hirds should he inoculated a week or so before needed for laboratory work. This is dlone by pricking a vein under the wing or in the leg of the infected hird, sucking up a drop of blood into a syringe containing physiological salt solution, and injecting into the breast muscles of the elcan bird.

The sexual cycle in the mosquito can be ohtained by the methods given in detail by Huff, 1927. Reared females of Culex pipiens are kept away from water for 24 hours and then allowed to feed on heavily infected eanaries at night. The feathers of the hird should he parted in the peetoral region and wetted down. It is immobilized by tying it surugly in a piece of netting and then placed on the erinoline-gatuze top of a lantern-ehimney hreeding cage in such a way that its exposed breast is aecessible to the mosquitoes. A strip of cloth is placed over it and extended down along the side of the lantern globe 
and held firmly in position by a robber band. The engorged miseres are then removert to another breeding rage amd maintained on soaked raisins for varying periods before dissection. The oörysts reath their maximun size about the tenth daty.

Crows are very commonly infeeted by Hamosporidia of the genus IIrmoprotens (Halteridimn), the forms in which MeCallum first worked out the signifieance of exflagellation. With living material from this somre the formation of the microgametes and the process of fertilization can readily be demonstrated.

Demonstration slides of Babesia bigemina and Babesia eanis ean be purchased.

For the praetiral work outlined it is, of eourse, desirable to use oil immersion lenses. If this is not feasible it is quite possible to make the study with the aid of high power dry lenses, supplemented by lemonstrations.

\section{CHARACTERISTICS OF THE H EMOSPORIDIA}

The order Hæmosporidia ineludes the blood-dwelling Sporozoa, intracorpuseular or free in the plasma, and with or without alternation of hosts. From the zoologieal viewpoint as well as from that of human pathology the most important are the malarial parasites belonging to the genus Plusmodium. Related species of the same genus oecur in sparrows and finches. Of much importanee in our Southern states is Babesia bigemina, the organism of Texas fever of cattle.

\section{PRACTICAL WORK}

There will be furnished a slide of blood from a case of benign tertian malaria, Plasmodium vivax. The preparation has been stained in Wright's stain. Preparatory to the seareh for malarial parasites in the slides furnished it is necessary to become acquainted with the normal elements of the blood. Particularly is it desirable to study the blood platelets and to distinguish the types of leueoeytes. For this purpose compare your findings with the chart (Fig. 26).

Plasmodium vivax.-Having completed this preliminary examination, begin at one corner of the preparation and search earefully the entire slide for various forms of the mialarial parasitr in the erythrocytes, or red blood corpuscles. If the ease from which the slide was prepared was one of simple tertian malaria, the parasites will be in approximately the same stage and slides from other cases must supplement each other. Not infrequently double or even triple infections may oecur from bites of infective 

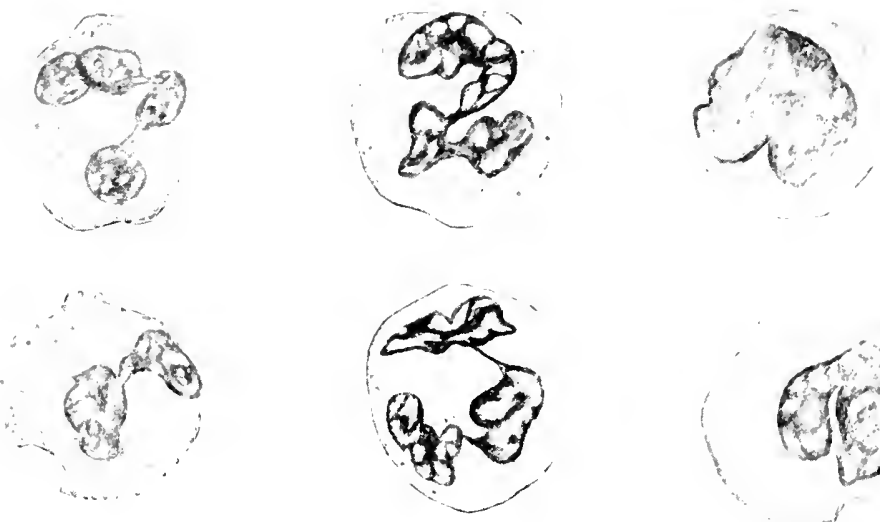

Eosimphils

Neutrophils
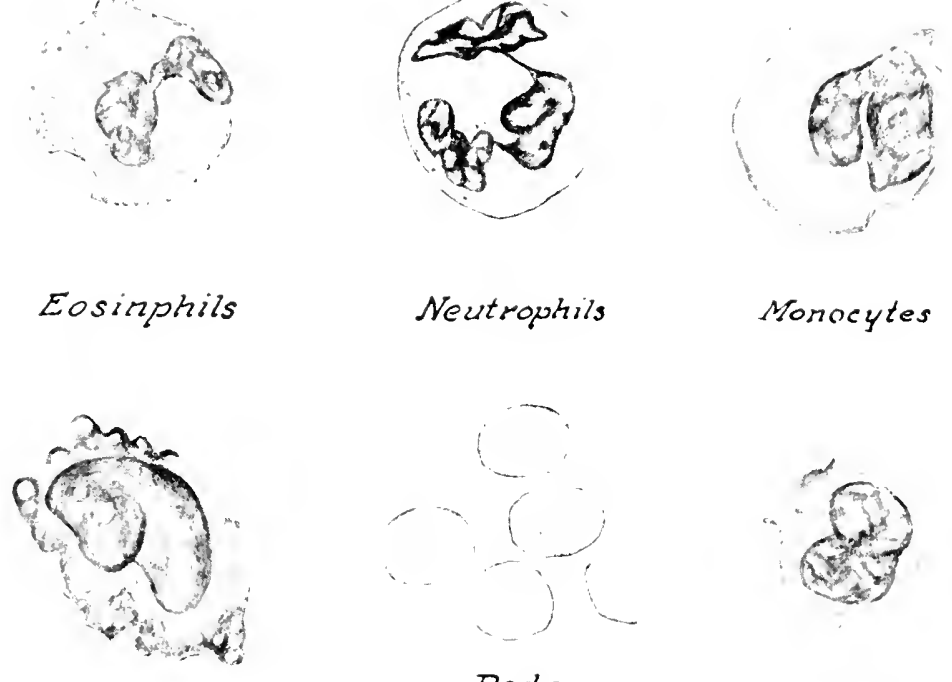

Reds
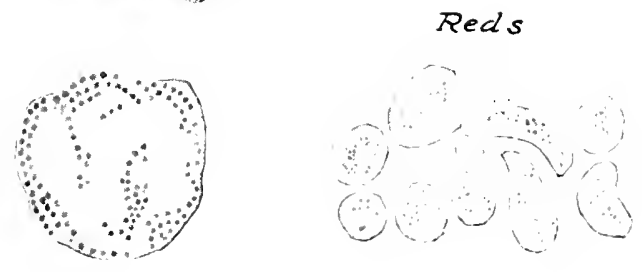

Monocytes

Mast Cells

Blood Platelets
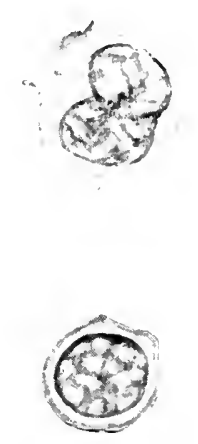

FIG. 26.- Normal human blood. (From ehart by Dr. Hal Downey.) 
mosquitoes on successive days. In such cases parasites in various stages will be found on the one slide.

The parasite is injected into the blood of man by the bite of an Anopheles mosquito, in the form of an elongate veriform sporozoite. This stage will not be found in blood smears. The

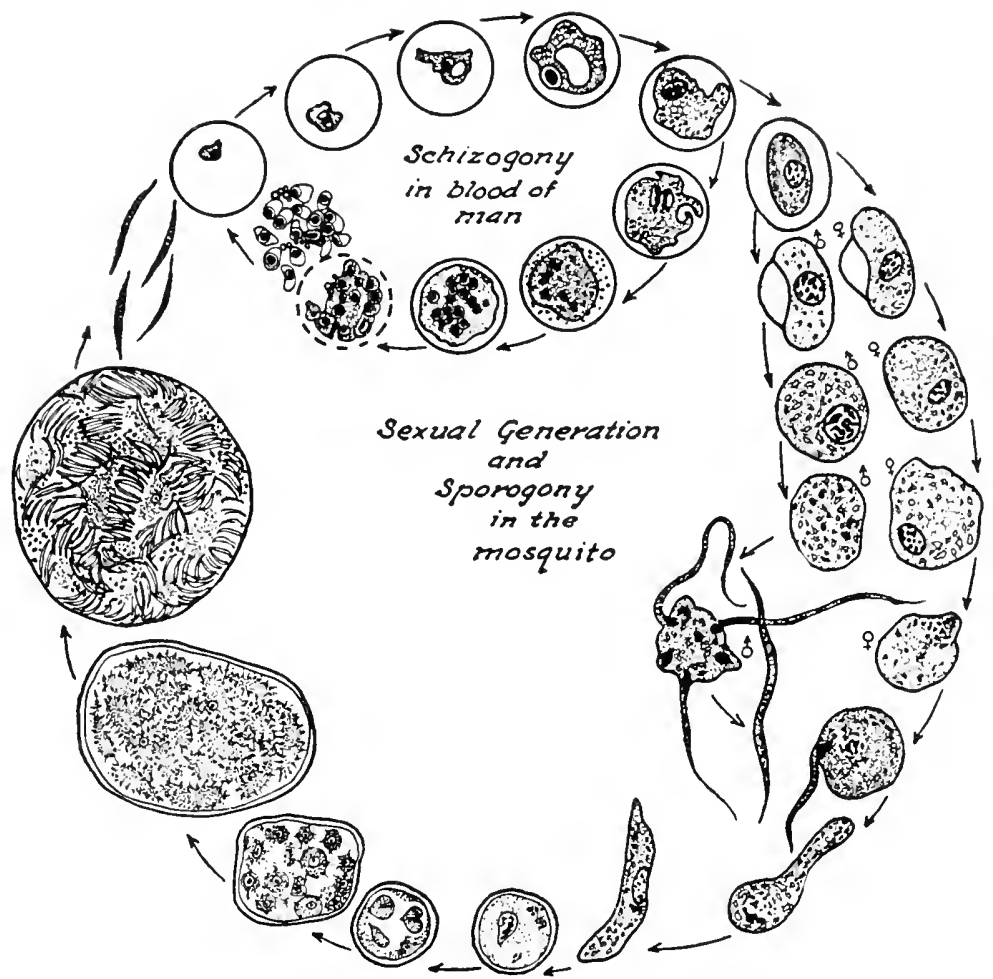

Fig. 27.-Diagram of the life cyele of a malarial parasite. The upper figures illustrate the asexual "Ycle of Plasmodium virax in human blood; to the right are the sexual forms of $P$. falciparum in the stomach of the mosquito and to the left are the stages to be foutud in the stomaeh wall and salivary glands of the insect host. (After linchin.)

youngest stage to be noted is the signet ring stage, so called because the protoplasm consists of a ring staining blue, with a clear unstained space, and a red-staining spot, the nucleus, suggesting the seal of a ring. This growing stage is called, as in other Sporozoa, the trophozoite.

As the parasite grows, the ring of protoplasm enlarges and a dark brown pigment, derived from the hrmoglobin of the blood 
eorpuscle, is deposited in it. This pigment makes it possible to detect the presence of malarial parasites even in freshly drawn and unstained preparations. It is characteristic of infeetions with Plasmodium vivax that the infected eorpuseles become enlarged as the parasite develops. Not infrequently they become stippled with deep-staining granules, the Sehüffner's dots. In the older parasites the dark pigment beeomes more concentrated and the red-staining ehromatin divides into small masses near the periphery. These with a small amount of protoplasm beeome the asexual spores or merozoites. In P. virax they number 15 to 25 , or thereabouts. The corpuscle ruptures and the merozoites, along with the pigment and a little residual protoplasm, eseape into the blood stream. Such of the merozoites as are not destroyed by phagocytes re-enter red corpuscles and thus continue the asexual phase, or schizogony. The entire cycle from sporulation to the next eseape of merozoites is undergone in 48 hours.

The sexual eycle, or sporogony, is completed in mosquitoes of the genus Anopheles, but the gametocytes are to be found in the human blood after the disease has progressed for some days. They can be distinguished from the schizonts by the fact that in the full-grown stage the chromatin forms one mass instead of being broken up preparatory to formation of merozoites. In the macrogametocyte this mass is compact and excentrically placed and the pigment consists of long rods. In the microgametocyte the chromatin is centrally placed and more diffuse, and the pigment is in small rods.

Plasmodium falciparum.-Preparations from a case of malignant malaria, caused by Plasmodium falciparum, should be compared with the above. As a rule only the ring stages and the mature gametocytes are found in the peripheral blood, the schizogony oecurring in the internal organs of the host. There will be demonstrated seetions of the brain from a fatal ease of malignant malaria showing the schizonts in the eapillaries. The gametoeytes are very characteristie erescent or sausageshaped forms. The macrogametocyte has its ehromatin in a single mass in the eenter and the pigment elumped, while the microgametoeyte stains less deeply, has more diffuse chromatin, and has its pigment scattered.

Plasmodium malariæ.-A third speeies of malarial parasite, Plasmodium malarie, is the cause of quartan malaria of man. The schizogony is eompleted in 72 hours. The infected corpus- 
cles are not enlarged and the number of merozoites produced from a single schizont varies from 6 to 12 . Specimens will be demonstrated if available.

Bird Malaria.- Several species of our native birds harbor malarial parasites (Fig. 28) which belong to the same genus, Plasmodium, as do those of man. The better known of these complete their asexual cycle in 24 hours. The gametocytes differ from the schizonts much as in the species affecting man.
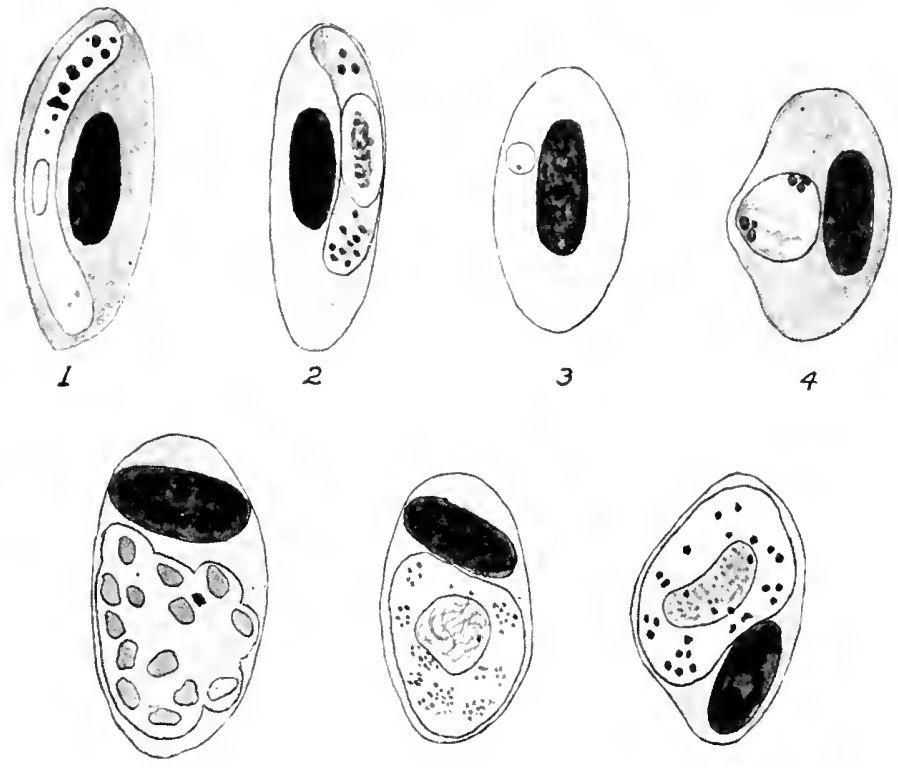

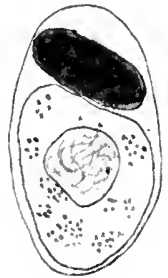

$\sigma$

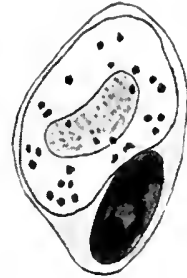

$\gamma$

FIG. 2S.-Malarial parasites from English sparrow. 1, microgametocyte of Plasmodium precox; 2, macrogametocyte of same; $3-5$. suages in the asexual development; 6 , microgametocyte of Plasmodium inconstans: 7 , marrogametoeyte of same. (After Hartman.)

Study the demonstration specimens, making drawings of typical stages.

The sexual cycle of the malarial parasites is not readily studied in an introductory course. Such stages as are available will be demonstrated. They are most readily obtained in the case of the bird malarias which undergo their development in a number of species of mosquitoes, including Culex pipiens, the common rain-barrel species.

Piroplasmidæ.-These are minute hrmosporidians which, like the malarial parasites, inhabit the red blood corpuseles of 
various mammals but do not form the pigment which is characteristic of the malarial organism. They undergo an essential part of their life cycle in ticks and are transmitted by these arthropods to the mamnralian host. There will be demonstrated (Babesia bovis) Piroplasma bigeminum, the cause of a widely distributed and highly fatal disease of cattle known in this country as "Texas fever." The organisms are minute pear-shaped bodies, usually two in a corpuscle. They vary in length from 2 to $4 \mu$ and in greatest width from 1.5 to $2 \mu$. This species was the first of the group to be studied in detail and the first in which was demonstrated the transmission of a protozoal disease by an arthropod.

\section{References}

Good diseussions of the malarial organisms of man are to be found in any morlern texthook of parasitology and in many of the medieal texts. The student who has aceess to a good library is advised to become aequainted with the epochal early researches on the transmission of malaria by moscuitoes.

The following references will serve as a starting point for studies on hird malarias:

Hegner, R., 1927. Experimental studies of bird malaria. Quart. Lev. Biol., 4 (1): 59-82.

Huff, C. G., 1927. Studies on the infectivity of plasmorlia of hirds for mosquitoes, with special reference to the problem of immunity in the mosquito. Am. Jour. Iyg., 7 (6): 706-734.

MacCallem, W. (i., 1898. On the hamatozoan infection of birds. Jour. Exptl. Med., 3 (1): 117-136.

simte, T., and F. L. Kilbourne, 1893. Investigations into the nature, causation and prevention of Texas or southern eattle fever. $U$. $s$. Dept. Agr., Bur. An. Ind., Bull. 1, 301 pp., 10 plates.

Whitmore, E. W., 1918. Ohscrvations on hird malaria and the pathogenesis of relapse in human malaria. Johns Hophins Hosp., Bull. 29: $62-67$. 


\section{CHAPTIR XVII}

\section{THE SARCOSPORIDIA}

\section{TECHNICAL SUGGESTIONS}

For the study of Sarcosporidia, small fragments of the muscle of pigs should be examined under pressure as in the search for trichinar. The small cysts of Sarcocystis miescheriana are not infrequently mistaken by beginners for those of the worm. They may be crusher] and examined in the fresh condition for study of the spores. For sections, heavily infected muscle is pinned out in an extended eondition and fixed for a half hour or more in picro-formol solution or in Schaulimn's sublimate alcohol. If the latter is seleeted metal pins must, of course, be avoided. Sections should be eut at $5 \mu$ and at $10_{\mu}$ and stained in hamatoxylin and eosin, or, for details, in iron hamatoxylin.

In many loealities Sarcocystis tenella is readily obtained from the (xsophagus of sheep. Hartmann recommends feeding the finely cut eysts in as fresh eonclition as possible to laboratory mice some two or three mont hs before needed. The eysts will be particularly numerous in the muscles of the abdomen and of the legs of the infected mice.

In connection with this practicum there may be demonstrated spores of the Myrosporidia and Microsporidia, forms which ean hardly be studied in detail but which the student should be able to recognize. We have found a Leptotheca from the kitheys of Rana pipicns al convenient and readily available illustration of the Myxosporidia, while Noscma apis in the ventrieulus of the honey bee is probably the most widely distributed of the Microsporidia in this country. The more famous Noscma bombycis can be obtained by purchase, if not otherwise available. Abundant material from other sources is available in every locality, and the important monographs of Kudo, 1919 and 1924 , should be available in every haboratory.

\section{CHARACTERISTICS OF THE SARCOSPORIDIA}

The Sarcosporidia are parasitic in the muscles of vertebrates, particularly mammals, and in a few cases have been reported for man. They are also recorded for birds and reptiles. Many of them are visible to the naked eye as whitish streaks or granules, often called Miescher's tubes, in the muscle fibers. Within these cysts are great numbers of thin-walled, sickle-shaped bodies called spores, although they are not homologous with the spores of other sporozoa. Indeed the group is an aberrent one which, for reasons 
that will be apparent when sections are studied, has even been regarded by some authorities as of metozoan rather than protozoan relationship. Practically nothing is known of the life history.

\section{PRACTICAL WORK}

Sarcocystis miescheriana is commonly found in the muscles of swine. Examine under pressure fragments of infected pork

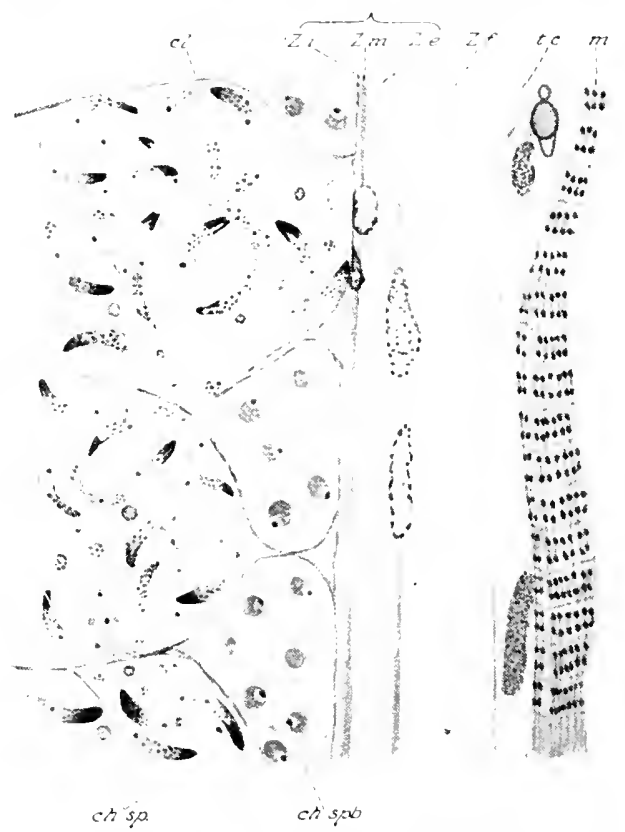

FIG. 29.-Longitudinal section of a cyst of Sacrocystis tenella from the œsophagus of a sheep. Cyst wall; Z.e., Z.m., Z.i., external, mid, and inner layers; $Z . f$., fibrous zone; t.c., connective tissue; m., muscle: $c h . s p$. chambers filled with spores; ch.spb., chambers with sporoblasts. (After Alexeieff.)

and note the small, white, elongated eysts, or "Miescher's tubes," measuring from 2 to $3 \mathrm{~mm}$. Dissect out some of these cysts and, crushing the thick enveloping membrane, note the numerous sickle-shaped spores.

Examine sections of muscle containing eysts of this species, or of Sarcocystis tenella of the sheep. Selecting a well-developed cyst, note that it is divided by membranous walls into a great number of chambers. The more central of these are empty, but the peripheral ones are filled with masses of the deep-staining, thin-walled falciform spores. The most peripheral chambers 
are filled with rounded eells, the pansporoblasts, from which the spores are developed. The enveloping membrane is regarded by some workers as derived wholly from the sarcoplasm of the infected muscle fiber. In favorable preparations there may be distinguished three lilyers: a delicate internal layer which passes inward to form the walls of the chambers, a compact middle layer, and a broad external layer (see Fig. 29).

Search your preparation for young stages of the parasite in the still distinctly recognizable muscle fiber.

Cnidosporidia.- In the superorder Cnidosporidia are placed Sporozoa infecting chiefly invertebrates and cold-blooded verto-

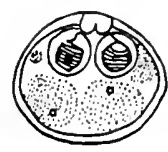

A.

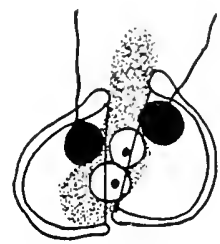

$\boldsymbol{B}$.

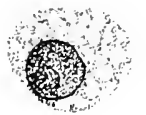

c.

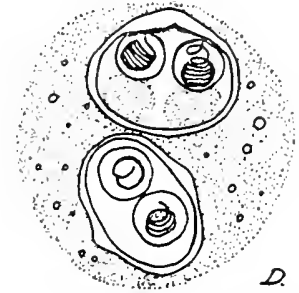

FIc. 30.-A myxosporidian, Leptotheca ohmacheri, from the kidney of the frog. $A$, spore; $B$, emerging amobula; $C$, amcebula whose nuelei are undergoing fusion: $D$, trophozoite containing two spores. (.lfter $K u d o$.

brates, which are peculiar in that spore formation takes place in the trophozoite while it is still growing. Still more characteristie is the fact that the spores possess one or more peculiar bodies known as polar capsules. Within these capsules there is an elongate polar filament which is extruded when the spore is taken into a new host and presumably serves to anchor it while the amoboid organism of the spore makes its way into the tissues. Note the available demonstration specimens.

\section{References}

Alexeieff, A., 1913. Recherches sur les Sircosporidies. Arch. zool. exper., $61: 521-569$.

Kudo, R., 1919. Studies on Myxosporidiat. A synopsis of genera and species of Myxosporidia. Illinois Biol. Honographs, 5 (3-4), 265 pp.

Kudo, R., 1924. A biologic and taxonomic study of the Microsporidia. Illinois Biol. Monographs, 9 (2-3), 268 pp.

Scott, J. W., and E. C. O'Roke, 1920. Sarcocystis tenella. Univ. Wyoming Agr. Exp. Sta., Bull., 124: 69-94.

Smith, T., 1901. The production of sareosporidiosis in the mouse by feeding infected muscular tissue. Jour. Exptl. Med., 6: 1-21 


\section{CHAP'TER XVIII \\ EXAMPLES OF PARASITIC INFUSORIA}

\section{TECHNICAL SUGGESTIONS}

Our native frogs furnish the most convenient single source of material for the study of parasitic Protozoa. Representatives of the genera Nyctotherus and Opalina are almost always present and a species of Balantidium is not uncommon. The examination of living material should be supplemented by study of permanent mounts.

Motile and encysted specimens of Balantidium are readily obtainable by examining fresh fecal material from hogs or by bringing to the laboratory freshly removed sections of the cxem and colon of hogs from slaughter houses. The organisms will remain alive for rlays at room temperature. Sections of heavily infected specimens will show numerous parasites in situ. Guinea-pigs occasionally harbor representatives of this genus, as do also cockroaches.

Where there is opportunity, some of the hizarre forms of eiliates from cattle and other ruminants should be demonstrated.

\section{CHARACTERISTICS OF THE INFUSORIA}

The Infusoria are Protozoa of definite form whose locomotory apparatus is constituted by a more or less considerable number of vibratile cilia on the surface of the body and which typically possess two forms of nuclei-a vegetative macronucleus and a much smaller reproductive micronucleus. In the subclass Opalinata the two or more nuclei present are of a single type. The transfer to new hosts is through formation of cysts. These may be purely protective, but in some forms multiplication occurs.

Many parasitic Infusoria are to be found in the higher animals, but in so far as is known they do not usually play an important role as pathogens. One species, Balantidium coli, is a widespread and serious parasite of man. Several species occur as ectoparasites of fish and are often the cause of serious epizoötics. As an introduction to the group, we shall study the infusorian parasites of the frog which harbors representatives of two genera, Nyctotherus and Balantidium, reported as infecting man. 


\section{PRACTICAL WORK}

Open a freshly killed frog and mount in a drop of physiological salt solution ( 0.6 per cent $\mathrm{NaCl})$ a bit of the black fecal content of the rectum. The infusoria are so large that they ean be seen with the naked eye as actively moving, minute specks. Of these the more opaque, oval forms will probably prove to be Nyctotherus cordiformis, which we shall take as a type.

Nyctotherus cordiformis (Fig. 2) is a heterotrichous form; that is, it possesses two types of eilia. Covering the entire cell are parallel rows of short, similar cilia; but in addition there is an "adoral zone" of large, coarse cilia, or membranelles, which form a peristome extending from the anterior end along the side to the mouth, or cytostome, and into the so-called cytopharynx. Note the movement of these cilia and of those covering the general body surface. Near the posterior end is a single contractile vacuole and at the end a cytopyge through which excreta are discharged. In stained preparations note the large beanshaped macronucleus and close to it, on the hinder concave side, the small micronucleus. Make a drawing showing the above features.

Balantidium entozöon (Fig. 2) is less common than Nyctotherus cordiformis in our native frogs but may be found. It is smaller and may be distinguished by the smaller peristome which is at the anterior end instead of extending halfway down the side. The important Balantidium coli of man and of the pig will be studied as a type of the genus.

Opalina (Fig. 31) species are the most common of the ciliates of frogs and toads. They are large, much-flattened Protozon with a uniform covering of cilia and without a cytostome. The most characteristic feature is the presence in the adult specimens of many nuclei of a uniform type. Reproduction in the adult state is by oblique division, but during the spring months there is adaptation to parasitic life in the form of the production of numerous minute individuals which encyst and pass out with the feces of the frog. These cysts are taken up by tadpoles and liberate microgametocytes and macrogametocytes in the rectum of their new host. These cells give rise to gametes which conjugate, forming zygotes which develop into the multi-nucleate opalinid.

Study motile and stained preparations of the stages available. 
Balantidium coli, a cause of dysentery in man, is also commonly found in pigs. If living specimens are available, note the distribution and the action of the two types of cilia. The peristome is a slitlike depression at the anterior end leading into the mouth, or cytostome. In the living specimen two contractile vacuoles may be seen, in addition to numerous food vacuoles.
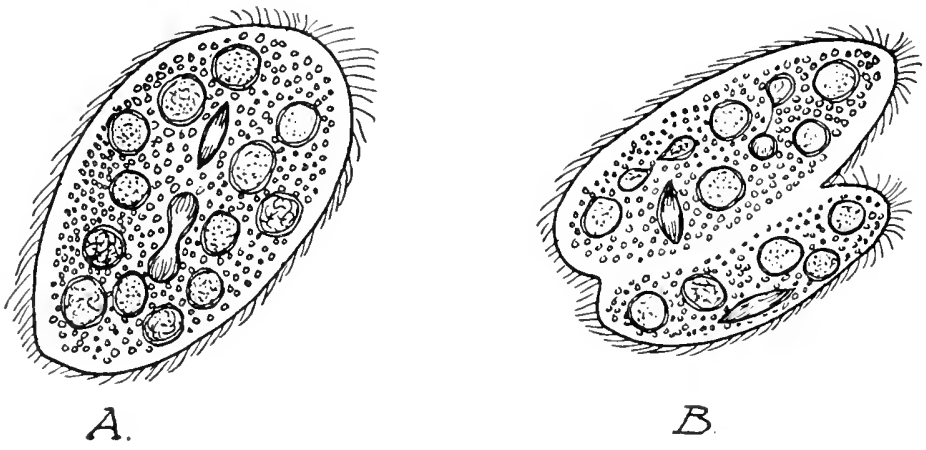

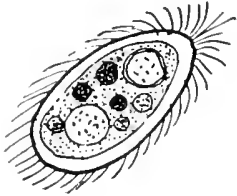

C.

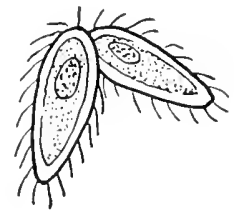

$D$
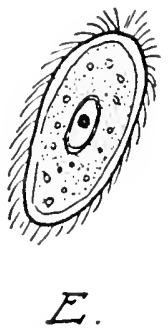

FIG. 31.-The life history of Opalina ranarum, after Neresheimer. $A$, multinucleate stage; $B$, oblique fission as it oceurs in summer, fall and winter; $C^{\prime}$, gametocytes produced by repeated divisions in the springtime, encyst, are taken up by tadpoles and produce, $D$, gametes which ropulate and form cysts from which escape; $E$, the uninucleate infusorian which develops in to $A$.

At the posterior end is the anus, or cytopyge. There is a beanshaped macronucleus and a rounded micronucleus.

Reproduction is by transverse fission and also by conjugation and eyst formation. Search your preparation for the large spherical cysts with a thick outer wall. Examine demonstration sections of the large intestine showing balantidia in situ.

\section{References}

McDonald, J. D., 1922. On Balantidium coli (Malmsten) and Balantidium suis (sp. nov.) with an account of their neuromotor apparatus. Univ. Calif. Pub. Zoölogy, $20: 243-300$.

Metcalf, M., 1923. The opalinid ciliate infusorians. U.S. Nat. Museum Bull. 120, 484 pp. (Extensive bibliography.) 
Nereshemer, E., 1907. Die Fortptlanzung der Opalinen. Areh. Protistenk., Suppl. 1: 1-42, plates 1-3.

REEs, C. W., 1927. Balantirlia from pigs and guinea-pigs: their viability, cyst production and cultivation. Science, 66 (1699): 89 91.

Sicotr, M. J., 1927. Studies on the Balantidium from the guinea-pig. Jour. Morpholeg!y, $44: 417-465$. 


\section{C'HAPTER XIX}

\section{THE LITERATURE OF ANIMAL PARASITOLOGY}

\section{TECHNICAL SUGGESTIONS}

Local conditions and facilities must deternine the most suitable place in the course for this practicum and the library materials to be used. It is suggested that the various texts, indices, and journals be shown and their use discussed in the laboratory period and that the problems be assigned for report at the following period.

In the assignment of problems a check should be made in order to insure that they can he answered from available facilities.

There should be insistance upon a standard form of citation, whether it be that given as an example or some other approved form.

\section{PRACTICAL WORK}

One of the chief objectives of a college course is that of affording a key to the stores of past and current information on the subject. Especially in a rapidly growing field, such as parasitology, a knowledge of methods of keeping in touch with present-day work is essential. It is the object of the present practicum to give an introduction to the literature of animal parasitology and to call attention to important bibliographic aids.

Examine the publications available in the following groups, and make the report indicated. Follow carefully the procedure suggested by your instructor.

A. Textbooks.-Examine the textbooks of animal parasitology on exhibit and list at least one each of American, German, and French publication, according to author, date, title, edition if more than first, number of pages, publisher, and place of publication. Example:

Chanderr, A. C., 1926. "Animal Parasites and Human Disease," 3d ed., xiii + 573 pp. John Wiley \& Sons, Inc., New York.

B. Periodicals. - In this group will be placed certain of the important publications dealing extensively with parasitology. List at least three of these, giving title, volume number, year, publisher, and address. Look over carefully one number of each 
of those you have selected and list in formal order an important article dealing with some phase of the work of this course. Example:

Caldwell, 1. C., and E. I. Caldweld, 1926. Are Ascaris lumbricoides and Ascaris suilla iclentical? Jour. Parasitology, 13 (2): 141-145.

C. Federal and State Publications.-An assortinent of Federal and state publications of value from the viewpoint of parasitology will be made available. Note the source of each of these and the general type of subjeet matter.

D. Indices.-The most important of these keys to the literature of parasitology are the following:

Agricultural Index. Vol. 1, 1916-_. New York.

Bibliographia zoologica. Vol. 1, 1S96-_ Leipzig.

Index Catalogue of Medieal and Veterinary Zoology. 1902-. Washington.

Index Catalogue of the Surgeon General's Library. 1850-. Washington.

Index medicus. Vol. 1, 1879-. Combines with the following in 1927: Quarterly Cumulative Index to Current Medieal Literature. Vol. 1, 1916-. Chicago.

Zoological Record. Vol. 1, 1864-. London.

Using such of the above indices as are available in the library, give a complete reference to each of the topics assigned and indicate where the reference was found. Examples:

1. A paper by (Hall), published in (1923), dealing with (internal parasites of dogs and eats).

2. An important paper, or book, published in (1925) which discusses (in a comprehensive mamer, human protozoology).

3. A paper published within the past 18 months dealing with (the fish tapeworm, Diphyllobothrium latum, in the United States).

E. Abstract Journals. - The more important abstraet journals for the student of animal parasitology are the following:

Biological Abstracts. Vol. 1, 1926—. Philadelphia.

Centralblatt für Bakteriologie, Parasitenkunde, und Infektionskraukheiten.

Vol. 1, 1857-_. Jena. (Beginning with Vol. 31, 1902, the abstracts are published as a separate part.)

Experiment Station Reeord. Vol. 1, 18s9-. Washington.

Institut Pasteur, Bulletin. Vol. 1, 1903-. Paris.

Review of Applied Entomology. Series B., Medical and Veterinary. Vol.

1, 1913-. London.

Tropical Disease Bulletin. Vol. 1, 1912_-. London.

Tropieal Veterinary Bulletin. Vol. 1, 1912-. London. 
Using two of the above aicls, give a complete citation to an important paper for each of the years (1920 and 1926), dealing with a parasite of man or animals. Cite not only the original place of publication but also the page reference to the abstract journal.

In not less than 100 or more than 200 words, give the essential points of the articles chosen. 


\section{APPENDIX}

\section{COLLECTION AND PRESERVATION OF ANIMAL PARASITES}

\section{INTESTINAL PROTOZOA}

The various intestinal Protozoa cannot be prepared satisfactorily by methods such as those used in blood or bacteriological work, which permit of drying at any stage. They must be fixed while still moist and earried through much the same procedure as that used for animal tissues in general.

A small amount of fresh fecal material is taken on an applieator stick or a glass rod, or a bit of intestinal mucosa or other tissue taken in forceps, and quickly smeared over a thoroughly cleaned slide. If a stool sample should be very fluid, it is desirable first to eover the slide with a thin film of egg albumen. The smear preparation should be thicker than for ordinary bacteriological work and should be passed immediately into the fixing fluid.

For general work a very convenient technique is that of fixing in Bouin's piero-formol (p. 113) for 10 to 30 minutes, washing in several ehanges of 70 per cent alcohol to remove the excess pieric aeid, rinsing in water, and staining for a few minutes in a weak solution of Delafield's hæmatoxylin. The intensity of the stain should be controlled by rinsing and examining in tap water. Then dehydrate in ascending grades of alcohol; pass from 80 per cent into a 0.1 per cent eosin in 95 per cent alcohol if a counterstain is wanted. Rinse in 95 per cent alcohol, elear in carbolxylol, and mount in balsam.

A standard and, once mastered, the best method for preparation of permanent mounts is that of fixation in warm Schaudinn's fluid and staining in iron hæmatoxylin.

Sehadinn's fluid is composed of 2 parts of saturated aqueous solution of corrosive sublimate, and 1 part of 95 per cent ethyl aleohol, acidulated by the addition of glacial acetic acid. A convenient quantity is:

Saturated aqueous solution of corrosive sublimate... $65 \mathrm{ec}$.

95 per cent ethyl alcohol. ................ 33 ec.

Glacial acetic acid .................... 2 ce. 
It should be heated until steam is given off $\left(60\right.$ to $70^{\circ} \mathrm{C}$.) immediately before using. Handling slides with forceps or allowing metal to come in contact with the solution in any way must be avoided or precipitates will ruin the preparations. The various stages may be outlined as follows:

1. Prepare smear as ahove deseribed.

2. Fix in warm sehaudinn's fluid, 15 minutes.

3. Rinse in 50 per cent alcohol, 3 to 5 minutes.

4. Transfer to 70 per cent alcohol to whieh has been added enough tincture of iodine to give at bright straw color, 10 minutes. If the fluid is bleached, renew it.

5. Harden in 95 per cent alcohol, 1 hour or more.

6. Seventy per cent alcohol, 5 minutes.

7. Fifty per cent alcohol, 5 minutes.

8. Rinse in distilled water.

9. Mordant in a 4 per cent solution of elear violet erystals of iron alum (ammonio-ferrie sulphate) in distilled water, 6 hours.

10. Rinse in water.

11. Stain in 0.5 per eent ripened solution of hematoxylin in distilled water, 6 hours to overnight.

12. Rinse in water.

13. Differentiate in 2 per cent iron alum solution, controlling by rinsing in water and examining under the mieroseope from time to time. The hackground should be grayish and it is desirahle to differentiate the slides to a slightly different degree since it is not feasible to scarch long for eysts as controls.

14. Wash in running water, or several changes, 20 minutes.

15. Dehydrate, in 50, 70, 95 per cent and absolute alcohol, 5 minutes each.

16. Clear in xylol, 5 minutes.

17. Mount in Canada balsam.

Instead of Canada baisam, euparol may be used as a mounting medium and the material passed directly from 95 per cent alcohol. Considerable economy results from the elimination of absolute alcohol and xylol.

Although the above method of preparing intestinal Protozoa is tedious and time consuming, it usually gives better results for inexperienced workers.

Kofoid and Swezy, 1925, recommend a rapid method through the use of alcoholic solutions: The stock solution 0.5 per cent iron hematoxylin is diluted with 10 parts of 70 per cent alcohol, and the stock solution of 4 per eent iron alum is diluted with 10 parts of 50 per cent alcohol. The iron alum will not remain long in solution in alcohol; hence the solution must be renewed frequently. After the usual fixation in Schaudinn's fluid, followed by ascend- 
ing grades of alcohol, preparations are mordanted in the iron alum for 10 minutes, rinsed in 50 per eent alcohol, and stained for 10 minutes or longer. One hour gives better results for chromatin staining. After staining, decolorize in iron alum and wash in 50 per cent alcohol, or in water, for two hours.

\section{Reference}

Koford, C. A., and Olre Swezr, 1925. Mitosis and multiple fission in trichomonad flagellates. Proc. Am. Acal. Arts sci., 81 (6): 2\$9-378, Fig. 104.

\section{CESTODA}

Collection. - For obtaining the smaller cestodes Meggitt uses the following technique:

Open the intestine in lengths of approximately 4 inches, one portion at a time, cut off the part opened and shake vigorously in a flat dish (a eonvenient size is 10 by 6 by 2.5 inches) filled with tepid water of approximately $40^{\circ} \mathrm{C}$. temperature; if the intestinal content be not fresh and consequently contains much mucus, a slightly higher temperature should be employed. Salt solution or cold water should never be used . . After washing in this manner, the intestine with the attached worms should be removed to another similar dish and examined with a powerful lens, preferably with a binocular, the scolices and smaller worms being dissected out with needles.

Rapid Examination.-For rapid examination the living scolex may be mounted directly from water into lacto-phenol. Mounted in this way the hooks are clearly visible and can be accurately studied. Meggitt advises ringing the cover slip with a mixture of Canada balsam and hard wax, melted, and applied with a glass rod.

For more permanent mounts harden the scolex in several changes of 95 per cent alcohol, clear in carbol-xylol, and mount in balsam.

The hooks of most tapeworms ean be isolated in water by teasing the scolex apart under a binocular microscope. With the aid of a small, finely pointed camel's-hair brush touched to Buxton's fluid to make it adhesive the hooks can be transferred directly to a slide and mounted in Buxton's mounting medium (p. 112).

For the examination of the genital organs staining is necessary. Meggitt, 1924, recommends: 97 parts of a saturated solution of 
earmine in 45 per cent aeetic aeid, and 3 parts of a saturated solution of ferric acetate in glacial acetic aeid, prepared immediately before use. The tapeworm is removed from a dish of water and placed alive in the stain for 5 to 30 minutes aceording to size. It can then be mounted directly in laeto-phenol or, preferably, placed for 5 minutes in absolute alcohol and then eleared in clove oil.

Killing and Fixation.-Many methods are recommended for killing tapeworms in an extended eondition. Large tapeworms present the greatest difficulty since the entire chain nust be killed instantly to prevent contraction. A method commonly employed (Baylis, 1922) is to piek up the worm by its eaudal end allowing it to streteh to its full length before immersing it quiekly into the fixative (Zenker's fluid, Bouin's fluid, or hot 70 or 80 per eent aleohol). It should then be dipped several times into the solution to insure uniform fixation.

Good results are likewise obtained by wrapping the speeinen around one end of a glass plate and immersing it quickly into the fixative. Using this method spontaneous eontrations which usually result are averted. Small speeimens may be killed to advantage by compressing them between two glass slides and pouring the fixative over them.

Speeimens killed in aleohols may be transferred direetly into fresh 70 or 80 per eent aleohol for preservation. Those killed in Zenker's fluid should be left in the solution from 6 to 24 hours, and washed in running water for 12 to 24 hours. They should then be transferred to 35, 50, and 70 per cent alcohols. some 20 minutes in each. Add to the 70 per eent aleohol sufficient iodine to give a yellowish eolor, to remove mereurie erystals which might be present. Iodine is added as long as the solution continues to bleach. Specimens are then transferred to several changes of 70 or 80 per cent aleohol to wash out the iodine. If Bouin's fluid is used, fix for 6 to 14 hours, depending upon the size of the speeimen, and then wash in 50 or 70 per eent aleohol until the color resulting from the pierie aeid is removed. Preserve in 70 or 80 per eent aleohol.

Staining and Mounting.-The most satisfactory stains are Delafield's homatoxylin, Ehrlieh's aeid hamatoxylin, boraxearmine, and paracarmine. For staining in borax-carmine or in paracarmine speeimens are transforred direetly from 70 per eent alcohol. The hamatoxylins are aqueous solutions which neees- 
sitate hydration to water before staining. The usual grades used are $70,50,35$ per cent and water.

Stain intensity is largely a matter of the particular structures to be brought out. The best results are obtained by overstaining and differentiating in acidulated alcohol ( 2 per cent H('l in 70 per cent aleohol). Large specimens may be left in the stain overnight; for smaller specimens an hour will suffice.

Dehydration is aceomplished by passing specimens through a series of graduated alcohols: $70,80,95$ per eent. Large specimens should be left in each grade for an hour, with a change to fresh 95 per cent aleohol for a second hour. They are then transferred to carbol-xylol until thoroughly cleared, and mounted in Canada balsam or damar.

In mounting, each slide should include scolex, mature and gravid segments, and developing segments.

Sectioning.- Satisfactory methods of sectioning are included in all manuals on microsepic technique. For general studies sections may be made from specimens stained in toto. Detailed histological studies neeessitate staining after sectioning. The usual paraffin method is most suitable.

\section{References}

Baylis, H. A., 1922. Notes on the collection and preservation of parasitic worms. Parasitology, $14:$ 402-408.

Meggitt, F. J., 1924. On the collection and examination of tapeworms. Parasitology, $16: 266-268$.

\section{TREMATODA}

Collection.-Trematodes are to be sought in a wide variety of locations in the animal body. Adults may occur in the liver, intestine, bladder, lungs, and blood vessels; while the encysted larval forms occur on the various organs, in the body eavity, intramuscularly, and, among other places, in the eyes of various hosts. Monogenetic species are to be found most commonly on the gills or at the base of the fins of various fish.

The presence of liver flukes is often most readily revealed by examination of the gall for eggs. Similarly scrapings of the trachea will betray the presence of lung trematodes (or nematodes). The liver should be cut into small pieces which are squeezed in water. Frequently the worms will emerge if the pieces are left standing in warm water. Trematodes of the digestive tract are often overlooked on account of their small 
size. The mucosa should be scraped into water and specimens sought with the aid of a microscope. The method of isolating adult trichinæ may be used to advantage, particularly if the water is near $38^{\circ} \mathrm{C}$.

Killing and Fixation.-Trematodes may best be fixed in concentrated aqueous solution of corrosive sublimate plus 2 per cent of glacial acetic acid, or in picro-formol. Under field conditions it is often necessary to drop the specimens into 5 per cent formalin or into 70 per cent alcohol. If the latter is used, specimens may subsequently be softened by soaking in water.

For small species Looss' shaking method is the most generally useful. The specimens are put in a small vial nearly filled with physiological salt solution and are shaken violently for 3 minutes. One-half of the salt solution is then quickly poured off and replaced by an equal amount of the acetic-sublimate solution and the shaking continued for a minute or so. Then replace with acetic-sublimate solution and fix for 15 to 30 minutes, or up to several hours if desired. Wash in 50 per cent alcohol, for 15 to 30 minutes, then in 70 per cent plus sufficient iodine to give it a bright straw color. If the fluid is bleached, change or add more iodine. Too much iodine will injure the staining quality. It is desirable to leave in the iodized alcohol for an hour or more, before washing in clear 70 per cent and storing or staining.

Often specimens are advantageously killed under light pressure under the cover glass or between two slides held together by rubber bands or thread, while running the fixing agent under. The slide or cover should be lifted occasionally to insure access of the fluid to all parts. Too much pressure will dislocate organs. Mühling kills muscular forms in an extended condition by placing the specimen on a cover glass, cleaning off attached mucus, then quickly pressing over it a hot slide which has been wet with the fixing fluid. Fresh fluid is gradually added from the side, the cover being lifted from time to time.

Staining and Mounting. - Specimens may be stained overnight in very dilute Delafield's hæmatoxylin or in borax-carmine. If in the former they should first be washed in water, but if boraxcarmine is used they should be transferred from 70 per cent alcohol. After staining wash in water and differentiate carefully in 70 per cent alcohol plus 2 per cent $\mathrm{HCl}$, dehydrate in 80 per cent and 95 per cent for 15 to 30 minutes each, clear in carbol-xylol, and mount in balsam. 
The periods given for the various operations are subject to wide modification, dependent on the size of the specimen and the convenience of the worker. Minute specimens can be carried through in 10 minutes eath, but when using Delafield's hiematoxylin as a stain it is always advisable to use a weak solution and stain for a considerable period. It should also be noted that if it is necessary to differentiate with acid alcohol after hamatoxylin stain, it is desirable to follow by alcohol rendered slightly alkaline by the addition of a few drops of a 0.1 per eent solution of bicarbonate of soda, in order to prevent fading.

\section{NEMATODA}

Collection.-Adult nematodes are no less widely distributed than are trematodes. Though most eommonly present in the alimentary tract, they should be sought in the liver, bladder, kidney, lungs, body cavity, and circulatory system. Larval forms are common in the tissues and organs.

Inconspicuous forms from the digestive tract are collected by slitting the various sections one at a time and washing their contents into tall jars of water to be repeatedly washed and sedimented until the fluid is clear. The sediment is then poured into shallow trays and earefully examined. In the meantime the wall of the section under study should be closely examined for adhering parasites. It should also be examined over a strong light for evidence of embedded forms.

Hall and Cram, 1926, point out the value of screening the contents of the digestive tract through a series of metal screens having mesh apertures $6,12,24$, and 40 to the inch. These are used in a rack which is placed in a sink and washed with a stream of water, after which the material on the screens is examined for parasites. The lungs, urinary bladder, gall bladder, etc., should be slit open in a dish of water and also examined in this way. The method is of eourse applicable to forms other than nematodes.

Killing and Fixation.--The specimens found should not be subjected longer than necessary to the action of the water but, should be vigorously shaken to clear them of adhering mucus and then killed in hot, almost boiling, 70 per eent alcohol to which, preferably, has been added 3 to 5 per cent of glycerine. The alcohol may be allowed to evaporate gradually or more rapidly in an oven at $c a .60^{\circ} \mathrm{C}$. until they are left in cleared condi- 
tion in pure glyercine. Care must be taken to insure that they are not exposed as the mixture evaporates.

The above-described method is not suitable for such forms as Trichosomum, Trichuris, and the like, since they become tightly coiled and shrink. Magath found that this could be prevented in great measure by placing the points of a pair of foreeps together and working the specimens to and fro in the hot fluid as soon as placed in it. In applying this method the fluid should first be heated and then the worms transferred to it.

Nematodes which have been gradually brought into pure glycerine, as above, may be permanently mounted in glyeerine jelly and the cover glass sealed with Noyer's cement or with very thick Canada balsam.

A simple and very satisfactory method of preservation and mounting recommended by Langeron is that of killing in 5 per eent formalin and transferring after several hours into lactophenol mixture. They may be mounted direetly in this mixture and the cover glass sealed as above.

For preservation of histological detail Magath recommends killing in 50 per cent alcohol heated to 60 to $75^{\circ} \mathrm{C}$. and transferring at once to a mixture of equal parts of alcohol, water, and acetic acid to which has been added 0.05 to 0.1 per cent osmic acid. In this the material is left for from 1 to 10 hours, depending on size.

The same author describes in detail a technique for infiltrating and mounting in Canada balsam, though this medium is thoroughly unsatisfactory for nematodes when the ordinary technique is attempted.

It should be noted that nematodes preserved in formalin or in alcohol can be cleared for temporary study by transferring to a mixture of 4 parts of melted carbolic acid crystals and 1 part absolute alcohol.

\section{References}

Hall, M. C., and E. B. Cram, 1925. Some laboratory methods for parasitological investigations. Jour. Agr. Research, 30 (S): 773-776.

Magath, T. B., 1916. Nematode technique. Trans. Am. Micro. Soc., 35 (4): $245-256$.

\section{SOIL NEMATODES}

Various methods for the isolation of not only soil inhabiting parasitic stages but also free-living nematodes from the 
soil have been devised. The most used employs the Batermann apparatus as modified by Cort and his assoeiates in hookworm work.

This isolation apparatus consists of a glass fumnel, the outlet, of which is closed by a clamp on a piece of rubber tubing. A

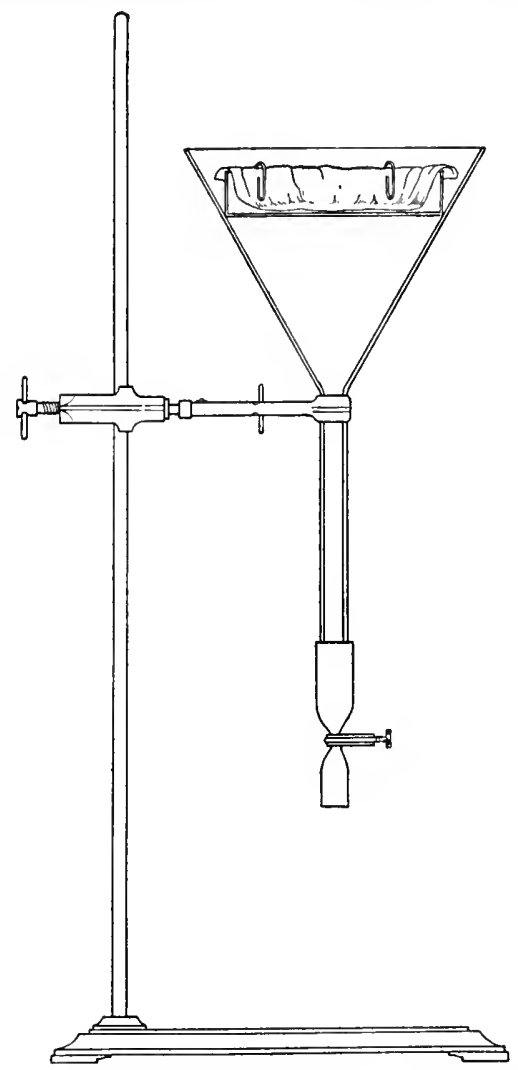

Fig. 32.-Baermann isolation apparatus for soil nematodes. (Orig.)

fine meshed sieve with one or two layers of muslin cloth in the bottom is set in the funnel and on this the soil sample is placed. The funnel is then filled with water at blood heat to a point above the lower surface of the soil. The majority of the nematodes under these conditions pass into the water and can be collected. For extensive work a rack of suitable height is used with a battery of funnels held in place by padded crossbars. For many purposes an ordinary ring stand may be used to support 
the apparatus, the funnel being held upright by ring clamps or burette clamps. In Fig. 32 is shown a simplified apparatus favorable for laboratory use, constructed of a 6-inch funnel, $1 / 2$-inch rubber tubing elosed by a screw clamp, and a 3/2-inch sieve of 14-mesh brass screen.

A simplified apparatus as given by Sandground, 1925, consists only of a 5-inch funnel with a piece of fairly coarse cotton fabric attached to the rim by paper clips. This is allowed to sag about one inch into the funnel. The funnel is closed by a Hoffmann clamp on a piece of rubber tubing. Water with a temperature of from 104 to $108^{\circ} \mathrm{F}$. is added until it covers the base of the fabric and then the culture is carefully added. Within little more than an hour the worms may be drawn from the funnel.

White, 1927, describes another very convenient method of isolating hookworm larva by trapping the migrating worms. Charcoal and feces are properly mixed in a large watch glass and transferred to the half of a Petri dish, with moistened filter paper in the bottom. Sterile water is poured into a crystallizing dish sufficient to cover the bottom and into it is placed the culture. A watch glass is used for a cover. Thus the larvæ reaching their third moulting stage, when they begin extensive migration, are trapped in the water surrounding the Petri dish. To collect them, the watch glass is removed and the Petri dish with the culture lifted out. The water containing the larvæ is poured into a test-tube, the supernatant fluid is removed, and a concentrate of the larvie remains.

\section{References}

Hegner, R. W., W. W. Cort, and F. M. Root. 1923. "Outlines of Medieal Zoology," $480 \mathrm{pp}$. The Macmillan Company, New York.

Sandground, H. J., 1925. Some observations of the life-cyele, methorls of diagnosis and ineidence of Strongyloides stercoralis in the tropics. Fourtcenth Annual Report of the United Fruit Co., Med. Dept.

White, G. F., 1927. A method for obtaining infective nematode larva from cultures. Science, 66 (1709): 302-303.

\section{INTESTINAL TRICHIN E}

Intestinal, sexually mature trichinæe are usually recovered from experimental animals 2 to 10 days after a feeding of infected flesh, by slitting open the intestine and examining scctions microscopically with the light well cut down. If their position in the mucosa is not being studied they may be recovered in 
considerable numbers by scraping the mucosa with the dull edge of a sealpel into a Petri disln with physiological salt solution.

To recover the adult worms in large numbers the following method has proved very satisfactory:

Starve a rat for 2 days and then feed it a pieee of heavily trichinosed tissue about the size of the end of the thumb. Lieep the animal unfed for 2 more days to climinate intestinal debris, kill, and remove the intestine to a container filled with warm water.

Take short unslit pieces of the intestine and, holding with foreeps over a vial filled with water, strip toward the free end with another pair. Apply suffieient pressure to remove all of the intestinal contents without tearing the intestine itself.

Emulsify the extruded material by vigorously shaking to disentangle the worms from what little debris is present. Sereen this out by emptying the vial on a 40 -mesh sereen placed over a stender dish filled almost to the rim with water. The sereen should sag well below the water surface. The worms soon work their way through into the water and drop to the bottom where they may be recovered.

For permanent mounts kill specimens in hot 70 per cent aleohol. Change to fresh 70 per cent alcohol for preservation. Dehydrate gradually through the alcohols, elear in xylol, and mount in thin damar or balsam.

\section{PERMANENT MOUNTS OF HELMINTH EGGS}

Feeal material containing eggs or eysts of parasitic forms may be preserved in 10 per cent formalin solution, with or without previous sedimentation. The fluid should be changed occasionally as the offensive odor is greatly reduced by this procedure.

Langeron adds 10 per eent of glyeerine as the eggs are thus rendered more transparent. They ean be mounted in this fluid and sealed with Noyer's cement, but we have found that such preparations are not likely to be satisfactory for more than two or three years.

The best method of permanent mounting of helminth eggs in feces is that of Looss. A well-sedimented and sieved specimen with just enough water to make a thin paste is gradually added, with constant stirring, to hot, almost boiling 70 per cent alcohol plus 5 per cent glycerine, and allowed to cool. When eold the 
supernatant fluid is carefully poured off and replaced by fresh. The preparation is then put in an oven at $50^{\circ} \mathrm{C}$. for a day or two, by which time the alcohol will have been evaporated and the fecal material evenly distributed through the glycerine. At laboratory temperatures this will, of course, require longer exposure and protection from dust. For mounts, a small drop of the sediment is placed in a small quantity of warm glycerine jelly on a slide, stirred carefully to distribute it, and the whole sealed with Noyer's lanoline cement.

\section{PREPARATION AND STAINING OF BLOOD SMEARS}

Preparation.-Slides and covers must be especially cleaned before using for the preparation of blood smears, or of fecal
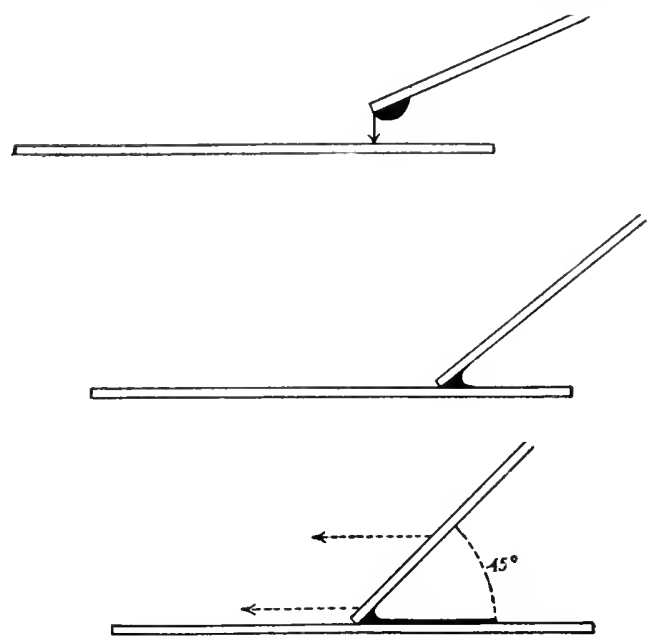

F1c. 33.-Method of making a blood film by pulling a drop of blood behind second slicte. (After Daniels.)

smears for the study of intestinal Protozoa. Pass slides over a flame to remove excess moisture and grease.

Experience in the preparation of films and in the use of blood stains is best gained with human blood. Wipe the finger with alcohol and prick it with a sterile needle or spring lancet until free, easy drops issue forth. Wipe away the first drop with sterile cotton and select one a little lirger than the head of a pin. Touch this with the end of a clean slide to be used as a "pusher" as illustrated by Fig. 33 . Place this at an angle of 45 deg. near the end of a clean slide held horizontally. The drop should 
instantly spread along the width of the slide. Push the slide steadily forward at a moderate rate of speed so that the blood follows and spreads out in at thin film. The thieknessis of the film ean be regulated by increasing or decreasing the angle at which the slide is held. Dry by waving it vigorously in the air. If a moist fixation is desired, the film should be fixed immediately, without drying, in Sehaudinn's fluid, and treated as usual for that method (p. 99).

Staining.-To obtain the best results blood films should be stained promptly. Wright's blood stain is the most satisfactory for staining blood-inhabiting Protozoa as well as the blood cells. This is purehased in the form of a powder, 0.3 gram of which is dissolved in $100 \mathrm{ee}$. of acetone-free methyl-aleohol (absolute).

To confine the stain, mark across the slide at both ends of the film with a grease peneil or a bit of soft paraffin, place it on a level place, and with a pipette add about 20 to 30 drops of stain. Leave this for one minute, which tends to fix the blood, and then add distilled water, drop by drop, until a greenish metallic seum appears on the surface. The amount of water added is usually half the amount of the stain, or not more than an equal amount. Allow the stain to aet for 2 to 3 minutes, rinse, and add distilled water for $2 \frac{1}{2}$ minutes or longer to differentiate the preparation. By watehing the slide under a microscope the desired differentiation may be seeured. Carefully blot dry.

A successful Wright's stain should show the following appearances of the blood cells: red cells, pink; nuclei of leucocytes, blue to violet; eosinophilic granules, red; mast granules, dark purple; neutrophilic granules, reddish lilac.

Blood smears may be mounted directly in balsam, after staining and drying, but are often dried and kept unmounted to be studied under immersion oil. Care should be taken to protect such slides from dust and from coming in contact with other objects. After use they should be flooded with xylol and very lightly wiped with lens paper or a bit of lint-free cloth to remove the cedar oil.

\section{FORMULAS FOR REAGENTS AND MOUNTING MEDIA}

Lacto-phenol.-Carbolic aeid erystals c.p. 1 part; lactic acid, 1 part; glycerine, 2 parts; distilled water, 1 part. This discolor's when exposed to the light, without affeeting its value. It retains its colorless condition if kept in yellow bottles. Delicate forms 
may first be put in half-strength solution and transferred after a few hours to full strength.

Glycerine Jelly.-Glycerine, 100 parts; distilled water, 120 parts; gelatine, 20 parts; carbolic aeid, melted erystals, 2 parts. Let the gelatine soak in water for a half hour and then dissolve with gentle heat. Add about 5 ee. of egg albumen and heat (not over $75^{\circ} \mathrm{C}$.) for half an hour. Filter through moist hot flannel and add the glyeerine and carbolie aeid. Warm for 10 to 15 minutes stirring continually. For mounting place a drop of melted jelly in the eenter of a slide and transfer the object from an aqueous solution or glycerine to the jelly and arrange it. Lower a clean cover glass upon the object and gently press it down. After the jelly has set, clean away any excess around the cover and seal.

Buxton's Medium.-Distilled water, 50 cc.; glycerine, 20 cc., gum arabic, 40 grams; chloral hydrate, 50 grams; eoeain hydrochlor., 0.5 grams. Dissolve gum in water, add chloral hydrate and cocain; when dissloved, add glycerine. Filter if necessary. This is a very useful medium in which objects ean be mounted directly from water; alcohol specimens must be thoroughly washed in water. Buxton, who used it particularly in studies of mites, placed them in it on the slide in the living condition and found that they died rapidly in an extended eondition.

Noyer's Lanoline Cement.-Langeron, who reeommends this cement highly, gives the following direetions: Anhydrous lanoline (mutton tallow), 20 grams, eolophane (rosin), 80 grams. The commereial lanoline is slowly heated in an evaporating dish until the traces of water are driven off, and then the rosin is added, the mixture being stirred continually until the fusion is complete and perfectly homogeneous. Store in metal salve boxes. The cement is applied by means of a heated wire bent at a right angle some $22 \mathrm{~mm}$. from the tip. Begin by putting a drop of the cement at each corner of the cover and then rapidly and smoothly applying to the edges. We have long used this cement with perfect satisfaction.

Apathy's Cement.-Equal parts of $60^{\circ}$ paraffin and Canada balsam are heated together in a porcelain evaporating dish until the mass takes on a golden tint and no longer emits vapors of turpentine. Apply with a warm wire or glass rod.

Carbol-xylol.--This useful mixture will elear imperfectly dehydrated objects direetly from 95 per eent alcohol and thus 
saves the expensive use of absolute alcohol. It consists of carbolic acid (melted crystals), 1 part; xylol, 3 parts.

Schaudinn's Fluid.- This invaluable fixing fluid for Protozoa consists of: saturated aqueous solution of corrosive sublimate, 65 parts; 95 per cent alcohol, 3.3 parts; glacial acetie acid, 2 parts. The corrosive sublimate solution is kept in stock and the mixture is made immediately before use. It may be used cold but better results are obtained by heating until steam begins to rise before putting the films into it. As with other corrosive sublimate mixtures, iodised alcohol should be used for washing.

Bouin's Picro-formol.--Saturated aqueous solution of picric acid, 30 parts; formalin, 10 parts; glacial acetic acid, 2 parts. Langeron, who regards this as a universal fixer, keeps a stock solution of 1 part of formalin and 3 of water saturated with picric-acid erystals. To this he adds 5 per cent of glacial acetie acid just before use. Tissues may be fixed for from 2 to 3 days to a week and are then placed in 80 per cent which is changed several times.

Brasil's Picro-formol is an alcoholic modification of Bouin's fluid which possesses great penetrating powers. Used warm, it is especially good for eysts. Eighty per eent alcohol, 150 ec.; formalin, 60 ce.; glacial acetic acid, 15 ce.; pieric acid, $1 \mathrm{gram}$.

Zenker's Fluid.-Potassium dichromate, 2.5 grams; corrosive sublimate, 5 grams; water, $100 \mathrm{ec}$; and add before using glacial acetic acid, 5 ce. Fix for 12 to 48 hours and wash in running water for an equal period, transfer to 70 per cent alcohol for 1 day, then to 80 per cent iodised alcohol to remove the corrosive sublimate. It is advisable to keep the tissues in the dark while in the alcohol.

Delafield's Hæmatoxylin.-Saturated aqueous solution of ammonia alum, 100 ce.; stock solution of hæmatoxylin (10 per cent in 95 per cent alcohol), $20 \mathrm{cc}$. Leave it exposed to the light and air in an unstoppered bottle for 3 or 4 days, filter, and add glycerine, $50 \mathrm{cc}$, and methyl alcohol, 50 cc. Let stand uncorked for a week or more, until the color is sufficiently dark; then filter. Solutions which have ripened for several months are best. For ordinary staining the solution should be diluted with 3 to 4 volumes of distilled water, but for staining tapeworms and flukes it may be so dilute as to have only a faint purple color and be allowed to act for 24 hours or more. If necessary to destain by the use of acid aleohol, follow this by alcohol made 
slightly alkaline by adding a few drops of 0.1 per cent sodium bicarbonate.

Grenacher's Borax-carmine.-Borax (4 per cent aqueous solution), 100 cc.; carmine, 3 grams. Boil until the carmine dissolves, dilute with an equal volume of 70 per cent alcohol, and filter after a day or so. Stain until penetration is complete, often requiring days, and differentiate with acidulated alcohol. For this 2 per cent of HCl in 70 per cent alcohol is often used, but better results are often obtained by using a weaker solution.

Heidenhain's Iron Hæmatoxylin (see p. 99).-Be sure that your mordant is made up from the clear violet crystals of the ferric alum (iron-ammonium-persulphate).

Wright's Stain.-This and the various other modifications of Romanowsky's stain are difficult to prepare and are best purchased from reliable dealers. Grübler's powdered form of Wright's stain has given us the best results. It should be dissolved at the rate of 0.3 gram in $100 \mathrm{cc}$. of absolute methyl alcohol (acetone free). For directions for use, see page 110.

\section{THE MORE IMPORTANT ENDOZOA OF LABORATORY ANIMALS}

The parasites discussed in the preceding outlines have been eonsidered in their systematic relationships without special regard to their souree. As an aid to the general examination of animals for endoparasites, the following lists of the more important species infecting laboratory animals and of the organs infected are given.

The papers rited are in most cases comprehensive reviews or contain important bibliographies.

\section{CAT}

\section{PROTOZOA :}

Rhizopoda :

Endamaba histolytica, intestine.

Mastigophora :

Giardia felis (Giardia cati), intestine.

Trichomonas felis, intestine.

$$
\text { felistome, mouth. }
$$

Sporozoa :

Eimcria felina, intestine.

Isospora bigemina, intestine.

felis, intestine.

rivolti, intestine.

Ilepatozoön folis, lencocytes. 


\section{PLATYHEL MINTHES :}

\section{Trematoda:}

Alaria americana, intestine.

Ascocotyle minuta, intestine.

Clonorehis sinensis, liver.

C'otylophallus verustus, intestine.

Heterophyes arqualis, intestine.

dispar, intestine.

heterophyes, intestine.

Opisthorchis felineus, liver.

pseudofelineus (A mphimerus pscudofelineus), liver.

wardi, liver.

Parametorchis complexus, liver.

\section{Cestoda:}

Genus Iipylidium, the following species have been reported from the intestine:
trinchesei
pasquelei
chyzeri
arleyi
caniusum

Diphyllobothrium dccipiens, intestine.

latum, intestine.

mansoni, intestine as arlult, in museulature as plerocereoid.

Echinococcus granulosus, intestine as adult, cystic in liver, mesenteries, ete.

Hesocestoides lineatus, intestine.

Trrnia hydatigena, intestine.

pisiformis (Tania scrrata), intestine.

toniaformis (T. crassicollis), intestine.

\section{NEMATHELMINTHES :}

Nematoda :

Ancylostoma caninum, intestine. braziliense, intestine.

Capillaria acrophila, trachea, bronchi, lungs.

lineare, trachea, bronchi, lungs.

Dirofilaria immitis, adults in heart, larvæ in circulating blood.

Ollulanus tricuspis, stomach, intestine.

Oxyuris compar, eceeum.

Toxascaris limbata, intestine.

Toxocara mystax (Belascaris mystax), intestine.

Trichinella spiralis, cysts in museles, adults in intestine.

\section{Acanthocephala :}

Echinopardalis pardalis, probably intestine. 
PROTOZOA:

\section{CHICKEN}

Rhizopoda:

Endamaba lagopodus, intestine.

Endolimax janiser, intestine.

Mastigophora:

Chilomastix gallinarum, intestine.

Eutrichomastix gallinarum, intestine.

Sporozoa:

Eimeria arium, intestine.

Leucocytozoon smithi, blood.

sarcocystis horvathi, muscles.

\section{PLATYHELMINTHES :}

\section{Trematoda :}

('ephalogonimus pellucirhus, (rsophagus.

Collyriclum faba, subcutaneous eysts on abtominal surfaces and in rloacal regions.

Echinostoma echinatum, intestine.

Mesogonimus commutatus, intestine.

Prosthogonimus pellucidus (?), hursa Fabricii.

\section{Cestoda:}

Amobotania sphenoides, intestine.

Davainea cesticillus (Raillictina ccsticillus), intestine.

echinobothridia (R. echinobothridia), intestine.

tetragona, (R. tetragona), intestine.

proglottina, intestine.

Hymenolcpi carioca, (Weinlandia), intestine.

\section{NEMATHEL MINTHES :}

Nematoda :

Ascarillin compar, small intestine.

lineata, small intestine.

Chcilospirura hamulosa, gizzard.

Dispharynx spirnlis, asophagus, proventriculus,

Gongylonema ingluvicola, in mueous lining of the erop.

Ileterakis galline, caecum.

Oxyspirura mansoni, under nictitating membrane, occusionally in nasal (alvities and sinuses.

Subulura brumpti, reest.

S'yngamus trachcalis, tracheis.

Tetrameres americana, proventriculus.

Trichostrongylus tenuis, cae:a and small intestine.

\section{DOG}

\section{PROTOZOA :}

\section{Rhizopoda :}

Endameba histolytica, intestinal mueosin. 


\section{Mastigophora :}

Giardia camis, intestine.

Trichomonas canistome, mouth.

Sporozoa :

Eimerin cemis, intestine.

Isespora bigemina, intestine.

felis, intrestine.

rivolti, intestine.

IIepatozoan canis, red blood corpuseles.

\section{PLATYHELMINTHES :}

Trematoda :

Alaria americana, intestine.

Ascocotyle italica, intestine.

mimuta, intestine.

michiganensis, intestine.

('entrocestus cuspidatus, intestine.

C'otylophallus verustus, intestine.

C'ryptocotyle lingua, aecidental, normal parasite of birds.

Clonorchis sinensis, liver.

IIeterophyes aqualis, intestine.

dispar, intestine.

heterophyes, intestine.

\section{Cestoda :}

Dipylidium, the following species have been reported from the intestine:

caninum (T'ania cucumerina)

arleyi

sexcoronatum

walkeri

Diphyllobothrium americanum, intestine.

cordatum, intestine.

latum, intestine.

Dithyridium clongatum, peritoneum in larval stage.

martis

taxi

Echinococcus granulosus, intestine; eystic in liver, testes, spleen, vagina, pelvis, onentum, peritoneum.

Mesacestoides lineatus (Tania lineata), intestine.

Multicepsi gaigeri, intestine.

serialis (Trenia serialis), intestint.

packi, intestinc.

multiceps, intestine.

Tienia, the following speeies have been reported from the intestine:
balaniceps
brachysoma
brauni
hydatigena
krabbei
ovis 
pisiformis (Tania serrata)

whium, cystic, in muscles, eye, peritoneum, brain.

\section{NEMATHELMINTHES :}

\section{Nematoda :}

Ancylostoma caninum, intestine.

braziliense, intestinc.

Capillaria arophila, lumgs, truchea, Jronchi.

Dioctophyme renale, kichey, body cavity.

Dirofilaria immitis, circulating blood as larva, in heart tiswe ats adult.

Oslerus asleri, respiratory passages.

Physaloptera rara, intestine.

Sipirocere sanguinolenta, asophitgus, stomath.

Strongyloides stereoralis, intestine.

Toxascaris limbata, intestinc.

Toxocara camis (Belascaris marginata) intestine.

vulpis (Bclascaris vulpis), intestine.

Trichinclla spiralis, erstic stage in muscle tissues; intestine as adults.

Trichuris ulpis, cæenm.

Uncinaria stenoccphala, intestine.

\section{Acanthocephala :}

Onicola canis, intestine.

\section{FROG}

\section{PROTOZOA :}

\section{Rhizopoda:}

Endamaba ranarum, intestine.

\section{Mastigophora :}

Giardia agilis, intestine.

chilomastix caulleryi, in intestine of tatpoles

Euglenamorpha hegueri, restum, tadpoles.

Hexamilus. batrachorum, sectum.

Phacuss sp., reetum.

Polymastix bufonis, rectum.

Trichomitus parms, reetum.

Trichomonas batrachorum, rectum.

Trypanosoma batrachorum, blood.

\section{Sporozoa :}

Iiplospora lieberkühni, kisker.

Eimeria rana, intestine.

Lantiestrella ranarum, bloon.

Leptothea ohlmacheri, tulules of kidher.

I'leistophora danilewsit, in mesenteries and museles.

\section{Infusoria :}

Balantilium entozoon, rectum.

Nyctotherus cordiformis, rectum.

Opelina species, rectum. 


\section{PLATYHELMINTHES :}

\section{Trematoda :}

Agamodistomum sp., muscles of leg.

C'ephalogonimus amerieanus, intestine.

('linostomum attenuatum, encysterl in museles of legs and body wall.

('ystagora totracystis (Agamentistomum marcianse), encysted in bouly cavity and throat.

Diplodiscus temperatus, reetum.

Glypthelmins quieta, intestine.

Gorgodera eirea'e, urinary bladder. minima, urinary bladkler.

Gorgoderina attenuatum, urinary bladder.

Halipegus occidualis, mouth, Eustarhian tube.

Holostomum nitidum, intestine.

Loxogenes arcanum, encysted on visceral.

Megalodiscus ranophilus, reetum.

Monostomum ornatum, body cavity.

Pneumonaces coloralensis, lungs.

complexus, lungs.

longiplexus, lungs.

medioplexus, lungs

parviplexus, lungs.

similiplexus, lungs.

Polystomum integerrimum, urinary bladder.

Tetracotyle pipientis, cystic in mesenteries and peritoneum also, in throat.

\section{Cestoda:}

Cylindrotania americanum, intestine.

Nematotonia dispar, intestine.

I'roteocephalus (Ophiotrenia) sp., intestine.

Plerocereoid sp., intestine.

\section{NEMATHELMINTHES :}

\section{Nematoda :}

Agamonema (larve), body eavity.

Aplectana americana, caeum.

longicaudata, crecum.

Foleyella americana, eysts in mesenteries.

Fileria sp., larva in hlood.

Isociella solitarin, connertive tissurs.

Osucaldoeruzia pipiens, intestine.

subaurieularis, probahly intestine.

Pharyngodon batrachiensis, intestine of tarlpole.

Rhablias rane, lungs.

\section{PIG}

\section{PROTOZOA :}

\section{Rhizopoda:}

"Endamcba coll," intestine.

Endamaba histolytica (?), intestine. 
"Endolimax nana," intestine.

Endameba polecki, intestine.

\section{Mastigophora :}

Bodo sp., intestine.

('hilomastix mesnili (?) intestine

Trichomonas suis, intestine.

\section{Sporozoa :}

Eimeria debliechi, intestinr.

\section{Infusoria :}

Balantidium coli, intestine.

\section{PLATYHEL MINTHES :}

\section{Trematoda :}

Distomum maeulosum, muscle.

Fasciola hepatica, liver.

Loossia romanicum, intestine.

Paragonimus westermani, hungs.

\section{Cestoda:}

$$
\text { kellicotti, lungs. }
$$

Echinococcus granulosus, cystic stage in practically every organ and tissue.

Multieeps multiceps, cystie stage in central nervous system.

Tania hydatigena (Cysticcrous tenuicollis), eystie stage in liver, free or attached to viscera in abdominal cavity. solium (Cysticercus cellulose), cyrstio stage in museulature, eye, brain, liver, panereas, spleen, and subeutaneous tissue.

\section{NEMATHELMINTHES :}

\section{Nematoda :}

Ancylostoma duodenale, intestine.

Arducnua strongylina, stomach.

Ascaris lumbricoides, (A. suis) intestine.

Bunostomum trigonocephalum, intestine.

Choerostrongylus brevivaginatus, bronehi and trachea.

Crassisoma urosubulatum, intestine.

Dioctophyme renale, kidney.

Filaria bauchei, lungs, pulmonary arteries.

Gongyloneme ransomi, murosia of tongue atul asophagus.

Ilyostrongylus rubidus, stomach.

Metastrongylus elongatus, bronehi and tracheia.

salmi, bronchi.

Necator americanus (?) intestine. suillus, intestine.

Esophagostomum dentatum, large intestine as adults, nodules in walls of intestine as larve.

Physoeephalus sexalatus, stomath.

Setaria bernardi, peritoneal cavity and encysted on the surface of the liver. 
Stephanurus dentatus, ablominal vine'rat.

strongyloides stercoralis, intestine.

suis, intestine.

Trichinella spiralis, intestine as alults, eystic in the museles an lantar.

Trichuris ovis, eatum and colon.

suis, "wexun and colon.

Incinaria stenocphala, intestine.

Acanthocephala :

Macracanthorhynchus hirudinacens: (Echinorhynchess gigas), small intestine.

\section{RABBIT}

\section{PROTOZOA :}

\section{Rhizopoda :}

Endamaba cumiculi, intestine.

\section{Mastigophora :}

('hilomastix cuniculi, cyerum.

Embatomonas cuniculi, rarom.

Enteromonas intestinalis, intestine.

Giardia duodenalis, intestine.

\section{Sporozoa:}

Eimeria perforans, intestine. stiedk, liver.

\section{PLATYHELMINTHES :}

\section{Trematoda :}

Fasciola hepatica, liver.

Hasstilesia texensis, intestinr. tricolor, intestine.

\section{Cestoda :}

Cittotania ctenoides, intestinc.

Multiceps packi, conums stage in heart, probably not limited to that tissue.

Multiecps serialis, subeutanous, axillary, intra-abdominal cavity, pleural eavity, ete., in cermurus stage.

Tenia pisiformis, early "ystie stages in liver, later as hladderworms in body cavity or as rysts attached to the mesenteries.

\section{NEMATHELMINTHES :}

\section{Nematoda :}

Graphidium strigosus, stomach.

Obeliscoides cuniculi, stomath.

Passalurus ambiguus, r'erum.

Trichuris leporis, ('æer'un and colon.

\section{RAT}

\section{PROTOZOA :}

\section{Rhizopoda :}

Endamaba decumani (Councilmania decumani), intestine.

histolytica, intestine.

ratti, intestine. 


\section{Mastigophora :}

Chilomastix bettencourti, intestine.

Giardia lamblia (G. intestinalis), intestine. muris, intestine.

Trichomonas muris, intestine.

Trypanosoma lewisi, blood.

Sporozoa :

Hepatozoon muris (Leucocytozoon muris), lencocytes.

\section{PLATYHEL MINTHES :}

\section{Trematoda :}

Ascocotyle (P'arascocotyle) diminuta, intestine.

Echinustoma spiculator, intestine.

Heterechinostomum magniovatum, intestinc.

\section{Cestoda:}

Catemotania pusilla, intestine.

Hymenolepis, the following species from the intestine:

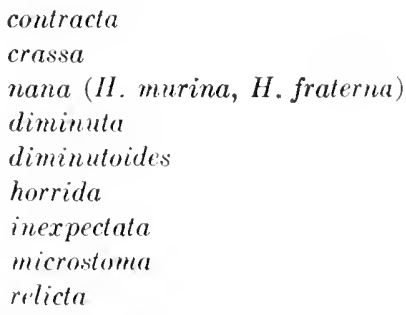

Multicapsiferina gnincensis, intestine.

Multiceps sp., larval stage in connective tissue.

Raillietina sp., intestine.

Teruia brachydera, intestine.

hydatigena, larval stage in mesenteries of abdominal cavity. trenieformis ( $T$. crassicollis), eystic stage in liver.

Tetrathyridium bailleti (Dithyridium), peritoneum.

(?) elongatum, peritoneum.

\section{NEMATHELMINTHES :}

Nematoda :

Heligmosomum muris, intestine.

He pationa hepatica, liver

IIfteratis spumosa, caecumn.

I'rotospirura muris (Spiroptera obtusa), stomach.

columbianu, stomach, asophagus, intestine.

Strongyloides papillosus, intestine.

Syphacia obvelata (Oxyuris obvelata), eserum and large intestine.

Trichinella spiralis, intestine as arlults, eystie in muscles.

Trichosomoides crassicauda, bladder.

\section{Acanthocephala:}

Moniliformis moniliformis (Echinorhynchus moniliformis), intestine. 


\section{SHEEP}

PROTOZOA :

Rhizopoda :

Endamaba ovis, intestine.

Mastigophora :

Trypranosoma melophagium, hlood.

Embadomonas ovis, rectum.

Sporozoa:

Babesia motasi, hlool.

oris, blood.

sergenti, blood.

Eimeria faurei, intestine.

intricata, intestine.

Globidium gilruthi, mucosia of stomach.

Pneumocystis cornit, lung tisisue.

Theileria hirci, peripheral blood, liver, and spleen.

Infusoria :

Balantidium sp., intestine.

\section{PLATYHELMINTHES :}

\section{Trematoda :}

Dicrocalium dendriticum, liver.

Fasciola hepatica, liver.

Fascioloides magna, liver.

\section{Cestoda :}

Echinococcus granulosus, cystic stage in all organs.

Monezia expansa, intestine. planissima, intestine.

Tania hydatigena, eystic stage attached to abdominal viscera.

mis, cystic stage in muscles and on surface of various organs of viscera.

Thysanosoma actinoides, intestine.

Multiceps multiceps, cystic stage in central nervous system.

\section{NEMATHELMINTHES :}

\section{Nematoda :}

Bunostomum trigonocephalum, intestine.

Dietyocaulus filaria, bronchi, bronchioles.

Hormonchus contortus, stomach.

Nematodirus spathiger, intestine.

Proteracrum columbianum, larvæin nodules on small and large intestines, arlults in large intestine.

Synthetocaulus rufescens, bronchioles and lung tissue.

Trichuris (Trichocephalus) ovis, cæeum, large intestine.

\section{References}

Andrews, J. M., 1926. Coccidiosis in mammals. Am.Jour. Hyg., 6 (6): 784-798.

Baylis, H. A., 1922. Observations on certain cestodes of rats with an account of a new species of Hymenolepis. Parasitology, 14:415-419. 
Barus, II. A., 1929. "A manual of belminthology," pp. 3-303. William Wood and Company, New York,

(mander, A. C., 1929. A new species of trematode worms belonging to the genus Hasstilesia from rabbits in Texas. Proc. U. S. Nat. Museum, 2792, 75:1-5.

Cont, W. W., 1912. North American frog bladder flukes. Trans. Am. Micro. Soe., 31: 151-165.

Cont, W. W., 1915b. North Ameriean frog hung flukes. Trans. Am. Micro. Soc., 34: 203-239

Cran, Elorse B., 1927. Bird parasites of the nematode suborders Strongylata, Ascaridata, and Spirurata. Smithsonian Institution, U.S. Nat. Museum, Bull. 140, pp. 1-465.

Cram, Eloise B., 1928. The present status of our kuowledge of poultry parasitism. North Am. Veter., 9 (1), 8 pp.

Dobeli, C. C., 1908. On the intestinal protozoan parasites of frogs and toads. Proc. Cambridge Philos. Soc., 14: 42S-433.

Dobell, C. C., 1909. Researches on the intestinal protozoa of frogs and toads. Quart. Jour. Miero. Sci., 53: 201-266.

Funrmann, O., 1926. "Cestodes. Museum d'Histoire Nat. de Genève, Catalogue des Invertebres de la Suisse." Georg \& eie, Genève.

Hall, M. C., 1910. The "gid" parasite and allied speeies of the cestode genus Multiceps. Historical Rev. U. S. Dept. Agr., Bur. An. Ind., Bull. 125: 1-68.

Hall, M. C., 1916. A synoptieal key to the adult trnioill cestodes of the dog, eat and some related earnivores. Jour. Am. Vet. Med. Assoc., 50: $350-360$.

HALt, M. C., 1916. Nematode parasites of mammals of the orders Rodentia, Lagomorpha, and Hyracoidea. Proc. U. S. Nat. Museum, 50: 1-258

HALL, M. C., 1919. The adult trenioid eestodes of dogs, and eats, and of some related earnivores in North America. Proc. U. א. Nat. Museum, $55: 1-94$.

Hall, M. C., 1920. Parasites and parasitic diseases of sheep. U. Dept. Agr., Farmer's Bull. 1150.

HaLl, M. C., 1923. Internal parasites of dogs and eats in the Inited States and treatments for removing these parasites. Jour. A m. I'et. Hed. Assoc., 63 (1): 11-51.

Hald, M. C., 1924. "Parasites of swine," pp. 7-160. L. A. Merillat, Chieago.

Hlall, M. C., 1925. Parasites and parasitic diseases of dogs. U. S. Dept. Agr., Circ. 338: 1-28.

Hegner, R. W., 1922. A comparative study of the giardias living in man, rabbit and dog. Am. Jour. IIyg., 2(4):442-454.

Hegner, R. W., 1922b. Frog and toad tadpoles as sources of intestinal protozoa for teaching purposes. Science, 56: 439-441.

Hegner, R. W., 1923. Giardias from wild rats and mice and Giardia cavio, sp. n. from the guinea-pig. Am. Jour. Hyg., 3(3):345-347.

Hegner, R. W., 1925. Giardia folis, n. sp. from the domestic eat and giardias from birds. Am. Jour IIyg., $\mathbf{5}(3): 345-349$.

Hegner, R. W., 1920. Endolimax cavia from the guinea-pig and Eudolimax janise n. sp. from the domestic fowl. Jour. Parasitology, 12: 146-147. 
Lisksel, J. T., 1924. The distinguishing characteristies of the paratitice amochar of culture rats and mice. L'niv. ('alif. I'ut). Zeology, 20 (2:3): $489-544$.

lienset J. T., 1928. Intextinal protozot of the domentie pig. $1 \mathrm{~m}$. Jemr. Trop. Ved., $8(5): 1 \$ 1-501$.

livon., R, 1922. On the protozon parasitic in frogs. Trans. fm. Wirm. Soc., $41: .39-76$.

Ranson, B. 11, 1911. The nomatoles parasitie in the alimentary tract of cattle, sheep and other ruminants. I'. S. Dept. Agr., Bur. An. Ind., Bull. 127, 132 pl).

Ransom, B. H., 1920. Synopsis of the trematode family Heterophyidit and descriptions of a gemus and five new species. Proc. L. St. Nat. U uscum, $57: 527-573$.

Riley, W. A., and II. C. II. Kemskanr 1921. Flukes of the gonus collyriclum as parasites of turkeys and ahickens. Jour. Am. let. Merl. Assoc., 64 (5): 591-599.

SchwarTz, B., and W. B. Sirook, 1928. Rabhit parasites and diseases. U.S. Dept. Agr., Farmer's Bull. $1568,30 \mathrm{pp}$.

Van Cecare, H. J., 1920. Acanthocephala parasitic in the dog. Jour. Parasitology, 7: 175-178.

Walton, A. C., 1929 . Studies on some nematodes of North Ancriean frogs. Jour. Parasitology 15 (4): 227-239.

Yorke, W., and P. A. MAPLestone, 1926. "The nematode parasites of vertebrates," 536 pp. P. Blakiston's Son and Company, Philadelphia

\section{SUPPLY HOUSES HANDLING PARASITOLOGICAL MATERIALS}

Intil recently there has been little opportunity to purchase well-prepared slides and gross materials of parasitological interest. The situation is changing and now a considerable mumber of biological supply houses carry sueh preparations. The following firms may be cited from porsonal knowledge. The list, of course, makes no pretense of completencss.

Bauer, Conrad, Johns Ilopkins Sihool of Hygiene, Baltimore, Maryland. Biological Supply Service, Soochow Iniversity, Soochow, China.

Denoyer-Geppert C., 5235 Ravenswood Ave., Chieago, illinois.

Etablissement du Docteur Auzoux, 56 rue de Vaugirard, Paris (6), France. Galigher, Albert E., 1057 Solono Ave, Berkeley, California.

General Biologieal Supply House, 661 E. 59th Place, Chicago Hlinois.

Pacifie Biologieal Laboratories, Pacific Grove, California.

Powers and Powers, Station A, Lincoln, Nebraska.

Sichlüter and Mass, Naturwissenschaftliche Lehrmittol-Anstalt Halle a. S.. Germany.

Southern Biologieal Supply Company, Natural History Building, New Orleans, Louisiana.

Watson and Sons, 313 High Holborn, W.C.I. London, England.

\section{COMPREHENSIVE TEXTS}

BAYlis, H. A., 1929. "A Manual of Helminthology, Medical and Veterinary," xi + 303 pp. William Wood and Company, New York. 
Barles, H. A., and R. Daubner, 1926. "A Synopsis of the Familes and Genera of Nematoda," xxxvi + 227 pp. London, British Museum.

Braun, M. and O. SeIfert 1925-26. "Die tierischen Parasiten des Menschen," 6th ed., 2 volk., 1198 pp. Kiblitsch, Leipzig (Second volume considers clinical and therapentic aspects).

Brumpt, E., 1927. "Précis de parasitologie," 4th edl, viii + 1452 pp. Masson et cie, Paris.

Calkins, C. N., 1926. "The Biology of the Protozoa," ix $+623 \mathrm{pp}$. Lea and Fehiger, Philadelphia.

Carazzi, D., 1922. "Parassitologia animale," 2nd ed., $x i+467$ pp. Societa Editrice Libraria, Milan.

Castellani, A., and A. J. Chalmers, 1919. "Manual of Tropical Medicine," 3l ed. 2436 pp. William Wood and Company, New York.

Chanderr, A. C., 1926. "Animal Parasites and Human Disease, 3d ed., xiii +573 pp. John Wiley and Sons, New York.

Craig, C. F., 1926. "A Manual of the Parasitie Protozoa of Man," viii +569 pp. J. B. Lippineott Company, Philadelphia.

Davaine, C., 1860. "Traité des entozoaires et des maladies vermineuses de l'homme et des animaux domestiques," xix + xeii + 838 pp. Baillière et fils, Paris. (A rich storehouse of historie interest.)

Doflein, F., 1916. "Lehrbuch der Protozoenkunde," 4th ed., xv + 1190 pp. Gustav Fiseher, Jena.

Fantham, H. B., J. W. W. Stephens, and F. V. Theobald, 1916. "Animal Parasites of Man," 900 pp. William Wood and Company, New York. (Based on the $3 d$ ed. of Braun.)

Faust, E. C., 1929. "Human Helminthology. A Manual for C'linicians, Sanitarians, and Medieal Zoologists," Lea and Fehiger, Philadelphia.

Fieblger, J., 1923. "Die tierischen Parasiten der Haus-und Nutztiere," 2 d ed., xvi +440 pp. Brammuller, Leipzig.

Gedoelst, L., 1911. "Synopsis de parasitologie de l'homme et des animaux domestiques," $\mathrm{xx}+332$ pp. Lambertin, Bruxelles.

Hartmann, M, 1921. "Praktikum der Bakteriologie und Protozoologie," Zweiter Teil-Protozoologie, 4th ed., viii + 146 pp. Gustar Fischer, Jena.

Hartmann, M., and C. Schilizang, 1917. "Die pathogenen Protozoen und die durch sie venursachten Krankbeiten. Zugleich eine Einführung in die allegemeine Protozocnkunde," $\mathrm{x}+426 \mathrm{pp}$., 337 figs. Apringer, Berlin.

Hegner, R. W., and W. H. Thliaferro, 1925. "IJuman Protozoology," xix $+597 \mathrm{pp}$. The Maemillan Company, New York.

Hegner, R. W., F. M. Root, and D. L. Augustine, 1929. "Animal Parasitology with Special Reference to Man and Domesticated Animals," xxi +731 pp. The Century Company, New York.

Knowles, R., 1928. "An Introduction to Medical Protozoölogy, with Chapters on the Spirochates and on Lahoratory Methods." Thacker, Spink \& Co., Calcutta.

Leuckart, K. G. F. R, 1886. "The Parasites of Man and the Diseases Which Proced from Them." "Trans. hy. W. E. Hoyle, xxvi + 7tl pp. Pentland, Edinburgh. (A rassie, invaluahle today for its biologieal viewpoint.) 


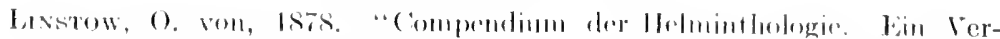

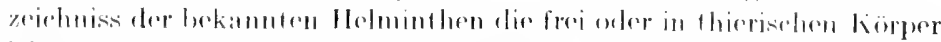
leben, georduet nath ibren Wobutheren, unter Angabe der Organe. in denen sir gefünden sind, und mit Beifügung der Litheraturguellen," xxii +382 pp. Hahn, Hanover.

-.., 1859. "Nachtrag-Die Litteratur der Jahre $1878-1859, " x v i+151$ pl).

Mavson, P., 1925. "Tropical Diseases," Sth ed., oflitel hy MansonBahr, $x x+\$ 95$ pp. William Wood and Company, Now Fork.

Marotel, G., 1926. "Parasitologie vétérinaire," vii + 5t5 pp. Bailliem et fils, Paris.

MeggitT, F. J., 1924. "The Cestodes of Mammals," iv + 252 pl. Elw. Goldston, London.

Messe, A. W. "llandluch der Tropenkrankheiten." 3il exl. in conrse of pulblication. Barth, leipzig.

Neumann, L. C., 1sy2. "A Treatise on the Parasites and Pamsitie Diseases of the Domesticated Animals." 'Tlans. and editeel by Geroge Fleming, $\mathrm{xxiii}+\mathrm{S}(0)$ pr. London.

Nedmann, R. O., and M. MaYer, 1914. "Atlas und leluhuch wirhtiger tierischen Parasiten und ihrer Überträger," vi + 580 pp., 45 col. plates. Lohmann, Munchen.

Neved-Lemaire, M., 1912. "Parasitologie des animanx domestiques," ii +1257 pp. Lamarre et cie., Paris.

Neveu-Lemaire, M., 1921. "Préeis de parasitologie humaine," 5th ed., vi $+466 \mathrm{pp}$. Lamare et eie., Paris.

NöLler, W., 1922. "Die wichtigsten parasitisehen Protozoen des Mensehen und der Thiere." Teil I. Einfühmung in die allgemeinc Konntnis und die Untersuchung der parasitishen Protozom umd Alschnitt 1: Die parasitischen Rhizopoden, 272 pp. Richard Schoetz. Berlin.

RaIlliet, A., 1895. " "Traité de zoologie medicale et agricole," 2d êl., $\mathrm{xv}^{+}$ 1303 pp. Asselin \& Honzeau, Paris.

'Thomson, J. G., and A. Robertson, 1929. "Protozoölogy. A Mammal for Medical Men," xiii + 376 pp. William Wood and Company, New York.

Underhill, B. M., 1920. "Parasites and Parasitosis of Dumestic Animals," xix. + $379 \mathrm{pp}$. The Maemillan Company, New York.

Verdun, P., and A. H. Mandoul, 1924. "Préeis de parasitologie humaine," 3 l ed., vi + 937 pp. Doin, Paris.

WARD, H. B., and G. C. WIIlppte, 1918. "Fresh-Water Biology," ix +111pp. John Wiley \& Sons, New York.

Wenyon, C. M., 1926. "Protozoölogy. A Manual for Medical Men, Veterinarians and Zoölogists," 2 vols, xvi + 156i3 pp. Balliere, 'Tindall and Cox, London.

Yorke, W., and P. A. Maplestonf, 1926. "The Nematode Parasites of Vertebrates," xi + 536 pp. P. Blakiston's Sot and Company, Philadelphia. 



\section{INIDEX}

(Boldface type indieates paiges on which illustrations appear.)

\section{A}

Aranthocephata, 2, 37

Acanthocephlitus rana, 37

Aclurostrongylus abstrusts, 5

Amothat of man, 61

Amphimerus psendofelineus, is

Ancylostomal ('ininum, 39, f(), 41 duodenale, 42

Anmulata, 2

Arthropodia, 2

Asriuris lumbricoides, 34, 35, 36

Asritroidea, 33

\section{B}

Babesia bovis, 88

Barmann apparatus, 42, 107

Balantilium, 92

(c)li, 6, 92, 93, 94

(ntozoun, 6, 93

Blood, normal human, 84

stmeirs, 110

staining, 111

Buxton's medium, 112

\section{C}

('ipillaria, 58

Catlol-xylol, 112

(at, parasites of, 114 exannination of, 55

('oments, seating, 112

('ephalogonimus anericamus, 4, 5)

('reratial alvite, 17 longifurea, 16

('rearix, 17 types of, 18

Cirstorla, 2 teehnique, 101

Chiztog:1ster, 16
Clicken, parasites of, 116 intestinal flagedlates of, 70

Chilomastigidae, 69

Chilomastix mesnili, 68, 69, 70 gallinarum, tis, 70

Clinostomum attenuatum, 3, 4

Clonorehis sinensis, 10

Cniclosporidia, 91

Corceidia, 78, 79

Coracidium, 29

Crithidia, 66, 67

Cysticereoid, 28

Cystiecreus, 24

Cytopharynx, 93

Cytopvge, 93

\section{D}

Dactylosoma lanarum, 3

Dientam(xba fragilis, 61

Digenea, 9

Diphyllohothrium latum, 29

Diplodiseus tempratus, 4, 5

Diplomonarlicla, 69

Diplospora lieberkühni, 7

Dirofilaria inmitis, 57

Dipylidium, 57

caninum, 28

Dog, parasites of, 116

E

Echinococeus gramulosus, 30 'yst, 31

Eggs, hedininth, 61

permanent mounts, 109

Eimeria, 7, 78, 79

avium, $7 \mathrm{~s}$

perforans, 78

ranx, 7

schubergi, $7 \mathrm{~S}$

steirla, 78 
Enclamoeha coli, 61, 62 gingivalis, 61 histolytica, 60,61 in kitten, 61 ranarum, 6, 7

Endamobe of man, 61

Endolimax nana, 61, 63

Eunematoda, 2, 34

Eutrichomastix, 68 batrachorum, 68 gallinarum, 68,70

F

Fasciola hepatica, 15

Fecal examinations, 47 rentrifuging, 49

rommon olsjects found in, 50 (cggs in, 51, 52, 53 sedimentation, 48 Willis' method of, 49 with dense liquids, 49

Fixatives, 113

Flame cells, 12, 17

Frog, parasites of, 118 protozoa, 6

Trematoda, 4

\section{G}

Giartia lamblia, 68, 71 muris, 72

Giardiasis, 71

Gregarinada, 74

Gregarine parasites, 76

Gingea danilewskyi, 4

Glycerine jelly, 112

Glypthelmins quieta, 5

(iordiacea, 2, 37

Gorgodera, 4, 7

Gorgoderina, 4, 7

(iorgoderinar, 7

(iyroclactilidas, 4

\section{II}

Iremosporidia, 82, 83

I1:1 lipegus oceitualis, 5

Herpetomonas, 66

musea-domesticx, 67
Hexaminth embryo, 22

Hirudinea, 2

Hookworms, 39, 57

Hymenelopis nana, 28

diminuta, 27, 28

I

Icthyotænia, proglottis, 21

Infusoria, 2, 6, 92, 94

Isospora, 78

L

Laeto-phenol, 111

Lambliasis, 71

Lankestrella ranarum, 3, 6

Laurer's eanal, 11

Leishmania, 66 donovani, 66

Leptomonas, 66, 67

Leptotheea ranax, 7 ohlmacheri, 91

Literature, 96

Loxogenes arcammm, 4, 5

M

Macrocanthorynehus gigas, 37

Malaria, 82 sparrow, 87

Mastigophora, 1, 64

Mehlis' gland, 12

Merozoa, 20

Metacerearize, 17

Miracidium, 14, 15

Monocystis agilis, 75 development of, 75

Monogenea, !

Monozoa, ?0

Mounting uredia, 112

Multiceps serialis, 30 cyst, 30

$\mathrm{N}$

Neeator americanus, 42 head, 41

Nematoda, 2 prepiation of, 105 
Nematheluminthes, 2

Noterdres catti, so

Niretetherus, !'2

comlifomis, 6, 93

\section{()}

()llukames tricuspis, 57

Opalina, 6

r:matrum, development of, 94

Opisthorehis viverrima, 10

Otoderetes eynotis, 56

\section{P}

Paragonimus, 57

Picro-formol, 113

Pig, parasites of, 119

Piroplasmielax, st

Plasmodium, development of 86

falciparm, 82,86

malaria, 82,86

priecox, 82

vivix, 82,83

Platyheminthes, 2, 9

Plerocercoid, 30

Pneumonares sp., 4, 5

Polystomm integerrinum, 7

Protozoa, 1

technirue, 99, 110

R

Rabbit, parasites of, 121

Rat, parasites of, 121

Rediæe, 17

Rhabdias bufonis, 5

raux, 4

Rhizopoda, 1, 6, 59, 61

Rostellum, 20

$S$

hatreocystis miescheriana, 90

tenella, 90
Sitreosporidia, development of, so

Sidhistosomat hamotohium, l:3 japonicum, miratciclinm, 15

Sheep, partasites of, 12:3

snatils, fresh-watere, $1 \mathrm{~s}$

Siporocyst, 11

Sperozor, 1, 7, 74, 7s

Sporozoites, 74

Sitrongyloidea, 4), 41

supply homises, 12:5

\section{T}

Tarnia pisiformis, 19, 23, 24

salginata, 27

solimm, 27

Tapeworms, 2, 5, 19, 26, 57

Toxocara canis, $3: 3$

mystax, 33, 57

Trematoda, 2 trehnique, 103

Trichinella spiralis, $43,44,58$

Trichomonalielat, (i!)

Trichomonas, 68

angusta, 68, 70

batrachorum, 68,70

eavie, 68

(b)erthi, 6s, 70

gallinarum, 68, 70

hominis, 68

muris, 68

Trichuris triehiura, 45

Trichumoidea, 44

Trypanosoma cruzi, $\mathbf{6 6}$ gambiense, 66

lewisi, 65

rotitorium, 3, 6

structure of, 65

$\%$

degenerstis, is

cometit, 74 








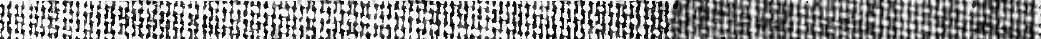

ats

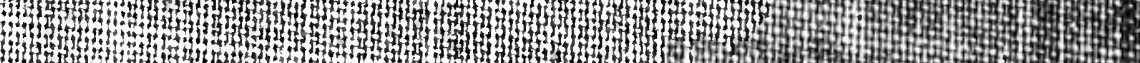
(2) : . (1).

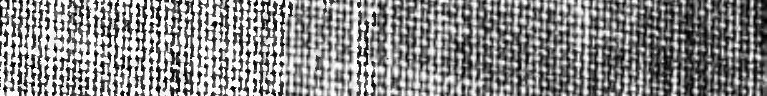
6

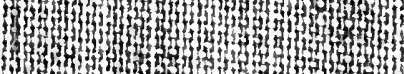
S tat

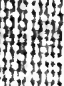
T.

(2):

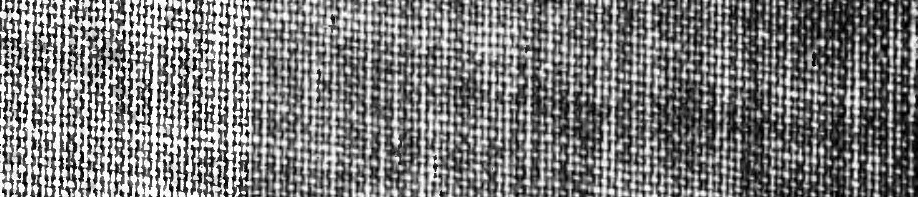

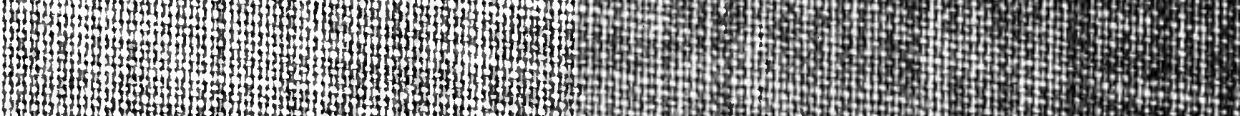
3. (3) H.

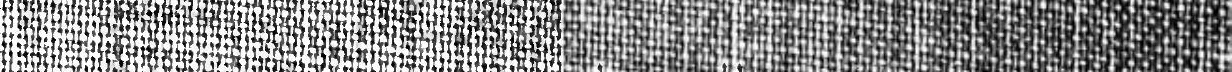
3. 10 4.2. 20. 3. H.

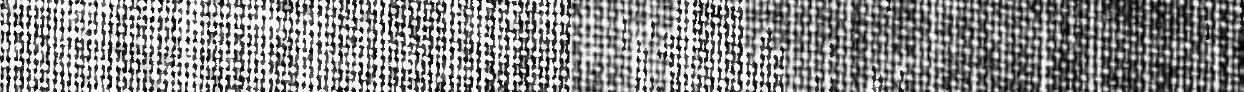

